\title{
Linked 3D modeling of megathrust earthquake-tsunami events: from subduction to tsunami run up
}

\author{
E. H. Madden ${ }^{1,2}$, M. Bader ${ }^{3}$, J. Behrens ${ }^{4}$, Y. van Dinther ${ }^{5,6}$, A.-A. Gabriel ${ }^{1}$, \\ L. Rannabauer ${ }^{3}$, T. Ulrich ${ }^{1}$, C. Uphoff ${ }^{1,3}$, S. Vater ${ }^{4,8}$, I. van Zelst ${ }^{5,7}$ \\ ${ }^{1}$ Department of Earth and Environmental Sciences, Ludwig-Maximilians-Universität München, Munich, Germany \\ ${ }^{2}$ Observatório Sismológico, Instituto de Geociências, Universidade de Brasília, Brasília, Brazil \\ ${ }^{3}$ Department of Informatics, Technical University of Munich, Garching, Germany \\ ${ }^{4}$ Numerical Methods in Geosciences, Department of Mathematics/CEN, Universität Hamburg, Hamburg, Germany \\ ${ }^{5}$ Seismology and Wave Physics, Institute of Geophysics, Department of Earth Sciences, ETH Zürich, Zürich, Switzerland \\ ${ }^{6}$ Department of Earth Sciences, Utrecht University, Utrecht, The Netherlands \\ ${ }^{7}$ Now at: Institute of Geophysics and Tectonics, School of Earth and Environment, University of Leeds, Leeds, LS2 9JT, \\ United Kingdom \\ ${ }^{8}$ Now at: Dept. of Mathematics and Computer Science, Freie Universität Berlin, Berlin, Germany
}

\section{SUMMARY}

How does megathrust earthquake rupture govern tsunami behavior? Recent modeling advances permit evaluation of the influence of 3D earthquake dynamics on tsunami genesis, propagation, and coastal inundation. Here, we present and explore a virtual laboratory in which the tsunami source arises from 3D coseismic seafloor displacements generated by a dynamic earthquake rupture model. This is achieved by linking open-source earthquake and tsunami computational models that follow discontinuous Galerkin schemes and are facilitated by highly optimized parallel algorithms and software. We present three scenarios demonstrating the flexibility and capabilities of linked modeling. In the first two scenarios, we use a dynamic earthquake source including time-dependent spontaneous 
failure along a 3D planar fault surrounded by homogeneous rock and depth-dependent, near-lithostatic stresses. We investigate how slip to the trench influences tsunami behavior by simulating one blind and one surface-breaching rupture. The blind rupture scenario exhibits distinct earthquake characteristics (lower slip, shorter rupture duration, lower stress drop, lower rupture speed), but the tsunami is similar to that from the surface-breaching rupture in run-up and length of impacted coastline. The higher tsunami-generating efficiency of the blind rupture may explain how there are differences in earthquake characteristics between the scenarios, but similarities in tsunami inundation patterns. However, the lower seafloor displacements in the blind rupture result in a smaller displaced volume of water leading to a narrower inundation corridor inland from the coast and a $15 \%$ smaller inundation area overall. In the third scenario, the 3D earthquake model is initialized using a seismo-thermo-mechanical geodynamic model simulating both subduction dynamics and seismic cycles. This ensures that the curved fault geometry, heterogeneous stresses and strength, and material structure are consistent with each other and with millions of years of modeled deformation in the subduction channel. These conditions lead to a realistic rupture in terms of velocity and stress drop that is blind, but efficiently generates a tsunami. In all scenarios, comparison with the tsunamis sourced by the timedependent seafloor displacements, using only the time-independent displacements alters tsunami temporal behavior, resulting in later tsunami arrival at the coast, but faster coastal inundation. In the scenarios with the surface-breaching and subduction-initialized earthquakes, using the time-independent displacements also over-predicts run-up. In the future, the here presented scenarios may be useful for comparison of alternative dynamic earthquake-tsunami modeling approaches or linking choices, and can be readily developed into more complex applications to study how earthquake source dynamics influence tsunami genesis, propagation and inundation.

Key words: Earthquake dynamics - Tsunami - Numerical modelling - Subduction zone processes - Seismic cycle - Earthquake hazards 


\section{INTRODUCTION}

Subduction zone earthquakes can trigger devastating tsunamis, such as the 2004 Sumatra, 2010 Maule and 2011 Tohoku earthquake-tsunami sequences. Numerical models of tsunami generation, propagation and inundation use observations and data inversions to both characterize the tsunami source and constrain simulation results. However, in many instances, the observed tsunami behavior is unexpected or tsunamis occur from unexpected sources (e.g. Jamelot et al. 2019; Ulrich et al.|2019b). Recent, wellrecorded events highlight the importance of dynamic tsunami source complexity. Tsunami generation may be impacted by splay faulting (Wendt et al. 2009; Geist \& Oglesby 2014; Kozdon \& Dunham 2014), long source duration (Maeda \& Furumura 2011), horizontal momentum transfer (Song et al. 2008: Lotto et al.|2017b; Amlani et al. 2019) and mixed faulting mechanisms (e.g. Saito 2017; Ulrich et al.2019b). These characteristics can be captured in dynamic earthquake rupture models, which aim to reproduce the physical processes that govern the way fault systems yield and slide (e.g. Andrews 1976; Oglesby et al. 2000; Day et al. 2005; Kaneko et al. 2008).

Computational advances now allow earthquake modeling to capture rupture dynamics on complex faults or fault systems on the scale of megathrust events (e.g. Murphy et al. 2016; Uphoff et al. 2017; Murphy et al. 2018; Ramos \& Huang 2019). In addition, such models can include physical processes non-linearly coupled to the earthquake dynamics, such as off-fault plasticity (e.g., Andrews 2005; Dunham et al. 2011; Gabriel et al. 2013; Roten et al. 2014; Wollherr et al. 2018) or thermal pressurization of pore fluids (e.g., Bizzarri \& Cocco 2006; Noda 2008; Gabriel et al. 2020). Such methods have realized realistic, observationally constrained simulations of several recent earthquakes, including the highly segmented crustal 2019 Ridgecrest, 2016 Kaikoura, 2010 Haiti, and 1992 Landers ruptures (Lozos \& Harris 2020; Klinger et al. 2018; Ando \& Kaneko 2018; Ulrich et al. 2019a; Douilly et al. 2015, Wollherr et al. 2019), the supershear 2018 Palu, Sulawesi earthquake (Amlani et al.|2019; Ulrich et al.2019b), the 2015 Gorkha earthquake (Weng \& Yang|2018; Wang et al.|2019), and large megathrust events (Galvez et al. 2014, Ma \& Nie 2019; Ulrich et al. 2020). These models show that dynamic earthquake rupture models are ready to provide mechanically viable tsunami source descriptions. However, incorporating these into tsunami modeling is not trivial.

Tsunami modeling is undertaken with varying degrees of complexity. The application of normal mode theory was an early development (e.g. Ward 1980; Okal 1982) and has been adapted to include propagation of dispersive waves (Watada et al. 2014). Several hydrological tsunami models employ a set of two-dimensional (2D) simplifications of the non-linear Navier-Stokes equations, such as the shallow water equations (e.g. Berger et al.2011; Heidarzadeh et al.2017) or Boussinesq type equations to model dispersive waves (e.g. Shi et al.2012). These tsunami models use more or less sophisticated 
Madden et al.

approximations to the earthquake induced uplift as initial conditions (for a review see e.g. Behrens \& Dias 2015).

To set tsunami model initial conditions, earthquake-induced seafloor displacements often are determined using an analytical solution for displacement due to a uniform rectangular dislocation within a homogeneous elastic half space (e.g. Okada 1985). A dislocation model may be taken from a finite fault model constrained by data inversion (e.g. Ji et al. 2002; Mai \& Thingbaijam 2014; Bletery et al. 2016) as done by Allgeyer \& Cummins (2014) and Jamelot et al. (2019), or designed to test certain source parameters as done by Geist \& Yoshioka (1996). Stochastic models of seismogenic tsunami generation (e.g. Davies 2019) can either specify static slip on the fault following Andrews (1980) together with the idea that the final slip distribution after an earthquake rupture is self-affine, or use earthquake rupture models in the presence of stochastic stress (Geist \& Oglesby|2014). In the context of an early warning system in Indonesia, complexity in space and time is achieved by including a grid of slip patches that together comprise a complex source model (Babeyko et al. 2010). Goda et al. (2014) highlight strong sensitivity of tsunami wave heights to site location and slip characteristics, and also to variations in dip, in stochastic random-field slip models for the 2011 Tohoku earthquake.

Several approaches also incorporate seismic waves into tsunami models. Saito et al. (2019) present a 2-step tsunami modeling method: first, the spatial and temporal evolution of seafloor surface height is determined from a seismic wave simulation; second, this vertical velocity is used to source a $2 \mathrm{D}$, nonlinear hydrodynamic tsunami model. As an earthquake source, Saito et al. (2019) use a series of dislocations derived from dynamic rupture modeling of a potential future earthquake rupture in the Nankai Trough, Japan by Hok et al. (2011). Maeda et al. (2013) perform tsunami models of the 2011 Tohoku earthquake using tsunami-coupled equations of motion solved by the finite difference method (Maeda \& Furumura 2011); these incorporate seismic waves and seafloor displacements generated from a 3D kinematic earthquake source.

Use of a data-driven finite earthquake source model to determine seafloor initial conditions for the tsunami model is advantageous when trying to understand a specific event. However, earthquake source imaging can suffer from inherent non-uniqueness (e.g. Mai et al.2016). Moreover, in a tsunami hazard context, observations are not readily available to constrain future earthquake sources, motivating stochastic approaches for example (e.g. McCloskey et al. 2008). While alternative approaches avoid characterization of fault slip altogether by using data assimilation (e.g. Maeda et al. 2015) or a double-couple source (e.g. Maeda et al. 2011), another way forward is incorporating earthquake rupture dynamics directly into tsunami models as the tsunami source. Ryan et al. (2015) use the final (time-independent) displacements from 3D dynamic rupture models of earthquakes on faults in offshore California as the tsunami source in models using the nonlinear shallow water equations solved 
by a finite difference scheme. Wendt et al. (2009) use the 3D, time-dependent displacements from dynamic rupture on a 3D fault with two planar segments (megathrust and splay) as the source for shallow-water, hydrodynamic tsunami models solved with finite difference methods. Dynamic modeling also may be used to produce stochastic models of tsunami generation and propagation as shown by Geist \& Oglesby (2014), who use a stochastic distribution of shear stress on the fault system and run multiple realizations of the random variables to produce a suite of earthquake and tsunami models. Time-dependent, 3D displacements from large-scale rupture scenarios of the 2018 Sulawesi earthquake and 2004 Sumatra earthquake, incorporating complex fault geometry and constitutive behavior, are linked to a hydrostatic shallow water tsunami model by Ulrich et al. (2019b) and Ulrich et al. (2020). 2D dynamic rupture simulations are fully coupled to the time-dependent response of water layers hosting tsunamis by Lotto et al. (2017a b, 2018). As Lotto et al. (2017a) concludes, the deep insight gained from this narrow study of three earthquake initial conditions on earthquake and tsunami behavior in $2 \mathrm{D}$ underscores the need for more investigation into the influence of complex earthquake dynamics on tsunamis.

Here, we present methods to harness the potential of complex, 3D dynamic rupture models as tsunami sources to enable direct studies of how earthquake initial conditions and earthquake dynamics affect tsunami genesis, propagation and inundation. These methods are based on the one-way linkage of a 3D dynamic earthquake rupture and seismic wave propagation model with a hydrostatic shallow water tsunami model. Both computational models are open-source and based on the discontinuous Galerkin method. They are linked using the integrated vertical surface velocity from the earthquake model to yield time- and space-dependent displacements to source the tsunami model, similar to methods by Saito et al. (2019) and Ulrich et al. (2019b). The influence of the horizontal displacements are accounted for following Tanioka \& Satake (1996). Because the displacements include fast waves that are not represented in the physical approximation of the hydrostatic model, we filter them by a spatialtemporal Fourier-transform.

We present two applications of this approach to earthquake-tsunami modeling, one simple and one more complex. The simple example links a rupture propagating across a gently dipping, planar fault surrounded by homogeneous, purely elastic media and an isotropic stress field. It includes two scenarios: one with high strength on the shallow fault leading to a blind rupture, and one with low strength on the shallow fault leading to a surface-breaching rupture. The seafloor displacements are Fourier-transform filtered in space and time to eliminate seismic waves that are incompatible with the hydrostatic, shallow water tsunami model. We compare both the earthquakes and the tsunamis in these two scenarios.

The second application uses a 2D seismo-thermo-mechanical model simulating long term sub- 
duction dynamics and seismic cycles to initialize the 3D dynamic earthquake rupture model (Fig. 11). Such TECSEAS models, bridging the time scales of tectonic (TEC) and seismic cycle (SEAS, Erickson et al. 2020) ) models, provide insight into the role of rheology, temperature, subduction dynamics, fault geometry, loading and evolution, including spontaneously evolving splay faults (e.g., van Dinther et al. 2013b, 2014; Sobolev \& Muldashev 2017; Tong \& Lavier 2018; Dal Zilio et al. 2019; D'Acquisto et al. 2020; Brizzi et al.|2020; Preuss et al. 2020). Earthquake rupture dynamics (including nucleation, propagation and arrest) are controlled by fault stress, strength and geometry and the surrounding material properties (e.g. Kame et al. 2003; Gabriel et al. 2012, 2013; Galis et al. 2015; Bai \& Ampuero 2017; van Zelst et al. 2019). Although these initial conditions may be informed by laboratory and regional observations (e.g. Aochi \& Fukuyama 2002; Aagaard et al. 2004; Murphy et al. 2018; Ulrich et al.2020), they remain difficult to constrain. This is particularly challenging in complex fault systems with lithological and geometric heterogeneities (e.g. Wendt et al.|2009), which impedes megathrust hazard assessment and mitigation. Constraints are particularly lacking in locations where observational data is sparse, either because earthquakes have not yet occurred or instrumentation is poor. Setting the earthquake model initial conditions from a subduction model provides much needed constraint on the earthquake model initial conditions.

This approach also ensures self-consistency amongst initial conditions. For example, the assigned fault stress and strength are consistent with the fault geometry and material properties on and surrounding the fault. It also ensures self-consistency between those conditions and long-term subduction. For example, the assigned fault stress, strength and geometry are consistent with crustal, lithospheric and mantle deformation over geological time scales. In contrast to highly simplified earthquake models, subduction-initialized 2D dynamic rupture models produce earthquakes with multiple rupture styles, shallow slip accumulation and fault reactivation (van Zelst et al.|2019).

Here, we extend the approach that initializes a 2D dynamic earthquake rupture with a subduction and seismic cycle model (van Zelst et al. 2019) to a 3D dynamic earthquake rupture. The linked initial conditions include a curved, blind fault geometry, heterogeneous fault stresses and strength, and spatially variable material properties. This linkage requires consideration of the incompressibility and visco-elasto-plastic, plane-strain conditions of the subduction model versus the compressible, elastic conditions of the earthquake model. The resulting 3D dynamic rupture is linked with the tsunami model through the time-dependent seafloor displacements, following the same methods as in the first two examples.

For each application, we outline the methods, describe the resulting earthquake and tsunami, calculate the efficiency of each earthquake in generating that tsunami, and compare the tsunami results with those generated by a source incorporating the time-independent seafloor displacements from the 
end of the earthquake model. We emphasize that these applications demonstrate the capabilities of the modeling framework; future, more involved and complex applications will certainly result in further knowledge gain.

\section{METHODS}

The earthquake and tsunami computational models utilized here are open-source, use discontinuous Galerkin schemes, and are facilitated by highly optimized parallel algorithms and software. The methods for one-way linking between these models and for setting earthquake model initial conditions from a subduction geodynamic and seismic cycling code are outlined in the following.

As a note on terminology; we use 'computational models' to describe the computer programs discretizing the model equations and implementing the numerical workflow, and 'physical models' to describe the structural setups, governing equations and selected input parameters. A 'scenario' refers to the results achieved by a computational model according to a specific physical model. We attempt to only use 'model' when the use of the term is unambiguous.

\subsection{Earthquake modeling with SeisSol}

SeisSol is the computational model used to simulate 3D dynamic earthquake rupture and seismic wave propagation (see App. A1). It solves the seismic wave equation in velocity-stress formulation using a Discontinuous Galerkin (DG) scheme with Arbitrary high-order DERivative (ADER) time stepping: ADER-DG (Dumbser \& Käser 2006; Käser \& Dumbser 2006). ADER is an explicit time-stepping method that achieves the same approximation order in space and time, but without requiring multiple stages for high discretisation order, as in e.g. Runge-Kutta schemes. The computational domain is discretized on a tetrahedral mesh, which simplifies automatic mesh generation for complicated geometries and facilitates static mesh adaptivity. Fast time to solution within SeisSol is enabled by recent hardware-aware computational optimizations targeting supercomputers with many-core CPUs (Breuer et al. 2014; Heinecke et al. 2014; Rettenberger et al. 2016) and an efficient local time-stepping algorithm (Breuer et al. 2016; Uphoff et al. 2017; Wolf et al. 2020). SeisSol has been validated against several community benchmarks (De La Puente et al. 2009; Pelties et al. 2012, 2014; Wollherr et al. 2018; Gabriel et al. 2020) following the SCEC/USGS Dynamic Rupture Code Verification exercises (Harris et al. 2009, 2018).

SeisSol is specifically suited to solve for rupture propagation along complex, 3D fault geometries. Its scalability enables large and long dynamic rupture models. For example, scenarios of the 2004 Sumatra-Andaman earthquake with up to 220 million element meshes and order 6 accuracy in space 
and time ran in 13.9 hours on the SuperMUC phase 2 supercomputer $(86,016$ cores) at the Leibniz Supercomputing Centre in Garching, Germany (Uphoff et al.|2017). Recent lower resolution scenarios require 4 hours on 5000 Sandy Bridge cores of the supercomputer SuperMucNG (Ulrich et al.|2020).

\subsection{Tsunami modeling with $\operatorname{sam}(\mathbf{o a})^{2}$-flash}

$\operatorname{sam}(\mathrm{oa})^{2}$-flash is the computational model used to simulate tsunami propagation and inundation (see App. A2). It solves the depth-integrated (hydrostatic) non-linear shallow water equations (e.g., LeVeque et al. 2011) using adaptive mesh refinement. It implements a second-order Runge-Kutta discontinuous Galerkin method on triangular grids (Cockburn \& Shu 1998; Giraldo \& Warburton 2008), allowing wave propagation with high accuracy. sam $(\mathrm{oa})^{2}$-flash features an accurate and robust wetting and drying scheme for the simulation of flooding and drying events at the coast (Vater \& Behrens 2014, Vater et al.|2015, 2019). The scheme is mass-conservative, preserves positivity of the fluid depth and accurately computes small perturbations from the water state at rest (e.g., tsunami waves). Bottom friction is parameterized through Manning friction by a split-implicit discretization (Liang \& Marche 2009). sam $(\text { oa })^{2}$-flash has been validated against a suite of benchmarks (Synolakis et al. 2008) (see App. A2,.

sam $(\mathrm{oa})^{2}$-flash provides parallelization in shared (using OpenMP) and distributed (via MPI) memory (Meister et al. 2016). It scales up to thousands of compute cores, with problem sizes that exceed one billion grid cells with dynamic adaptive refinement and coarsening of cells (Meister et al.2016). Efficient adaptive mesh refinement is based on tree-structured triangular meshes (see App. A2).

\subsection{Linking methods and initial conditions}

Fig. 1 shows schematically linkage between a subduction, earthquake and tsunami model. As we discuss here, this linkage requires consideration of assumptions inherent to each computational model, model dimensionality, and the time and space scales efficiently spanned by the computational models.

\subsubsection{Tsunami initial conditions}

Linkage from an earthquake model to a tsunami model requires several considerations. The recorded extent and the sampling rate of the domain and time frame of the earthquake model must be high enough to represent the required wavelength and frequency bands. For the transfer between models, the unstructured output from the earthquake model is bilinearly interpolated to an intermediate uniform Cartesian mesh. Also, we find that the earthquake model domain must be at least one fault length in each direction from the fault in order to minimize boundary effects. In terms of temporal resolution, 
we find that a $1 \mathrm{~Hz}$ sampling rate of the earthquake displacement field is sufficient, as it is much smaller than the typical temporal scale of a tsunami waves.

To build the tsunami source, the time-dependent variations in the 3D vertical and horizontal coseismic seafloor displacements are mapped into vertical perturbations of the $2 \mathrm{D}$ initial bathymetry field of the tsunami model, similar to the approaches in Saito et al. (2019), Wendt et al. (2009) and Ulrich et al. (2019b). The time-dependent displacement fields are given by the 3D vector $(\Delta x, \Delta y, \Delta z)$. The east-west and north-south horizontal components, $\Delta x$ and $\Delta y$, are incorporated into the tsunami source by the method proposed by Tanioka \& Satake (1996), which combines the vertical component of the displacement vector with vertical changes induced by the interaction of horizontal displacement components and bathymetry gradients:

$$
\Delta b=\Delta z-\Delta x \frac{\partial b}{\partial x}-\Delta y \frac{\partial b}{\partial y}
$$

where $b=b(x, y)$ is the bathymetry (increasing in the upward direction). This contribution has been shown to be important both in general (e.g. Lotto et al. 2019) and for specific events, for example the 2011 Tohoku earthquake and tsunami (Murotani et al. 2015). However, for a physical model that includes flat bathymetry, the inclusion of horizontal displacement components has no effect on the tsunami source. $\Delta b$ is time-dependent, since $\Delta x, \Delta y$ and $\Delta z$ are time-dependent. The tsunami is sourced by adding $\Delta b$ to the initial bathymetry and topography of the tsunami model.

The tsunami computational model is capable of accurately modeling gravity wave propagation as well as non-linear effects due to advection and shoaling. The fastest resolved waves in the hydrostatic tsunami model are gravity waves, characterized by their linear wave speed of $v=\sqrt{g H}$, where $H$ is the mean water depth and $g$ the gravitational acceleration constant. For the applications presented in Sec.s 3 and 4 , the average water depth is $2000 \mathrm{~m}$, thus, the maximum wave propagation speed is approx. $140 \mathrm{~m} / \mathrm{s}$. Seismic surface waves in the earthquake rupture models are much faster, approaching approx. $2500 \mathrm{~m} / \mathrm{s}$. These seismic surface waves feature large transient amplitudes of up to $1 \mathrm{~m}$, which is of the same order as the static uplift at the end of the earthquake models. In nature, fast seismic surface waves at the elastic-acoustic interface are converted into infra-sound or damped in the weakly compressible water column as the ocean response becomes non-hydrostatic at short wavelengths. However, seismic surface waves from an earthquake model may lead to spurious gravity waves in the tsunami shallow water approach. In addition, since a rupture model is not required to span the same spatio-temporal dimensions as the tsunami model, trailing seismic waves may show up as artifacts in final seafloor deformation. Thus, a space-time Fourier-transform based filter that removes unwanted signals from the tsunami source is applied. 


\subsubsection{Earthquake initial conditions}

In the second example presented in Sec. 4, we initialize the earthquake model according to information from a subduction model that extends the long-term geodynamic model of Gerya \& Yuen (2007) to seismic cycles using seismo-thermo-mechanical models (van Dinther et al. 2013ab, 2014). This 2D subduction model solves for the conservation of mass, momentum and heat in an incompressible visco-elasto-plastic medium (Gerya \& Yuen 2007, see App. C). After modeling millions of years of subduction, spontaneous frictional instabilities are simulated by reducing the time step combined with a strongly slip rate dependent friction law. Slip, stress and spatial characteristics of these frictional instabilities resemble those of natural earthquakes, albeit at very low slip rates van Dinther et al. $2013 \mathrm{a}$ b). We refer to these instabilities as 'slip events' to distinguish them from dynamic earthquake ruptures modeled with SeisSol, which capture frictional failure along a pre-existing fault and the accompanying seismic wave emissions.

To initialize the earthquake model using the subduction model, we port information from a single slip event following methods similar to those for initializing a $2 \mathrm{D}$ earthquake model by van Zelst et al. (2019), but here extended to a 3D earthquake model that is then linked to a tsunami model. We must pre-define a 3D fault geometry in the earthquake model and do so by extending the 2D fault that evolves during yielding in the subduction model in the third dimension. In addition, the material properties, stress state and friction coefficients from the 2D slip event are extended into the third dimension in the earthquake model.

The computational subduction model is $2 \mathrm{D}$ and assumes plane-strain. The $3 \mathrm{D}$ computational earthquake model is not restricted to plane-strain conditions. We here extend the subduction model stress field into the third dimension for the earthquake model by setting the out-of-plane shear stresses to zero and the out-of-plane normal stress component to be a function of the two in-plane normal stresses and Poisson's ratio $\nu$. Taking the in-plane coordinates from the subduction model as $x$ and $z$ and the out-of-plane coordinate as $y$, this is:

$$
\begin{aligned}
\sigma_{y y} & =\nu\left(\sigma_{x x}+\sigma_{z z}\right), \\
\sigma_{x y} & =0, \\
\sigma_{y z} & =0 .
\end{aligned}
$$

We here adopt $\nu=0.5$, which is the Poisson's ratio used in the subduction model. This value arises from the assumption of incompressible rock, a valid assumption for modeling the long-term deformation at convergent margins.

Because the assumption of incompressible rock is not appropriate for dynamic earthquake rupture modeling, Poisson's ratio must be reassigned to $\nu<0.5$ when transferring the material properties 
from the subduction model to the earthquake model. Lame's parameter is then calculated from the assigned $\nu$ and the shear modulus from the subduction model.

\subsubsection{Data management in massively parallel simulations}

The earthquake and tsunami computational models and their linkage requires input at several stages. For example, output from the subduction model is used to set the initial conditions for the earthquake model. Also, bathymetry data and seafloor displacements from the earthquake model are initial conditions in the tsunami model. To manage such data in massively parallel simulations, we use ASAGI (pArallel Server for Adaptive GeoInformation), an open-source library with a simple interface to access Cartesian material and geographic datasets (Rettenberger et al. 2016) (www.github.com/ TUM-I5/ASAGI). ASAGI organises Cartesian data sets as a collection of tiles. For dynamically adaptive simulations, the parallel partitions that are assigned to each compute node may grow or shrink,as the mesh resolution is adapted. ASAGI automatically replicates or migrates the corresponding data tiles across compute nodes, which greatly simplifies the computing access to material or geographic data at a specific location.

\section{TSUNAMIS SOURCED BY A BLIND VERSUS A SURFACE-BREACHING DYNAMIC RUPTURE}

Here, we demonstrate methods and highlight key results for linking a generic 3D megathrust rupture on a planar fault to tsunami generation and propagation in a basin with flat bathymetry and inundation on a linearly sloping beach. We compare tsunamis sourced by two earthquake scenarios that differ only by their near-surface fault strength, which controls the propagation of slip to the trench and results in one blind and one surface-breaching rupture.

We find that the surface-breaching rupture exhibits higher maximum and average fault slip and higher maximum and average vertical seafloor displacements. These differences are reflected in differing initial tsunami peak heights and wave shapes. However, the difference in peak height diminishes during tsunami propagation towards the beach and the inundation patterns are similar in both scenarios; inundation occurs along the same stretch of the beach and has the same run-up. The width of the inundated corridor inland from the coast and the timing of inundation do differ between scenarios, however, reflecting differences in timing in displacement of the water mass and in the magnitude of water displaced.

We can here study tsunami sensitivity to source time dependence, complementing heuristic findings (e.g. Davies 2019). By comparing these results to tsunamis sourced by the time-independent 
displacements, we find differences in the maximum run-up distances and in the temporal behavior of the tsunami.

\subsection{Dynamic earthquake rupture model and scenarios}

The earthquake physical model incorporates a planar fault that is $200 \mathrm{~km}$ along strike and extends from the surface to $35 \mathrm{~km}$ depth at a $16^{\circ} \mathrm{dip}$. It intersects the seafloor and has an along-dip length of $127 \mathrm{~km}$. The material around the fault is homogeneous with properties that reflect those estimated for oceanic crust in a subduction zone (density $\rho=3775 \mathrm{~kg} / \mathrm{m}^{3}$, shear modulus $G=67.5 \mathrm{GPa}$, Lamé parameter $\lambda=85.3 \mathrm{GPa}$, from Stephenson et al. (2017)). The computational mesh for this structural model has 16 million tetrahedral elements and coarsens gradually off the fault to a maximum mesh size of $100 \mathrm{~km}$. A resolution of $66 \mathrm{~m}$ at the fault captures the dynamics in the process zone (Day et al. 2005) in which shear traction decreases from its static to its dynamic value just behind the earthquake rupture front (see App. B).

In this earthquake model, we use linear slip-weakening friction (Ida 1972). At any position on the fault, dynamic fault slip is modeled in two stages: first, there is static failure when the shear stress resolved on the fault exceeds the fault's static strength. Then, after failure, slip initiates, the fault weakens, and seismic waves are emitted. The static failure criterion is (using a compression negative sign convention):

$$
\left|\tau_{s}\right|=c-\mu_{s} \tau_{n}^{\prime}
$$

where $\tau_{s}$ is the shear traction on the fault, $\tau_{n}^{\prime}$ is the effective normal traction, $c$ is the on-fault cohesion, and $\mu_{s}$ is the static friction coefficient. The right-hand-side in Eq. 3 is the static fault strength. $\tau_{n}^{\prime}$ and $\tau_{s}$ increase linearly with depth (Fig. 2 a,b) and we assign a uniform $\mu_{s}$ of 0.275 (Fig. 2k). The effective normal traction includes the effect of pore fluid pressure, which we set to be depth-dependent and near-lithostatic $\left(P_{f}=\rho_{f} g z\right.$, where $\rho_{f}=-3000 \mathrm{~kg} / \mathrm{m}^{3}, g$ is gravitational acceleration and $z$ is depth, Fig. 2a).

The two earthquake scenarios that we compare here differ only by the static fault strength near the surface, controlled by $c$ (Fig. 2 $\mathrm{d}$ ). In Scenario A, $c=0.4 \mathrm{MPa}$ everywhere below $15 \mathrm{~km}$, but gradually increases above $15 \mathrm{~km}$ to $8 \mathrm{MPa}$ at the top of the fault. In Scenario B, $c=0.4 \mathrm{MPa}$ everywhere.

We implement fault weakening in this model following the linear slip weakening friction law formulation proposed by Andrews (1976). $\mu_{s}$ drops linearly to the dynamic coefficient of friction $\mu_{d}=0.25$ (Fig. 2 2 ) over the slip weakening distance $D_{c}=0.5 \mathrm{~m}$ (Fig. 2e). The earthquake rupture begins by forced weakening over time in a predefined patch following the nucleation procedure in several benchmarks from Harris et al. (2018). This nucleation patch is in the southeast corner of the 
fault at $26 \mathrm{~km}$ depth. Slip propagates spontaneously outward across the fault from this location for $\sim 60 \mathrm{~s}$ and is geometrically stopped at the three buried fault edges.

In Scenario A, the higher strength near the top of the fault smoothly stops the rupture as it approaches the surface, while in Scenario B, slip continues to the top of the fault and breaks the surface. Fig. 3 shows the accumulated fault slip as well as the final and maximum vertical surface displacements for both scenarios.

Key earthquake characteristics for the blind (Scenario A) and surface-breaching (Scenario B) ruptures are compared in Table 1 . The surface-breaching rupture results in a comparable moment magnitude $\left(M_{w} 8.6\right)$ to the blind rupture $\left(M_{w} 8.5\right)$, while the average dynamic stress drop is $3.9 \mathrm{MPa}$ in the surface breaching rupture and 3.0 MPa for the blind rupture. In distinction, the average and maximum accumulated fault slip are considerably lower in the blind rupture, at $3.8 \mathrm{~m}$ and $7.6 \mathrm{~m}$, while the surface-breaching rupture has average slip of $6.5 \mathrm{~m}$ and maximum slip of $10.9 \mathrm{~m}$. The fault slip is also differently distributed: the surface-breaching rupture presents large shallow slip, whereas the peak slip occurs deeper in the blind earthquake scenario.

In both earthquakes, the average rupture velocity resembles a typical megathrust tsunamigenic earthquake, but not a slower 'tsunami' earthquake Kanamori (1972). The mean values are similar in both scenarios, at $3.5 \mathrm{~km} / \mathrm{s}$ for the blind rupture and $3.7 \mathrm{~km} / \mathrm{s}$ for the surface-breaching rupture. Rupture velocity remains subshear relative to the $4.3 \mathrm{~km} / \mathrm{s}$ S-wave speed in the surrounding material along most of the fault during the blind rupture, but transitions locally to supershear speed up-dip from the nucleation location and along the upper part of the fault in the surface-breaching rupture.

For both earthquake scenarios, the maximum and minimum vertical seafloor displacements over the entire earthquake occur at $t=56 \mathrm{~s}$. In the blind rupture, these are $2.6 \mathrm{~m}$ and $-1.0 \mathrm{~m}$, respectively. For the surface-breaching rupture, the maximum is larger at $3.3 \mathrm{~m}$, but the minimum is comparable at $-1.1 \mathrm{~m}$. The average vertical displacement at this time is $0.6 \mathrm{~m}$ for the blind rupture and twice as large, at $1.2 \mathrm{~m}$, for the surface-breaching event. The displacements continue to change after this time in both scenarios until they reach constant values. For the blind rupture, this occurs at $\sim t=80 \mathrm{~s}$, when spatial maximum is $1.9 \mathrm{~m}$, the minimum is $-1.0 \mathrm{~m}$ and the average is $0.9 \mathrm{~m}$. For the surfacebreaching rupture, this occurs later at $\sim t=95 \mathrm{~s}$, when the spatial maximum is $2.6 \mathrm{~m}$ and the minimum is $-1.2 \mathrm{~m}$. However, the average final displacement is $0.9 \mathrm{~m}$, which matches that for the blind rupture. In both scenarios, surface waves continue to propagate until the predefined end of the model run, which is set to $t=120 \mathrm{~s}$ for the blind rupture and at $t=124 \mathrm{~s}$ for the surface-breaching rupture. 


\subsection{Tsunami propagation and inundation model and scenario}

The tsunami physical model includes a flat seafloor and a linearly sloping beach (Fig. 4). Hence, we define the bathymetry by

$$
b(x, y)= \begin{cases}0.05\left(x-x_{0}\right) & \text { for } x>x_{0} \\ 0 \mathrm{~km} & \text { otherwise }\end{cases}
$$

where $x_{0}=200 \mathrm{~km}$ is the beach toe, where the slope begins. The initial sea surface is flat ('sea-atrest') and located at $z=2 \mathrm{~km}$, which means that the coastline is located at $x=240 \mathrm{~km}$. Above this level, the water depth is set to zero. We refer to the sea surface height $(s s h)$ as the deviation from the reference height of $2 \mathrm{~km}$. The model domain, which ranges from $x=-400$ to $400 \mathrm{~km}$ and from $y=-400$ to $400 \mathrm{~km}$, is set to be larger than the horizontal extent of the earthquake physical model to minimize model boundary effects. The minimum mesh size is $12.2 \mathrm{~m}$.

The bathymetry perturbation field $\Delta b$ (Eq. 1), accounting for the time-dependence of the simulated displacement field, is used to initiate the tsunami model. The unstructured output from the earthquake model is bilinearly interpolated to an intermediate uniform Cartesian mesh with a resolution of $1000 \mathrm{~m}$, which is used for the transfer between models. We also apply a space-time Fourier filter to remove unwanted signals from the tsunami source that are present in the output from the earthquake model (Sec. 2.3.1). This filtering approach is further discussed in Sec. 5.1. Fig. 4 shows $\Delta b$ at $t=102 \mathrm{~s}$.

Snapshots of the simulated tsunami wave-field are shown in Fig. 5. Also, key characteristics of the tsunami sourced by the blind rupture (Scenario A) and the surface-breaching rupture (Scenario B) are summarized in Table 2 .

Maximum initial $s s h$ resembles the maximum coseismic seafloor uplift of $2.6 \mathrm{~m}$ from the blind rupture and $3.3 \mathrm{~m}$ from the surface-breaching rupture. As shown in Fig. 6, the (filtered) source displacements of the blind rupture in Scenario A produce a smooth wave while those in Scenario B produces more abrupt initial displacements of the water column, as discussed in Sec. 5.1. The crosssection at $y=0$ and $t=120 \mathrm{~s}$ in Fig. 6a shows that the wave peak is initially higher for the surfacebreaching rupture source. At $t=1200 \mathrm{~s}$, just before first inundation in both scenarios, the heights of the peaks nearest the beach are more similar (Fig. 5 b). For the blind rupture source, the tsunami reaches a maximum of $s s h=3.0 \mathrm{~m}$ at $\mathrm{t}=1470 \mathrm{~s}$, while for the surface-breaching rupture source, the tsunami reaches $s s h=3.4 \mathrm{~m}$ at $t=1480 \mathrm{~s}$, a difference of $0.4 \mathrm{~m}$. By $t=1600 \mathrm{~s}$, the approximate time of maximum inundation, differences in peak heights have diminished, while tsunami wave distribution still differs (Fig. 5r).

We track the wave heights on land by comparing time series at $10 \mathrm{~km}$ inland from the coast near 
$x=240 \mathrm{~km}$ along cross-sections at $y=-150,0$ and $150 \mathrm{~km}$ (Fig $4 \mathrm{~d}$ ). The highest wave height occurs at $y=0 \mathrm{~km}$ in both Scenario A and Scenario B. However, the wave heights are asymmetric due to the uni-directional earthquake ruptures. Higher waves occur at $y=150 \mathrm{~km}$, the part of the coast that is closer to locations of larger fault slip and uplift in both earthquake scenarios. Lower waves occur at $y=-150 \mathrm{~km}$, the part of the coast that is closer to the earthquake hypocenter. The height of the tsunami wave at the coast from the blind rupture is $0.8 \mathrm{~m}$ higher than the maximum wave height near the source, though this difference is only $0.1 \mathrm{~m}$ for the tsunami sourced by the surface-breaching rupture (Table 2).

In general, wave peaks in Scenario B appear delayed relative to peaks in Scenario A, which is at least partially due to the fact that the location of highest seafloor displacement is farther away from the coast in Scenario B. This delay is more pronounced at $y=150 \mathrm{~km}$ and $y=-150 \mathrm{~km}$ than at $y=0 \mathrm{~km}(\mathrm{Fig} 4 \mathrm{~d})$, where it is approximately $100 \mathrm{~s}$. The average velocity from $t=1000 \mathrm{~s}$ to $t=1100 \mathrm{~s}$ of the wave peak from blind rupture source in Scenario A is $157 \mathrm{~m} / \mathrm{s}$, faster than that for the surfacebreaching rupture source in Scenario B of $142 \mathrm{~m} / \mathrm{s}$. This is in contrast to the earthquake rupture speed, which is on average faster in Scenario B and features supershear episodes.

The difference in propagation velocity does not affect the time of first inundation, which occurs at almost the same time in Scenario A ( $t=1210 \mathrm{~s})$ and Scenario B $(t=1220 \mathrm{~s})$ (Table 2). Inundation maps for both scenarios are shown in Fig. $7 \mathrm{~b}$ and $7 \mathrm{~b}$. In both scenarios, the waves reach a maximum runup of $73 \mathrm{~m}$ at the center of the beach (near $y=0$ ). Away from the center, the runup is lower. The inundation area is slightly asymmetric and skewed toward $y=150 \mathrm{~km}$ in both scenarios.

Fig. 77 shows that, even though the first arrival occurs at approximately the same time, inundation in Scenario B is delayed near the coast and laterally along the coast by up to $100 \mathrm{~s}$ relative to Scenario A. This is probably due to the delay in the wave peak in Scenario B (relative to Scenario A) shown in Fig. $4 \mathrm{~d}$ and the faster wave propagation speed in Scenario A. In contrast, inundation at locations farther inland from the coast occurs earlier in Scenario B by approximately $60 \mathrm{~s}$. The final inundated area for the surface-breaching rupture in Scenario B $\left(18.3 \mathrm{~km}^{2}\right)$ is $15 \%$ larger than for the blind rupture in Scenario A $\left(15.6 \mathrm{~km}^{2}\right)$. The differences occur inland from the coast, where Scenario B inundates a wider corridor.

\subsubsection{Comparison to tsunamis sourced using the time-independent displacements}

We now compare the tsunamis from both scenarios when the time-independent filtered displacements from the end of the earthquake model are used in the sources instead of the time-dependent displacements from throughout the dynamic earthquake rupture scenario. The time-independent seafloor uplift has a maximum of $1.9 \mathrm{~m}$ for the blind rupture in Scenario A versus $2.6 \mathrm{~m}$ for the surface-breaching 
rupture in Scenario B. This is lower than the maximum uplift during the entire earthquake at $t=100 \mathrm{~s}$ of $2.6 \mathrm{~m}$ and $3.3 \mathrm{~m}$ in these scenarios, respectively (Table 1 ). However, the average time-independent displacements are equivalent at $0.9 \mathrm{~m}$ for both scenarios.

In general, the tsunamis from the time-independent sources inundate the coast earlier than those from the dynamically sourced models. To compare them, we equalize the times of first inundation: the time-independent source from the blind rupture in Scenario A is shifted by $40 \mathrm{~s}$ and the source from the surface-breaching rupture in Scenario B by 60 s. Fig.s $7 \mathrm{~d}$ and $7 \mathrm{e}$ show the inundation corridors. These are best analyzed by looking at their differences to other results. The similarity of Fig. $7 f$ with Fig. 7 suggests that the differences between the two scenarios are unaffected by the change from a time-dependent to a time-independent source.

Fig.s $7 \mathrm{~g}$ and $7 \mathrm{~h}$ show the differences between tsunamis for each scenario with the change in the source. Importantly, in the surface rupturing Scenario B, the maximum run-up distance near $y=0$ is over-predicted with the time-independent source (Fig.s 7 e). In other characteristics, the two scenarios respond in a similar way to this change in source. The waves from the time-independent source arrive later at the coast along $y<0$ and earlier at the coast along $y>0$. So, coastal inundation occurs over a shorter time. This is consistent with the source from a single time-step, rather than over the entire lifetime of the earthquake rupture. Farther inland, this trend is less pronounced. These differences in wave timing are visible in (Fig 8$)$ as well, which shows that the tsunamis from time-independent sources lag behind those from the time-dependent sources at $y=0 \mathrm{~km}$ and precede the time-dependent sources at $y=150 \mathrm{~km}$. The tsunami from the time-independent sources also over predict wave height at $y=0 \mathrm{~km}$.

\subsection{Summary}

Using our virtual laboratory, we simulate tsunamis sourced by two megathrust earthquake scenarios that differ only by their near-trench fault strength and, as a result, slip behavior. This results in one blind and one surface-breaching rupture that differ in fault slip distribution and rupture kinematics. The surface-breaching rupture exhibits $70 \%$ larger average fault slip and $40 \%$ larger peak fault slip. Despite this, the surface-breaching rupture causes a maximum seafloor displacement that is only $35 \%$ higher than the blind rupture and the spatial averages of the seafloor displacements at the end of both earthquake scenarios are equal. The difference in maximum displacement is reflected in different initial tsunami peak heights, but this difference diminishes during tsunami propagation towards the beach and at the time of maximum inundation at the coast at $y=0 \mathrm{~km}$, the peak wave height differential is only $0.4 \mathrm{~m}$. The tsunamis in both scenarios flood asymmetric regions due to the uni-directional earthquake rupture and inundate the same $400 \mathrm{~km}$ of the coast and exhibit the same run-up of $73 \mathrm{~m}$. 
However, the tsunami generated by the surface-breaching rupture inundates a $15 \%$ larger area overall due to a wider inundation corridor inland from the coast.

For both scenarios, using the time-independent displacements in place of the time-dependent displacements in the tsunami source results in later arrival at the coast, but faster coastal inundation. For the surface-breaching rupture source, using the time-dependent displacements also over-predicts run-up.

\section{TSUNAMI SOURCED BY A SUBDUCTION-INITIALIZED DYNAMIC RUPTURE}

We now use output from a 2D subduction model (Sec.2.3) to build the 3D earthquake model (Scenario C). In this way, earthquake initial conditions are assigned self-consistently and the tsunami source reflects the conditions developed over long-term subduction and seismic cycling. This adds complexity to the earthquake source relative to scenarios $\mathrm{A}$ and $\mathrm{B}$ in the previous section.

The earthquake initial conditions are heterogeneous and characterized by stark material contrasts, e.g., between sedimentary and basaltic regions, as well as smaller scale heterogeneous conditions reflected in fault geometry, fault strength, friction drop and stresses. Pore fluid pressure is elevated at a ratio of 0.95 to the lithostatic stress. Also, the critical slip weakening distance $D_{c}$ here varies with depth to resemble the friction drop measured during the geodynamic slip event.

We use the same methods as in Sec. 3.2 to link the earthquake model to the tsunami model. The fault does not intersect with the surface, so the rupture is blind, but it efficiently generates a tsunami.

\subsection{Dynamic earthquake rupture}

\subsubsection{Earthquake physical model}

We initialize the dynamic rupture model by porting the fault geometry and strength, material properties and stress state from one slip event in the subduction model. Both the geodynamics and seismic cycling phases of the subduction model and the definition of a slip event are described in App. C. The workflow for linking subduction to a $3 \mathrm{D}$ earthquake model is detailed here, which expands the approach for a 2D earthquake presented in van Zelst et al. (2019).

The sides of the earthquake physical model are $1600 \mathrm{~km}$ and it extends to $500 \mathrm{~km}$ depth (Fig.99). The fault from the subduction slip event is a curve that extends for $320 \mathrm{~km}$ in the fault dip direction to a depth of $100 \mathrm{~km}$. Fault dip gradually increases with depth, ranging from $2.3^{\circ}$ to $34^{\circ}$ and averaging $14.8^{\circ}$. To pre-define the 3D fault in the earthquake model, fault locations are taken from the subduction slip event every $500 \mathrm{~m}$ in the $\mathrm{x}$-direction (distance from trench) at the depth (z-direction) of the maximum strain rate over the entire slip event and smoothed with a moving average filter. To expand 
this line to a 3D fault surface, we assume that it is uniform in the third dimension, along fault strike, and extend it for $400 \mathrm{~km}$ (Fig. 9 ). The fault does not intersect the surface, neither in the subduction nor earthquake models. We spatially discretize this structural model with elements of an edge length of $1 \mathrm{~km}$ on the fault, $5 \mathrm{~km}$ within a mesh refinement zone surrounding the fault, and a maximum element edge length of $20 \mathrm{~km}$ (App. B and Fig. A1).

The material properties and stress state are taken from the start of the subduction slip event (Fig. A2). As discussed in Sec. 2.3, the material properties for the earthquake model are determined by reassigning Poisson's ratio, here to $\nu=0.25$. This results in a Poisson solid with Lame's parameter equal to the shear modulus $(\lambda=G)$. The material properties used in the earthquake model are shown in a slice through the 3D volume in Fig. $9 \mathrm{p}$. These are applied uniformly in the third dimension, along fault strike, in the earthquake model. The Cartesian stresses are ported to the earthquake model and stress in the third dimension (parallel to fault strike) is set by honoring the plane-strain assumption taken in the subduction model (Sec. 2.3).

In the earthquake model, fault failure occurs according the stress resolved on the fault as:

$$
\left|\tau_{s}\right|=c-\mu_{s}^{\prime} \tau_{n}
$$

This is equivalent to Eq. 3. but expressed in terms of the absolute normal traction, $\tau_{n}$, and the effective static coefficient of friction, $\mu_{s}^{\prime}$, at the beginning of the subduction slip event. We use the term effective here because $\mu_{s}^{\prime}$ accounts for the pore fluid pressure, which has a ratio to the lithostatic stress of 0.95 along the fault during this slip event. $\tau_{n}$ increases with depth, while $\tau_{s}$ reaches a maximum near $43 \mathrm{~km}$ depth and minima near the surface and at large depths (Fig. 10 a,b). We assign the frictional cohesion, $c$, to equal the bulk cohesion, $C$, in the subduction slip event (Fig. 10d). We do, however, increase $c$ in the earthquake model along the part of the fault that cuts through the sediments, as discussed at the end of this section. The Cartesian stress tensors are initialized in the earthquake model and SeisSol determines the tractions on the fault. Hence, it is critical that the fault and stresses in the earthquake model are in the same location relative to one another as in the subduction model (App. D).

After the onset of failure, the earthquake model fault weakens according to a linear slip-weakening friction law (Andrews 1976) and $\mu_{s}^{\prime}$ changes with slip to an effective dynamic value, $\mu_{d}^{\prime}$. If the fault location is in a velocity strengthening region of the subduction model, we assign $\mu_{d}^{\prime}$ to equal the maximum effective friction reached at that location during the entire subduction slip event, which may be locally larger than $\mu_{s}^{\prime}$. If the fault location is in a velocity weakening region, we assign $\mu_{d}^{\prime}$ to equal the minimum value effective friction reached at that location during the entire subduction slip event. The 2D slip weakening distance, $D_{c}$, is assigned such that the friction drop is equivalent to that 
along the 1D fault in the subduction slip event (van Zelst et al. 2019). As shown in (Fig. 10 ), such constrained $D_{c}$ varies with depth.

In a pre-modeling step taken before running the earthquake model, we check for points of static failure according to the earthquake model criterion (Eq. 5) along a cross-section through the 3D fault shown in Fig. 11. The failure criterion is met in three locations: within the shallow sediments, at one isolated point at $74.7 \mathrm{~km}$ depth, and in the region of $40-43 \mathrm{~km}$ depth.

In the subduction model, the slip event spontaneously initiates at $40-43 \mathrm{~km}$ depth. This is a location where the correct brittle failure mechanisms also are active. We predefine 3D a nucleating patch here in the earthquake model centered at $x=267 \mathrm{~km}, y=0 \mathrm{~km}, z=-41.5 \mathrm{~km}$ and with a radius of $1.3 \mathrm{~km}$. Inside the patch we assign $\mu_{s}^{\prime}=0.019$, equal to the minimum value of $\mu_{s}^{\prime}$ in the subduction model inside this nucleating region. In order to restrict nucleation laterally, we then set $\mu_{s}^{\prime}=0.025$ in the regions outside of, but at the same depths as, the nucleation zone. This is the value of $\mu_{s}^{\prime}$ above $40 \mathrm{~km}$ depth. We discuss linkage related to nucleation further in Sec. 5.2

In the subduction model, nucleation of a slip event in the shallow sediments and at $74.7 \mathrm{~km}$ depth is inhibited. The shallow sediments are always at plastic failure, but velocity strengthening allows continuous creep through time without nucleation of brittle failure. However, localized exceeding of the failure criterion in the earthquake model would lead to rupture nucleation. Therefore, we prevent failure by assigning $c=5 \mathrm{MPa}$ in the sediments above $25 \mathrm{~km}$ depth, which is the value of $c$ in the deeper basalt.

At $74.7 \mathrm{~km}$ depth, high temperatures ensure deformation occurs predominantly through dislocation creep in the subduction model. Again, isolated exceeding of the failure criterion in the earthquake model leads to rupture nucleation here. To prevent this, we assign $\mu_{s}^{\prime}=0.02$, which is the value of $\mu_{s}^{\prime}$ nearby.

We make one minor, additional adjustment to the earthquake model. Near the material contrast at $27 \mathrm{~km}$ depth, $\mu_{s}^{\prime}$ and $\mu_{d}^{\prime}$ are anomalously large due to interpolation inaccuracies near stark material contrasts (Fig. 10 c). We relax $\mu_{s}^{\prime}$ and $\mu_{d}^{\prime}$ at these points to the values of material below, such that $\mu_{s}^{\prime}=0.025$ and $\mu_{d}^{\prime}=0.0097$.

\subsubsection{Earthquake rupture scenario}

This subduction-initialized earthquake in Scenario C initiates spontaneously within the nucleation patch due to the locally high $\tau_{s}$ and locally low $\mu_{s}^{\prime}$ inherited from the 2D subduction slip event (Fig. 11). Slip then progresses outward in all directions along the fault, producing a $M_{w} 9.0$ earthquake with an average dynamic stress drop of $2.2 \mathrm{MPa}$, which is lower than in Scenarios A and B (Sec. 3). The rupture does not progress to the shallowest or deepest parts of the fault due to the stress 
and strength conditions there and is stopped by the fault edges along the central fault. The accumulated fault slip reaches maxima of $95.5 \mathrm{~m}$ in two locations, as shown in Fig. 12a, and the average accumulated slip is $42.2 \mathrm{~m}$, which is higher than in Scenarios A and B. Slip prevails for approximately $150 \mathrm{~s}$. Waves continue to propagate after this time and surface waves and waves trapped in the sediments are still present at the end of the earthquake scenario at $t=241 \mathrm{~s}$ (Fig. $12 \mathrm{p}$ and $12 \mathrm{c}$ ). The large modeled slip results from the effect of reverberating seismic waves and the chosen Poisson's ratio, similar to the 2D case (van Zelst et al. 2019).

The S-wave speed for the basalt around the fault is $3.2 \mathrm{~km} / \mathrm{s}$. The earthquake rupture velocity exceeds this locally, reaching supershear speeds near the nucleation location and laterally along the fault at the depth of nucleation. Elsewhere along the fault, the rupture proceeds at sub-shear speeds. On average, the rupture velocity is $2.1 \mathrm{~km} / \mathrm{s}$, which is slower than the average velocities of the ruptures in Scenarios A and B, but still higher than a 'tsunami' earthquake Kanamori (1972).

The maximum vertical surface displacement over the entire earthquake is $28.1 \mathrm{~m}$ and occurs at $t=100 \mathrm{~s}$ (Fig. 13). At this time, the minimum vertical displacement is $-5.6 \mathrm{~m}$ and the average is $3.6 \mathrm{~m}$. After the earthquake simulation ends at $t=241 \mathrm{~s}$ (Fig.s 12p and 12 $\mathrm{p}$ ), the maximum and minimum displacements are $15.7 \mathrm{~m}$ and $-6.7 \mathrm{~m}$, respectively, and the average is $3.3 \mathrm{~m}$. All characteristic displacements are larger than in Scenarios A and B (see Table 1).

\subsection{Tsunami propagation and inundation}

The tsunami physical model in Scenario C is the same as that used in Sec. 3.2, but its spatial dimensions are adjusted to the larger earthquake model. The beach slope begins at $x_{0}=500 \mathrm{~km}$, the coast is located at $x=540 \mathrm{~km}$, and the size of the domain extends from $x=-600$ to $600 \mathrm{~km}$ and $y=-600$ to $600 \mathrm{~km}$ (Fig. 13). As in Sec. 3.2, the tsunami source, $\Delta b$, incorporates the time-dependent 3D seafloor displacements from the earthquake scenario following Eq.11. The unstructured output from the earthquake model is bilinearly interpolated to a structured mesh at a resolution of $1000 \mathrm{~m}$. As previously done, we apply a space-time Fourier filter to $\Delta b$ which is discussed in Sec. 5.1

The seafloor displacements are symmetric about the $x$-axis during the entire earthquake (Fig.s 12 c and 13, as expected based on the symmetrically centered nucleation region. Fig. 14a-d shows the field of the sea surface height ( $s s h$ ) for different moments in time. Initially, ssh reflects the vertical displacement magnitudes from the earthquake (Fig. 14a), then the tsunami develops a circular wave propagating away from the source (Fig. 14p) until it reaches the coast at $t=2050 \mathrm{~s}$. At this time, the wave at $y=0$ reaches $s s h=24 \mathrm{~m}, 0.4 \mathrm{~m}$ lower than the maximum height near the earthquake source, but much higher than in Scenarios A and B (Table 2). Fig. 14k shows the wave just after the time of first inundation and Fig. $14 \mathrm{~d}$ shows the wave at the approximate time of maximum inundation 
at $t=2400 \mathrm{~s}$. Cross sections through the sea surface along $y=0$ are shown in Fig. $15 \mathrm{a}$-c. On average, the peak of the wave travels at a speed of $148 \mathrm{~m} / \mathrm{s}$, a propagation speed that falls between those for the tsunami in scenarios A and B in Sec. 3,

Fig. 16a shows the history of inundation. First inundation occurs at $2050 \mathrm{~s}$. The final inundation area is $27 \mathrm{~km}^{2}$ and the maximum run-up length is $492 \mathrm{~m}$ after $t=2410 \mathrm{~s}$. These characteristics are an order of magnitude larger than in Scenarios A and B, highlighting the impact of large and slow slip on a curved fault even during a fully buried, low stress drop event. Maximum run-up is increased in particular.

\subsubsection{Comparison to tsunami from a time-independent source}

We now model the tsunami using only the time-independent filtered displacements from the end of the earthquake model, instead of the time-dependent filtered displacements from throughout the dynamic earthquake rupture in Scenario C. The tsunami from this time-independent source arrives at the coast $200 \mathrm{~s}$ earlier than the tsunami from the time-dependent source, so we shift the simulation results by $200 \mathrm{~s}$ to synchronize the scenarios to the time when the coast is first inundated. The maximum timeindependent seafloor uplift is lower than the maximum uplift during the entire earthquake, though the mean displacement values for both cases are much closer (Table 1 .

Fig. 16 shows the inundation region for the tsunami from the time-independent source and Fig. 16. compares this to the original tsunami in Fig. 16. Using a time-independent source overpredicts the run-up distance, as for the tsunami sourced by the surface breaching rupture in Scenario $\mathrm{B}$, but produces a narrower inundation corridor at all distances from the coast. While the timeindependent source generally delays inundation, it advances the time of first inundation near $y=$ $-200 \mathrm{~km}$ and $y=200 \mathrm{~km}$. It also advances inundation at the points most distant from the coast. In general, the temporal characteristics are more distorted by the change to a time-independent source than the spatial characteristics, as may be expected.

Fig. 17a and Fig. 17p compare the wave profiles from the time-independent and time-dependent sources at $t=420 \mathrm{~s}$. Along $y=0$, the wave pattern is similar for both sources, but the timeindependent source produces a $1.1 \mathrm{~m}$ higher peak and this peak is advanced ahead of that in the original source (Fig. 17). At $y=150$, the time-independent source produces a wave peak that is $1.3 \mathrm{~m}$ lower than for the time-dependent source, but the two wave peaks are in similar locations (Fig. 17p). Fig. 17f and Fig. 17d compare the waves for the static and dynamic cases in time at the coast ( $x=540 \mathrm{~km})$. At $y=0$, the time-independent source again over predicts the peak wave height (Fig. 17k), but the peak from the time-independent source is again slightly under-predicted at $y=150$ (Fig. 17d). 


\subsection{Summary}

In comparison to the two scenarios in Sec. 3, the average dynamic stress drop and rupture velocity for this subduction-initialized earthquake are lower, but fault slip and seafloor uplift are larger. The fault does not intersect with the surface, so the rupture is blind. We find that large and slow slip on a curved fault significantly impact tsunami characteristics, particularly maximum run-up, even in a fully buried and low stress drop event. Use of time-independent instead of time-dependent filtered displacements in the tsunami source over-predicts wave peaks at $y=0$, but under-predicts peaks away from this location. This results in an under-estimate of the width of the inundation corridor everywhere except in the central region inland from the coast. Run-up is also over-predicted. Temporal differences include delayed arrival at the central coast, but advanced arrival along the more distant coast and at the locations farthest inland.

\section{DISCUSSION}

We here discuss selected aspects of the presented methods for linking subduction, dynamic earthquake rupture and tsunami models. We generalize on the use of time-independent versus time-dependent displacements as tsunami sources, compare the earthquakes and tsunamis in Scenarios A, B and C with real events, and contrast the tsunami-generating efficiency of the earthquakes in all three scenarios. We end with a look forward.

\subsection{D dynamic earthquake model - shallow water tsunami model linking}

Use of a hydrostatic shallow water tsunami model in the linked modeling chain allows for evaluation of not only tsunami generation and propagation through open water, but also inundation at the coast. In this workflow, we remove trailing seismic waves and specifically surface waves with a space-time Fourier-transform based filter. Fig. 18 shows the filtered vs. unfiltered source at $t=249 \mathrm{~s}$, the end of the dynamic rupture model in the subduction-initialized earthquake (Scenario C). Note that the general uplift is kept unchanged, while the waves characterized by high ratios of frequency to wavelength (fast propagating waves/short wavelengths) surrounding the uplift area are effectively damped. We note that Saito et al. (2019) use a low-pass filter, which does not completely eliminate the seismic waves from the tsunami signal near the source. Although we leave a full computational analysis to future work, we additionally find that the discretized shallow water solver also acts as a filter, since the fast wave creates a short impulse of momentum that decays immediately after the wave has passed, leaving the water column basically untouched.

The linked modeling approach permits study of tsunami sensitivity to source time dependence in 
scenario cases, complementing heuristic findings (e.g. Davies 2019). We compare tsunami sourced by the time-dependent, filtered bathymetry perturbation with those sourced by the perturbation considering the time-independent displacements at the end of each earthquake scenario. We find, as may be expected, that temporal differences are larger than spatial differences.

In all three scenarios, use of a time-independent source results in more constant arrival times at the coast; the coast near the hypocenter is inundated later and the more distant coast is inundated earlier than for the tsunami with the time-dependent source. This behavior is consistent with a simulation of the 2004 Indian Ocean tsunami (Poisson et al. 2011), where earlier wave arrivals result from a time-independent tsunami source.

Use of a time-independent source in Scenarios B and C (with surface-breaching and subductioninitialized earthquakes, respectively) over-predicts run-up. In Scenario C, the width of the inundation corridor is under-predicted at all distances from the coast. This is not the case for Scenarios A or $\mathrm{B}$, however, where the width of the inundation corridor remains relatively unchanged. This effect in Scenario C may be related to over-prediction of the central wave peak (at $y=0$ ) and under-prediction of the wave peaks away from here.

We see that the highest seafloor displacements over the entire duration of the earthquake do not control the tsunami heights during propagation to first order, but may control the width of the inundation corridor inland from the coast. This is seen in Scenarios A and B, which have seafloor displacements that differ by $35 \%$, but exhibit a decreasing difference in peak wave height during propagation. The narrower inland inundation corridor for the blind rupture reflects its lower maximum seafloor displacements. This is also seen when comparing tsunamis from time-dependent and time-independent sources. In all scenarios, the highest seafloor displacements are consistently higher than the maximum displacements from the end of the earthquake that are used in the time-independent source (by up to an order of magnitude in case of Scenario C, Table 1). However, the peak wave heights from the time-dependent and time-independent sources are similar. This suggests that it is the more comparable average displacements that control tsunami wave heights, because they control the volume of water displaced.

In Scenario C, the inundation area of the tsunami from the time-independent source is narrower than that from the time-dependent source (Fig. 16c). This is also seen when comparing the tsunamis from the time-dependent sources from Scenario A versus Scenario B (Fig. 7f) and when comparing the tsunamis from the time-independent sources from Scenario A versus Scenario B (Fig. 7f). We attribute the narrower inundation corridors to the relatively low transient displacements during the associated earthquakes. However, this effect is not pronounced when comparing the tsunamis from the time-dependent versus time-independent sources in Scenario A (Fig. $7 \mathrm{~g}$ ) or from the time-dependent 


\section{Madden et al.}

versus time-independent sources in Scenario B (Fig. 7h). These types of differences, shown here in generic models, may be challenging to distinguish from field data, for which regional and data-driven adjustment of the scenarios may be required.

\subsection{Subduction model - 3D dynamic earthquake rupture model linking}

Initializing the earthquake dynamic rupture model with a subduction model provides coherent initial conditions in the earthquake model that typically are poorly constrained. Furthermore, this ensures compatibility of those conditions, i.e., with long term subduction and seismic cycling, as shown here, as well as with splay faulting in the accretionary wedge (van Dinther et al. 2013b, 2014; van Zelst et al. 2019). This is particularly relevant in cases where splay faulting may be a major part of the tsunami source, for example in the 2004 Sumatra-Andaman earthquake and Indian Ocean tsunami (e.g. Chauhan et al. 2009; DeDontney \& Rice 2011).

Linearly varying or constant stress with depth is often incorporated into dynamic rupture models (e.g. Kozdon \& Dunham 2013; Ramos \& Huang 2019; Ulrich et al. 2019b) alongside constant frictional parameters and homogeneous material properties. Initial conditions for the earthquake scenarios in Sec. 3 reflect these assumptions, including a homogeneous material, linearly increasing normal and shear tractions, a planar fault, and constant frictional parameters. The fault experiences a linearly increasing static strength with depth (Fig. 2). However, what the initial conditions in the subductioninitialized earthquake in Sec. 4 reveal are shear traction and static friction depth profiles that vary with both depth and material, with the most obvious change from sediments to oceanic crust at approx. $28 \mathrm{~km}$ depth (Fig. 10). There is also variability in the static and dynamic friction coefficients with depth. This is a far greater (and continuous) range of values than are provided by laboratory measurements on a select number of samples. It also provides context for different results that may emerge from field studies of a single subduction zone.

Because we assume that the fault, material properties and all linked on-fault conditions are constant in the third dimension not provided by the 2D subduction model, this approach still simplifies conditions relative to nature. Nonetheless, the heterogeneity directly influences the earthquake dynamics and therefore the tsunami source. For example, although the maximum fault strength is similar in all three scenarios presented here, the heterogeneous initial conditions for the subduction-initialized earthquake result in larger fault slip, but lower average dynamic stress drop and rupture velocity. This may correspond to natural megathrust behaviour. In addition, we observe that seismic waves traveling through complex materials around the fault (as opposed to a homogeneous material) influence earthquake dynamics, affecting rupture style and shallow slip accumulation.

These linking methods also provide avenues for investigating earthquake nucleation. We here run 
the entire seismic cycling phase of the subduction model and then select one slip event from the series of quasi-periodic events. We then identify the beginning of this event as the time step when two adjacent points are at failure due to local exceeding of the failure criterion. In $2 \mathrm{D}$ coupling by van Zelst et al. (2019), these two points constitute the nucleation line on a 1D fault that lead to a dynamic earthquake rupture. Along a 3D fault, we must laterally restrict this location and do so by creating a 2D nucleation patch centered on these points at failure. Assigning a lower effective dynamic friction coefficient inside than outside of this patch, with both values taken directly from the subduction model, sustained dynamic earthquake rupture is initiated. Future work may investigate the sensitivity of nucleation to patch radius, patch shape or other characteristics. Also, future exploration of the relationship between slip initiation in the earthquake model and strain rate or slip rate in the subduction model may provide insight into the nature of slip nucleation itself.

\subsection{Realistic scenarios?}

Here we compare the linked scenarios against observed events, evaluating not only if a reasonable and/or realistic modeled tsunami is produced from a particular earthquake source, but also if that modeled earthquake is itself a reasonable/realistic event. We discuss the effects of slip-to-the-trench, and compare the tsunami-generating efficiency of the earthquakes in all three scenarios.

\subsubsection{Blind versus surface-breaching ruptures (Scenarios A and B)}

Prior to the 2011 Tohoku earthquake, the compliance and velocity strengthening behavior of shallow subduction zone materials was thought to prohibit fault slip near the trench. Most finite fault inversions restricted shallow slip, as for example slip inversions for the 2004 Sumatra-Andaman earthquake (Shearer \& Burgmann 2010). In this case, the large Indian Ocean tsunami originally was attributed to splay faulting, launching both field and modeling investigations (e.g. Chauhan et al. 2009; DeDontney \& Rice 2011). However, seafloor observations of the 2011 Tohoku earthquake changed this view. In the case of the 2004 Sumatra-Andaman earthquake, recent investigations suggest that lithification of shallow sediments could permit slip at near or at the trench (Hüpers et al. 2017; Gulick et al. 2011; Hüpers et al. [2017).

These considerations motivated the two tsunami sources in Sec. 3. We expected that the blind and surface-breaching ruptures in scenarios A and B would produce distinctly different tsunamis and the surface-breaching rupture would inundate a larger area than the blind rupture (Fig. 7F). Inundation area is $15 \%$ larger for the surface-breaching rupture. However, despite differences in the earthquake slip distributions and maximum slip values, the difference in peak wave height at the coast is small, 
and coastal inundation extent and run-up are the same in both scenarios. We note that the seafloor displacements in both scenarios differ less than the slip, partially explaining this contrast.

To better understand this, we calculate the efficiency of the Scenario A and Scenario B earthquakes in generating the resulting tsunamis as $\epsilon$ following Lotto et al. (2017a):

$$
\epsilon=h_{\max } /<s>
$$

where $h_{\max }$ is the maximum wave height near the source (here, taken at $t=56 \mathrm{~s}$ ) and $\langle s\rangle$ is mean slip. In Scenario A, $\epsilon_{A}=0.7$. In Scenario $\mathrm{B}, \epsilon_{B}=0.5$. Thus, although Scenario B includes shallow slip and larger maximum seafloor displacements that contribute to a higher initial wave height, the source is less efficient at producing a tsunami than is the source in Scenario A. Such trade-off may explain why the differences between the two tsunami events are limited. We also note that the highly complex Scenario C earthquake matches the efficiency of Scenario A at $\epsilon_{C}=0.7$ (see Sec. 5.3.2). The relative loss of efficiency in Scenario B may be due to inefficiency of shallow slip in this surfacebreaching earthquake.

The presented 3D scenarios lead to tsunami efficiencies that are considerably higher than for those from the 2D models in Lotto et al. (2017a). The tsunami potential energy as defined by Melgar et al. (2019) may be useful to further compare scenarios, as it accounts for the combined effects of various source properties on the sea surface dislocation. However, it is yet a time-independent parameter.

Extending dynamic rupture conditions in linked 3D earthquake-tsunami modeling beyond the slipweakening on-fault behavior and elastic off-fault deformation also will deepen understanding of how near-surface earthquake dynamics control tsunami behavior and $\epsilon$. For example, $\mathrm{Ma}(2012)$ and $\mathrm{Ma}$ \& Nie (2019) highlight the importance of plastic yielding in modeling uplift landward of the trench for the 2011 Tohoku earthquake. In a detailed study of the role of accretionary prisms in 2D coupled earthquake-tsunami models, Lotto et al. (2017a) find that prisms that are more compliant than the surrounding material tend to slow earthquake rupture speeds, increase slip, and induce larger tsunamis. Here, the relatively low strength of the shallow fault in Scenario B permits surface-breaching rupture, but leads to localized supershear rupture velocities. Incorporating off-fault deformation should allow for modeling slip at the trench at locally slow rupture velocity.

We next compare the modeled Scenarios A and B with real earthquakes and tsunamis. Based on their magnitudes $\left(M_{w} 8.5-8.6\right)$, fault area $(125 \mathrm{~km}$ by $200 \mathrm{~km})$, and slip distributions, the two earthquakes scenarios are comparable to tsunami-generating subduction zone events such as the $M_{w} 8.5$ Bengkulu earthquake that occurred off the southwestern coast of Sumatra in 2007 (Gusman et al.2010; Seno 2014) and the $M_{w}$ 8.5 South Peru earthquake that occurred in 2001 (Pritchard et al. 2007; Seno 2014). The Bengkulu earthquake had slip restricted to below $10 \mathrm{~km}$ depth, with most slip occurring at 
16-40 km depth and reaching a maximum of 6-7 $\mathrm{m}$ (Gusman et al. 2010). The slip distribution and maximum slip in the Scenario A earthquake are consistent with this event. In the 2001 South Peru earthquake, high slip may have occurred at shallow depths, though whether or not slip occurred at the trench is inconclusive (Pritchard et al.|2007). The slip distribution in the Scenario B earthquake is similar to this, though slip in this scenario reaches a maximum of approx. $10 \mathrm{~m}$ at the trench, versus the $6 \mathrm{~m}$ maximum slip in the South Peru event (Pritchard et al.2007).

The blind Bengkulu earthquake rupture produced a tsunami that was recorded at several tide gauges in the Indian Ocean, with a maximum peak-to-trough wave height of $2.3 \mathrm{~m}$ at Padang (USGS accessed 2020-07-03). The potentially surface-breaching rupture in the 2001 South Peru earthquake produced a tsunami with wave heights of 1.0-2.5 $\mathrm{m}$ at three different tide stations (USGS accessed 2019-07-22). These maximum recorded wave heights are lower than the peak wave heights at the coast for the modeled blind rupture in Scenario A and surface-breaching rupture in Scenario B of $3.4 \mathrm{~m}$ and $3.8 \mathrm{~m}$, respectively (Table 2). However, the difference between the observed waves produced by the (potentially) surface-rupturing and blind earthquakes are similar for the observed and modeled events, which may motivate future studies accounting for fault slip in the South Peru earthquake indeed reaching the surface.

Using purely tsunami based observations and linked models, for example of historical megathrust events, distinguishing between possible blind or surface rupturing earthquakes may be feasible. Satellite data capturing wave heights in the ocean have resolutions on the order of $\mathrm{cm}$ (Hayashi 2008) and data used to determine inundation areas have resolutions on the order of $m$ to tens of $m$ Koshimura et al.2020), both of which are at the scale of the modeled differences between tsunamis in Scenarios A and B. Future modeling can also strive to quantify differences of the same orders of magnitude attributed to other dynamic earthquake and tsunami characteristics.

\subsubsection{Subduction-initialized earthquake and tsunami (Scenario C)}

The subduction-initialized earthquake in Sec. 4 is a $M_{w} 9.0$ event. The efficiency of this earthquake in generating the modeled tsunami is calculated using Eq. 6. With $h_{\max }$ is taken near the source at $t=100 \mathrm{~s}, \epsilon_{C}=0.7$, which matches the efficiency of the blind earthquake rupture in Scenario A.

Scenario C's magnitude and the model fault dimensions are similar to those for the $2011 M_{w} 9.0$ Tohoku megathrust earthquake. The rupture speed in this scenario varies along the fault, but averages $2.1 \mathrm{~km} / \mathrm{s}$, somewhat similar to the $2.5 \mathrm{~km} / \mathrm{s}$ mean rupture speed estimated for the Tohoku earthquake by Ammon et al. (2011) after the first $80 \mathrm{~s}$ of the rupture. The average and maximum accumulated slip for the modeled earthquake (42.2 $\mathrm{m}$ and $95.6 \mathrm{~m}$, respectively) are at or above the upper limit of what is observed in smoothed slip inversions for the 2011 Tohoku earthquake (Sun et al.2017). In addition, 
the modeled maximum vertical seafloor displacement is $28.1 \mathrm{~m}$ and not at the trench, while maximum values from the Tohoku earthquake are estimated to be $\sim 10 \mathrm{~m}$ at the trench (Fujiwara et al. 2011; Sun et al. 2017). Direct comparison between the modeled tsunami results and the Tohoku tsunami observations is hampered by the complex interplay of bathymetry, sea surface height, and wave travel time, but we expect higher slip in the scenario than observed for this event to also be reflected in a larger tsunami in the scenario than observed. Indeed, the modeled peak-to-trough height at the coast is $24 \mathrm{~m}$, compared to observations following the Tohoku rupture of $6.8 \mathrm{~m}$ at Iwate Kamaishi-oki and $6 \mathrm{~m}$ at several other locations (Japan Meteorological Agency 2019).

To modify Scenario C to capture, for example, the Tohoku earthquake and tsunami or other past or future megathrust earthquake scenarios, lower modeled slip could be achieved with different model linking choices, such as a higher Poisson's assigned ratio, or by adding fault complexity in the third dimension. For instance, choosing a larger $\nu$, keeping all other parameters constant, results in less fault slip during an earthquake modeled in 2D (van Zelst et al.|2019). Alternatively, adjusting the subduction model itself to be region specific, e.g. to the Japan trench, would provide more direct constraints on fault geometry and other initial conditions.

\subsection{Looking forward}

One main advantage of linked earthquake-tsunami modeling is that the model complexity can be readily increased or decreased, depending on the hypothesis being tested. For example, realistic representations of complex topography and bathymetry are permissible in both the earthquake and tsunami computational models, which may be critical not only for inundation modeling, but also for modeling tsunami genesis and propagation in deep water (e.g. Salaree \& Okal 2020).

Similarly, we here restrict the off-fault constitutive behavior of the earthquake physical models to purely elastic and employ a linear slip weakening friction law on-fault. However, recent 3D earthquake-tsunami models of the 2004 Sumatra earthquake reveal the sensitive trade-off between shallow fault slip and off-fault elastoplastic deformation in controlling the tsunami height (Ulrich et al. 2020). Future linked modeling can help to elucidate how these aspects of earthquake dynamics influence tsunami behavior by readily switching to, for example, alternative friction laws such as rate-and-state, elastoplastic off-fault and wedge behavior, or thermal pressurization of pore fluids.

Tsunami generation from landslides is simulated well by established software (e.g. Clawpack, Mandli et al. 2016), but landslide sources are not incorporated into the presented modeling chain. However, this chain can provide a way to test the importance of earthquake dynamics in the tsunami source (e.g. Ulrich et al. 2019b) and trade-offs with other sources. For example, several recent modeling efforts related to the 2018 Sulawesi earthquake and tsunami, combining displacements from 
earthquakes and landsliding, underscore the importance of dual source mechanisms (e.g. Heidarzadeh et al. 2019; Aránguiz et al. 2020).

When initializing the earthquake model from a subduction model, we must honor the plane-strain conditions of the 2D subduction model while mapping the stress field into the $3 \mathrm{D}$ earthquake model. This most likely does not reflect conditions in-situ. Ideally, one would incorporate the dynamic earthquake rupture into seismic cycling in the subduction model. Methodological advances may enable linking with a 3D subduction model and working toward this two-way coupling between earthquake dynamics and long term behavior.

Coupled feedback mechanisms beyond one-way linking from earthquake to tsunami also may be analysed in future work. For example, the two-way interaction of the water column and the solid Earth may be considered. As the feedback of pressure differences in the water column to the solid bottom is small in the models presented here ( $1 \mathrm{~m}$ of water wave height corresponds to approx. $0.1 \mathrm{bar}$ or $10 \mathrm{kPa}$ ), the assumption of a rigid crust may not affect rupture evolution. However, assuming a rigid crust has been shown to influence the tsunami in the far-field and lead to earlier arrival times than observed (Watada et al.2014). Interest in how acoustic waves affect tsunami signals is growing with the expansion of near-source ocean-bottom sensors (e.g. Maeda et al. 2011; Saito et al. 2019; Saito \& Kubota 2019). Saito et al. (2019) find that they do affect the near-source tsunami signal, but have little influence on propagation beyond the time it takes for the waves to exit the region of the slower tsunami. Full 3D coupling of the seismic, acoustic and gravity seafloor and water column displacements using the same computational tools is underway (Abrahams et al. 2019; Krenz et al. 2019), but is computationally challenging.

The scenarios presented in this paper are accompanied by detailed input files and model information (see App. A). This provides sufficient detail for other modellers to run all or parts of these scenarios in their linked model setup and compare their results to these. In future work, these applications may also be useful for community-wide comparison of dynamic earthquake-tsunami modeling approaches and alternative linking methods.

\section{CONCLUSIONS}

Surprises with devastating consequences in past earthquake-tsunami sequences motivate a better understanding of the physical connections between subduction, earthquake dynamics and tsunami from genesis to inundation. Modeling approaches bridging physical parameters and processes across these temporal and spatial scales are suited to help advance such research. We here use 3D dynamic rupture models as tsunami sources by building a virtual laboratory using open-source earthquake and 
tsunami computational models. We present three scenario applications to demonstrate the flexibility and capabilities of this linked modeling.

These methods are well-suited for hypothesis testing, such as isolating the influence of a single parameter on earthquake and tsunami behavior. In scenarios A and B, we compare tsunamis from a blind rupture and a surface-breaching rupture due to differing fault strength near the surface. The surface-breaching rupture does inundate a wider area inland from the coast, but we find that slip to the trench does not cause differences in inundation shape, change run-up or alter the length of coast impacted. This similarity may result from trade-off between the blind rupture's higher tsunamigenerating efficiency and the surface-breaching rupture's larger shallow slip, which leads to higher seafloor displacements and a larger displaced volume of water.

We use a subduction model to initialize the earthquake model in Scenario C. This approach provides reasonable earthquake initial conditions that typically are poorly constrained by data, but which exert first-order control over rupture behavior. Setting up the earthquake model in this way ensures physical consistency of the tsunami source with characteristics of both the subduction channel and the earthquake kinematics and dynamics. The resulting earthquake model includes a curved fault geometry and heterogeneous material properties and stress field, and the frictional parameters along the fault vary with depth. Due to these highly heterogeneous on- and off-fault conditions, the earthquake in this scenario has larger slip, but lower stress drop and slower rupture speed relative to the ruptures in scenarios $\mathrm{A}$ and $\mathrm{B}$.

Future applications of these linked modeling methods can take advantage of the flexible adjustment of tsunami and earthquake model complexity. Direct studies of how subduction characteristics, earthquake initial conditions and earthquake dynamics govern tsunami behavior can help understand hazard in a given subduction zone. Such modeling may be specifically useful to constrain earthquake rupture and tsunami generation, propagation and inundation in complex megathrust systems, producing tsunami sources accounting for, for example, the effects of the slip to the trench, dynamic interaction between different fault segments (including splay faults), and off-fault coseismic deformation.

\section{ACKNOWLEDGEMENTS}

This effort has and continues to require intense cross-disciplinary collaboration and we want to acknowledge the strong team effort that has made it possible. In addition to the authors, a wide group has contributed to this effort. First, we would like to thank the Volkswagen Foundation (VolkswagenStiftung) for extended funding and excellent support of the ASCETE and ASCETE II projects (www.ascete.de). Second, we want to recognize the following researchers that have contributed directly to this project over its years in development: N. Beisiegel, A. Breuer, L. Dalguer, A. Fichtner, 
P. Galvez, H. Igel, A. Jeschke, M. Käser, O. Meister, C. Pelties, K. Rahnema, S. Rettenberger and S. Wollherr.

Finally, participants in the 1st and 2nd ASCETE Workshops on Coupling Earthquakes and Tsunamis held in Sudelfeld Bayrischzell, Germany provided motivation for the development of these test cases and feedback on their design. We look forward to continuing discussions with the earthquake and tsunami modeling communities. We also would like to recognize the exceptional editorship by Editors Gabi Laske and Duncan Agnew, and to thank the reviewers, Joao Duarte, Brittany Erickson, Duncan Agnew and one anonymous reviewer, for their collegial and constructive reviews.

Computing resources were provided by the Institute of Geophysics of LMU Munich (Oeser et al. 2006), the Leibniz Supercomputing Centre (LRZ, projects no. h019z, pr63qo and pr45fi on SuperMUC), the Center for Earth System Research and Sustainability (CEN) at University of Hamburg, and the Swiss National Supercomputing Center (project no. s741).

E.H.M., T.U. and A.-A.G. acknowledge additional support by the German Research Foundation (DFG) (projects no. GA 2465/2-1, GA 2465/3-1), by BaCaTec (project no. A4) and BayLat, by KONWIHR - the Bavarian Competence Network for Technical and Scientific High Performance Computing (project NewWave), by KAUST-CRG (GAST, grant no. ORS-2016-CRG5-3027 and FRAGEN, grant no. ORS-2017-CRG6 3389.02), by the European Union's Horizon 2020 research and innovation program (ExaHyPE, grant no. 671698, ChEESE, grant no. 823844 and TEAR, grant no. 852992).

We would like to thank the editorial team at GJI under Editor Prof. Gabi Laske for handling this cross-disciplinary manuscript in such a careful and constructive way. We also appreciate the collegial reviews from Joao Duarte, Brittany Erickson, Duncan Agnew and one anonymous reviewer.

\section{DATA AVAILABILITY}

We provide all necessary information and data sets required to reproduce the results presented in this work at https://tinyurl.com/yxn6zrqc. The archive includes all required configuration files, compilation parameters and input data. 


\section{REFERENCES}

Aagaard, B. T., Anderson, G., \& Hudnut, K. W., 2004. Dynamic rupture modeling of the transition from thrust to strike-slip motion in the 2002 denali fault earthquake, alaska, Bulletin of the Seismological Society of America, 94(6B), S190-S201.

Abrahams, L. S., Krenz, L., Dunham, E. M., \& Gabriel, A.-A., 2019. Verification of a 3D Fully-Coupled Earthquake and Tsunami Model, in AGUFM, pp. NH43F-1000, AGU.

Allgeyer, S. \& Cummins, P., 2014. Numerical tsunami simulation including elastic loading and seawater density stratification, Geophysical Research Letters, 41(7), 2368-2375.

Amlani, F., Bhat, H. S., Simons, W. J. F., Schubnel, A., Vigny, C., Rosakis, A. J., Efendi, J., Elbanna, A., \& Abidin, H. Z., 2019. Supershear tsunamis and insights from the $m_{w} 7.5$ palu earthquake.

Ammon, C. J., Lay, T., Kanamori, H., \& Cleveland, M., 2011. A rupture model of the 2011 off the Pacific coast of Tohoku Earthquake, Earth, Planets and Space, 63(7), 693-696.

Ando, R. \& Kaneko, Y., 2018. Dynamic Rupture Simulation Reproduces Spontaneous Multifault Rupture and Arrest During the $2016 M_{\mathrm{w}} 7.9$ Kaikoura Earthquake, Geophysical Research Letters, 45(23).

Andrews, D., 1980. A stochastic fault model: 1. static case, Journal of Geophysical Research: Solid Earth, 85(B7), 3867-3877.

Andrews, D. J., 1976. rupture velocity of plane strain shear cracks., J Geophys Res, 81(32), 5679-5687.

Andrews, D. J., 2005. Rupture dynamics with energy loss outside the slip zone, Journal of Geophysical Research, 110(B1), B01307.

Aochi, H. \& Fukuyama, E., 2002. Three-dimensional nonplanar simulation of the 1992 landers earthquake, Journal of Geophysical Research: Solid Earth, 107(B2), ESE-4.

Aránguiz, R., Esteban, M., Takagi, H., Mikami, T., Takabatake, T., Gómez, M., González, J., Shibayama, T., Okuwaki, R., Yagi, Y., Shimizu, K., Achiari, H., Stolle, J., Robertson, I., Ohira, K., Nakamura, R., Nishida, Y., Krautwald, C., Goseberg, N., \& Nistor, I., 2020. The 2018 Sulawesi tsunami in Palu city as a result of several landslides and coseismic tsunamis, Coastal Engineering Journal, pp. 1-15.

Babeyko, A. Y., Hoechner, A., \& Sobolev, S. V., 2010. Source modeling and inversion with near real-time GPS: A GITEWS perspective for Indonesia, Natural Hazards and Earth System Science, 10(7), 1617-1627.

Bai, K. \& Ampuero, J.-P., 2017. Effect of seismogenic depth and background stress on physical limits of earthquake rupture across fault step overs, Journal of Geophysical Research: Solid Earth, 122(12), 10-280.

Behrens, J. \& Dias, F., 2015. New computational methods in tsunami science, Philosophical Transactions of the Royal Society A: Mathematical, Physical and Engineering Sciences, 373(2053), 20140382.

Berger, M. J., George, D. L., LeVeque, R. J., \& Mandli, K. T., 2011. The GeoClaw software for depth-averaged flows with adaptive refinement, Advances in Water Resources, 34(9), 1195-1206.

Bizzarri, A. \& Cocco, M., 2006. A thermal pressurization model for the spontaneous dynamic rupture propagation on a three-dimensional fault: 1. methodological approach, Journal of Geophysical Research: Solid Earth, 111(B5).

Bletery, Q., Sladen, A., Jiang, J., \& Simons, M., 2016. A Bayesian source model for the 2004 great Sumatra- 
Andaman earthquake, Journal of Geophysical Research: Solid Earth, 121(7), 5116-5135.

Breuer, A., Heinecke, A., Rettenberger, S., Bader, M., Gabriel, A.-A., \& Pelties, C., 2014. Sustained Petascale Performance of Seismic Simulations with SeisSol on SuperMUC, in Supercomputing. ISC 2014. Lecture Notes in Computer Science, vol 8488, pp. 1-18, eds Kunkel J.M., Ludwig T., \& Meuer H.W., Springer, Cham.

Breuer, A., Heinecke, A., \& Bader, M., 2016. Petascale local time stepping for the ADER-DG finite element method, in 2016 IEEE International Parallel \& Distributed Processing Symposium, pp. 854-863.

Brizzi, S., van Zelst, I., Funiciello, F., Corbi, F., \& van Dinther, Y., 2020. How sediment thickness influences subduction dynamics and seismicity, Journal of Geophysical Research: Solid Earth, 125(8), e2019JB018964, e2019JB018964 10.1029/2019JB018964.

Chauhan, A. P. S., Singh, S. C., Hananto, N. D., Carton, H., Klingelhoefer, F., Dessa, J. X., Permana, H., White, N. J., \& Graindorge, D., 2009. Seismic imaging of forearc backthrusts at northern Sumatra subduction zone, Geophysical Journal International.

Cockburn, B. \& Shu, C.-W., 1998. The Runge-Kutta discontinuous Galerkin method for conservation laws V: Multidimensional systems, Journal of Computational Physics, 141(2), 199-224.

Crameri, F., Schmeling, H., Golabek, G. J., Duretz, T., Orendt, R., Buiter, S. J. H., May, D. A., Kaus, B. J. P., Gerya, T. V., \& Tackley, P. J., 2012. A comparison of numerical surface topography calculations in geodynamic modelling: an evaluation of the 'sticky air' method, Geophysical Journal International, 189(1), 38-54.

D’Acquisto, M., Dal Zilio, L., Molinari, I., Kissling, E., Gerya, T., \& van Dinther, Y., 2020. Tectonics and seismicity in the northern apennines driven by slab retreat and lithospheric delamination, Tectonophysics, 789, 228481.

Dal Zilio, L., van Dinther, Y., Gerya, T., \& Avouac, J.-P., 2019. Bimodal seismicity in the himalaya controlled by fault friction and geometry, Nature Communications, 10(48).

Davies, G., 2019. Tsunami variability from uncalibrated stochastic earthquake models: tests against deep ocean observations 2006-2016, Geophysical Journal International, 218(3), 1939-1960.

Day, S. M., Dalguer, L. A., Lapusta, N., \& Liu, Y., 2005. Comparison of finite difference and boundary integral solutions to three-dimensional spontaneous rupture, Journal of Geophysical Research: Solid Earth, 110(B12307).

De La Puente, J., Ampuero, J. P., \& Käser, M., 2009. Dynamic rupture modeling on unstructured meshes using a discontinuous Galerkin method, Journal of Geophysical Research: Solid Earth, 114(10), 1-17.

DeDontney, N. \& Rice, J. R., 2011. Tsunami Wave Analysis and Possibility of Splay Fault Rupture During the 2004 Indian Ocean Earthquake, Pure and Applied Geophysics, 169(10), 1707-1735.

Douilly, R., Aochi, H., Calais, E., \& Freed, A. M., 2015. Three-dimensional dynamic rupture simulations across interacting faults: The $\boldsymbol{M}_{\boldsymbol{w}}$ 7.0, 2010, Haiti earthquake, Journal of Geophysical Research: Solid Earth, 120(2), 1108-1128.

Dumbser, M. \& Käser, M., 2006. An arbitrary high-order discontinuous Galerkin method for elastic waves on 
unstructured meshes - II. The three-dimensional isotropic case, Geophysical Journal International, 167(1), 319-336.

Dunham, E. M., Belanger, D., Cong, L., \& Kozdon, J. E., 2011. Earthquake Ruptures with Strongly RateWeakening Friction and Off-Fault Plasticity, Part 1: Planar Faults, Bulletin of the Seismological Society of America, 101(5), 2296-2307.

Erickson, B. A., Jiang, J., Barall, M., Lapusta, N., Dunham, E. M., Harris, R., Abrahams, L. S., Allison, K. L., Ampuero, J., Barbot, S., Cattania, C., Elbanna, A., Fialko, Y., Idini, B., Kozdon, J. E., Lambert, V., Liu, Y., Luo, Y., Ma, X., Best McKay, M., Segall, P., Shi, P., van den Ende, M., \& Wei, M., 2020. The Community Code Verification Exercise for Simulating Sequences of Earthquakes and Aseismic Slip (SEAS), Seismological Research Letters, 91(2A), 874-890.

Fujiwara, T., Kodaira, S., No, T., Kaiho, Y., Takahashi, N., \& Kaneda, Y., 2011. The 2011 Tohoku-Oki Earthquake: Displacement Reaching the Trench Axis, Science, 334(6060), 1240.

Gabriel, A.-A., Ampuero, J.-P., Dalguer, L. A., \& Mai, P. M., 2012. The transition of dynamic rupture styles in elastic media under velocity-weakening friction, Journal of Geophysical Research: Solid Earth, 117(B9).

Gabriel, A.-A., Ampuero, J.-P., Dalguer, L. A., \& Mai, P. M., 2013. Source properties of dynamic rupture pulses with off-fault plasticity, Journal of Geophysical Research: Solid Earth, 118(8), 4117-4126.

Gabriel, A.-A., Vyas, J. C., Ulrich, T., Ampuero, J., \& Mai, M. P., 2020. 3D dynamic rupture modeling with thermal pressurization, in Poster Presentation at 2020 SCEC Annual Meeting, Southern California Earthquake Center.

Galis, M., Pelties, C., Kristek, J., Moczo, P., Ampuero, J.-P., \& Mai, P. M., 2015. On the initiation of sustained slip-weakening ruptures by localized stresses, Geophysical Journal International, 200(2), 890-909.

Galvez, P., Ampuero, J. P., Dalguer, L. A., Somala, S. N., \& Nissen-Meyer, T., 2014. Dynamic earthquake rupture modelled with an unstructured 3-D spectral element method applied to the 2011 M9 Tohoku earthquake, Geophysical Journal International, 198(2), 1222-1240.

Geist, E. \& Yoshioka, S., 1996. Source parameters controlling the generation and propagation of potential local tsunamis along the cascadia margin, Natural Hazards, 13(2), 151-177.

Geist, E. L. \& Oglesby, D. D., 2014. Tsunamis: Stochastic Models of Occurrence and Generation Mechanisms, pp. 1-29, Springer New York, New York, NY.

Gerya, T. V. \& Yuen, D. A., 2007. Robust characteristics method for modelling multiphase visco-elasto-plastic thermo-mechanical problems, Physics of the Earth and Planetary Interiors, 163, 83-105.

Geuzaine, C. \& Remacle, J.-F., 2009. Gmsh: A 3-D finite element mesh generator with built-in pre- and post-processing facilities, International Journal for Numerical Methods in Engineering, 79(11), 1309-1331.

Giraldo, F. X. \& Warburton, T., 2008. A high-order triangular discontinuous Galerkin oceanic shallow water model, International Journal for Numerical Methods in Fluids, 56(7), 899-925.

Goda, K., Mai, P. M., Yasuda, T., \& Mori, N., 2014. Sensitivity of tsunami wave profiles and inundation simulations to earthquake slip and fault geometry for the 2011 tohoku earthquake, Earth, Planets and Space, 66(1), 105. 
Gorczyk, W., Willner, A. P., Gerya, T. V., Connolly, J. A., \& Burg, J.-P., 2007. Physical controls of magmatic productivity at pacific-type convergent margins: Numerical modelling, Physics of the Earth and Planetary Interiors, 163(1-4), 209-232.

Gulick, S. P. S., Austin, J. A., McNeill, L. C., Bangs, N. L. B., Martin, K. M., Henstock, T. J., Bull, J. M., Dean, S., Djajadihardja, Y. S., \& Permana, H., 2011. Updip rupture of the 2004 Sumatra earthquake extended by thick indurated sediments, Nature Geoscience, 4(7), 453-456.

Gusman, A., Tanioka, Y., Kobayashi, T., Latief, H., \& Pandoe, W., 2010. Slip distribution of the 2007 Bengkulu earthquake inferred from tsunami waveforms and InSAR data, J. Geophys. Res, 115.

Harig, S., Chaeroni, Pranowo, W. S., \& Behrens, J., 2008. Tsunami simulations on several scales: Comparison of approaches with unstructured meshes and nested grids, Ocean Dynamics, 58(5-6), 429-440.

Harris, R. A., Barall, M., Archuleta, R., Dunham, E., Aagaard, B., Ampuero, J. P., Bhat, H., Cruz-Atienza, V., Dalguer, L., Dawson, P., Day, S., Duan, B., Ely, G., Kaneko, Y., Kase, Y., Lapusta, N., Liu, Y., Ma, S., Oglesby, D., Olsen, K., Pitarka, A., Song, S., \& Templeton, E., 2009. The SCEC/USGS Dynamic Earthquake Rupture Code Verification Exercise, Seismological Research Letters, 80(1), 119-126.

Harris, R. A., Barall, M., Aagaard, B., Ma, S., Roten, D., Olsen, K., Duan, B., Liu, D., Luo, B., Bai, K., Ampuero, J.-P., Kaneko, Y., Gabriel, A.-A., Duru, K., Ulrich, T., Wollherr, S., Shi, Z., Dunham, E., Bydlon, S., Zhang, Z., Chen, X., Somala, S. N., Pelties, C., Tago, J., Cruz-Atienza, V. M., Kozdon, J., Daub, E., Aslam, K., Kase, Y., Withers, K., \& Dalguer, L., 2018. A Suite of Exercises for Verifying Dynamic Earthquake Rupture Codes, Seismological Research Letters, 89(3), 1146-1162.

Hayashi, Y., 2008. Extracting the 2004 Indian Ocean tsunami signals from sea surface height data observed by satellite altimetry, Journal of Geophysical Research: Oceans, 113(1), 1-9.

Heidarzadeh, M., Murotani, S., Satake, K., Takagawa, T., \& Saito, T., 2017. Fault size and depth extent of the Ecuador earthquake (Mw 7.8) of 16 April 2016 from teleseismic and tsunami data, Geophysical Research Letters, 44(5), 2211-2219.

Heidarzadeh, M., Muhari, A., \& Wijanarto, A. B., 2019. Insights on the Source of the 28 September 2018 Sulawesi Tsunami, Indonesia Based on Spectral Analyses and Numerical Simulations, Pure and Applied Geophysics, 176(1), 25-43.

Heinecke, A., Breuer, A., Rettenberger, S., Bader, M., Gabriel, A. A., Pelties, C., Bode, A., Barth, W., Liao, X. K., Vaidyanathan, K., Smelyanskiy, M., \& Dubey, P., 2014. Petascale High Order Dynamic Rupture Earthquake Simulations on Heterogeneous Supercomputers, in International Conference for High Performance Computing, Networking, Storage and Analysis, SC.

Hok, S., Fukuyama, E., \& Hashimoto, C., 2011. Dynamic rupture scenarios of anticipated Nankai-Tonankai earthquakes, southwest Japan, Journal of Geophysical Research: Solid Earth, 116(12), 1-22.

Hüpers, A., Torres, M. E., Owari, S., McNeill, L. C., Dugan, B., Henstock, T. J., Milliken, K. L., Petronotis, K. E., Backman, J., Bourlange, S., Chemale, F., Chen, W., Colson, T. A., Frederik, M. C. G., Guèrin, G., Hamahashi, M., House, B. M., Jeppson, T. N., Kachovich, S., Kenigsberg, A. R., Kuranaga, M., Kutterolf, S., Mitchison, F. L., Mukoyoshi, H., Nair, N., Pickering, K. T., Pouderoux, H. F. A., Shan, Y., Song, I., 
Madden et al.

Vannucchi, P., Vrolijk, P. J., Yang, T., \& Zhao, X., 2017. Release of mineral-bound water prior to subduction tied to shallow seismogenic slip off Sumatra, Science, 356(6340), 841-844.

Ida, Y., 1972. Cohesive force across the tip of a longitudinal-shear crack and Griffith's specific surface energy, Journal of Geophysical Research, 77(20), 3796-3805.

Jamelot, A., Gailler, A., Heinrich, P., Vallage, A., \& Champenois, J., 2019. Tsunami Simulations of the Sulawesi Mw 7.5 Event: Comparison of Seismic Sources Issued from a Tsunami Warning Context Versus Post-Event Finite Source, Pure and Applied Geophysics, 176(8), 3351-3376.

Japan Meteorological Agency, 2019. Tsunami Warnings/Advisories, Tsunami Information.

Ji, C., Wald, D. J., \& Helmberger, D. V., 2002. Source description of the 1999 Hector Mine, California, earthquake, part I: Wavelet domain inversion theory and resolution analysis, Bulletin of the Seismological Society of America, 92(4), 1192-1207.

Kame, N., Rice, J. R., \& Dmowska, R., 2003. Effects of prestress state and rupture velocity on dynamic fault branching, Journal of Geophysical Research: Solid Earth, 108(B5).

Kanamori, H., 1972. Mechanism of tsunami earthquakes, Physics of the earth and planetary interiors, 6(5), 346-359.

Kaneko, Y., Lapusta, N., \& Ampuero, J.-P., 2008. Spectral element modeling of spontaneous earthquake rupture on rate and state faults: Effect of velocity-strengthening friction at shallow depths, Journal of Geophysical Research: Solid Earth, 113(B9).

Käser, M. \& Dumbser, M., 2006. An arbitrary high-order discontinuous Galerkin method for elastic waves on unstructured meshes - I. The two-dimensional isotropic case with external source terms, Geophysical Journal International, 166(2), 855-877.

Klinger, Y., Okubo, K., Vallage, A., Champenois, J., Delorme, A., Rougier, E., Lei, Z., Knight, E. E., Munjiza, A., Satriano, C., Baize, S., Langridge, R., \& Bhat, H. S., 2018. Earthquake damage patterns resolve complex rupture processes, Geophysical Research Letters, 45(19), 10,279-10,287.

Koshimura, S., Moya, L., Mas, E., \& Bai, Y., 2020. Tsunami damage detection with remote sensing: A review, Geosciences (Switzerland), 10(5), 1-28.

Kozdon, J. E. \& Dunham, E. M., 2013. Rupture to the Trench: Dynamic Rupture Simulations of the 11 March 2011 Tohoku Earthquake, Bulletin of the Seismological Society of America, 103(2B), 1275-1289.

Kozdon, J. E. \& Dunham, E. M., 2014. Constraining shallow slip and tsunami excitation in megathrust ruptures using seismic and ocean acoustic waves recorded on ocean-bottom sensor networks, Earth and Planetary Science Letters, 396, 56-65.

Krenz, L., Uphoff, C., Abrahams, L. S., Gabriel, A.-A., Dunham, E. M., \& Bader, M., 2019. ElasticAcoustic Coupling for 3D Tsunamigenic Earthquake Simulations with ADER-DG on Unstructured Tetrahedral Meshes, in AGUFM, pp. T52C-09, AGU.

LeVeque, R. J., George, D. L., \& Berger, M. J., 2011. Tsunami modelling with adaptively refined finite volume methods, Acta Numerica, 20, 211-289.

Liang, Q. \& Marche, F., 2009. Numerical resolution of well-balanced shallow water equations with complex 
source terms, Advances in Water Resources, 32, 873-884.

Liu, P. L. F., Cho, Y. S., Yoon, S. B., \& Seo, S. N., 1995. Numerical Simulations of the 1960 Chilean Tsunami Propagation and Inundation at Hilo, Hawaii, pp. 99-115, Springer Netherlands, Dordrecht.

Lotto, G. C., Dunham, E. M., Jeppson, T. N., \& Tobin, H. J., 2017a. The effect of compliant prisms on subduction zone earthquakes and tsunamis, Earth and Planetary Science Letters, 458, 213-222.

Lotto, G. C., Nava, G., \& Dunham, E. M., 2017b. Should tsunami simulations include a nonzero initial horizontal velocity?, Earth, Planets and Space, 69(1), 117.

Lotto, G. C., Jeppson, T. N., \& Dunham, E. M., 2018. Fully coupled simulations of megathrust earthquakes and tsunamis in the Japan Trench, Nankai Trough, and Cascadia Subduction Zone, Pure and Applied Geophysics, pp. 1-33.

Lotto, G. C., Jeppson, T. N., \& Dunham, E. M., 2019. Fully Coupled Simulations of Megathrust Earthquakes and Tsunamis in the Japan Trench, Nankai Trough, and Cascadia Subduction Zone, Pure and Applied Geophysics, 176(9), 4009-4041.

Lozos, J. C. \& Harris, R. A., 2020. Dynamic rupture simulations of the m6.4 and m7.1 july 2019 ridgecrest, california, earthquakes, Geophysical Research Letters, 47(7), e2019GL086020, e2019GL086020 2019GL086020.

Ma, S., 2012. A self-consistent mechanism for slow dynamic deformation and large tsunami generation for earthquakes in the shallow subduction zone, Geophysical Research Letters, 39(11), 1-7.

Ma, S. \& Nie, S., 2019. Dynamic wedge failure and along-arc variations of tsunamigenesis in the japan trench margin, Geophysical Research Letters, 46(15), 8782-8790.

Maeda, T. \& Furumura, T., 2011. FDM Simulation of Seismic Waves, Ocean Acoustic Waves, and Tsunamis Based on Tsunami-Coupled Equations of Motion, Pure and Applied Geophysics, 170(1-2), 109-127.

Maeda, T., Furumura, T., Sakai, S., \& Shinohara, M., 2011. Significant tsunami observed at ocean-bottom pressure gauges during the 2011 off the Pacific coast of Tohoku Earthquake, Earth, Planets and Space, 63(7), 803-808.

Maeda, T., Furumura, T., Noguchi, S., Takemura, S., Sakai, S., Shinohara, M., Iwai, K., \& Lee, S. J., 2013. Seismic- and Tsunami-wave propagation of the 2011 Off the Pacific Coast of Tohoku earthquake as inferred from the Tsunami-coupled finite-difference simulation, Bulletin of the Seismological Society of America, $\mathbf{1 0 3}(2 \mathrm{~B}), 1456-1472$.

Maeda, T., Obara, K., Shinohara, M., Kanazawa, T., \& Uehira, K., 2015. Successive estimation of a tsunami wavefield without earthquake source data: A data assimilation approach toward real-time tsunami forecasting, Geophysical Research Letters, 42(19), 7923-7932.

Mai, P. M. \& Thingbaijam, K. K., 2014. SRCMOD: An online database of finite-fault rupture models, Seismological Research Letters, 85(6), 1348-1357.

Mai, P. M., Schorlemmer, D., Page, M., Ampuero, J. P., Asano, K., Causse, M., Custodio, S., Fan, W., Festa, G., Galis, M., Gallovic, F., Imperatori, W., Käser, M., Malytskyy, D., Okuwaki, R., Pollitz, F., Passone, L., Razafindrakoto, H. N., Sekiguchi, H., Song, S. G., Somala, S. N., Thingbaijam, K. K., Twardzik, C., Van 
Driel, M., Vyas, J. C., Wang, R., Yagi, Y., \& Zielke, O., 2016. The earthquake-source inversion Validation (SIV) project, Seismological Research Letters, 87(3), 690-708.

Mandli, K. T., Ahmadia, A. J., Berger, M., Calhoun, D., George, D. L., Hadjimichael, Y., Ketcheson, D. I., Lemoine, G. I., \& LeVeque, R. J., 2016. Clawpack: building an open source ecosystem for solving hyperbolic pdes, PeerJ Computer Science, 2, e68.

McCloskey, J., Antonioli, A., Piatanesi, A., Sieh, K., Steacy, S., Nalbant, S., Cocco, M., Giunchi, C., Huang, J., \& Dunlop, P., 2008. Tsunami threat in the indian ocean from a future megathrust earthquake west of sumatra, Earth and Planetary Science Letters, 265(1-2), 61-81.

Meister, O., Rahnema, K., \& Bader, M., 2016. Parallel, memory efficient adaptive mesh refinement on structured triangular meshes with billions of grid cells, ACM Transactions on Mathematical Software, 43(3), 19:1-19:27.

Melgar, D., Williamson, A. L., \& Salazar-Monroy, E. F., 2019. Differences between heterogenous and homogenous slip in regional tsunami hazards modelling, Geophysical Journal International, 219(1), 553-562.

Murotani, S., Iwai, M., Satake, K., Shevchenko, G., \& Loskutov, A., 2015. Tsunami Forerunner of the 2011 Tohoku Earthquake Observed in the Sea of Japan, Pure and Applied Geophysics, 172(3-4), 683-697.

Murphy, S., Scala, A., Herrero, A., Lorito, S., Festa, G., Trasatti, E., Tonini, R., Romano, F., Molinari, I., \& Nielsen, S., 2016. Shallow slip amplification and enhanced tsunami hazard unravelled by dynamic simulations of mega-thrust earthquakes, Scientific reports, 6, 35007.

Murphy, S., Di Toro, G., Romano, F., Scala, A., Lorito, S., Spagnuolo, E., Aretusini, S., Festa, G., Piatanesi, A., \& Nielsen, S., 2018. Tsunamigenic earthquake simulations using experimentally derived friction laws, Earth and Planetary Science Letters, 486, 155-165.

Noda, H., 2008. Frictional constitutive law at intermediate slip rates accounting for flash heating and thermally activated slip process, Journal of Geophysical Research, 113(B9), B09302.

Oeser, J., Bunge, H.-P., \& Mohr, M., 2006. Cluster design in the earth sciences: Tethys, in International conference on high performance computing and communications, pp. 31-40, Springer.

Oglesby, D. D., Archuleta, R. J., \& Nielsen, S. B., 2000. The three-dimensional dynamics of dipping faults, Bulletin of the Seismological Society of America, 90(3), 616-628.

Okada, Y., 1985. SURFACE DEFORMATION DUE TO SHEAR AND TENSILE FAULTS IN A HALFSPACE, Bulletin of the Seismological Society of America, 75(4), 1135-1154.

Okal, E. A., 1982. Mode-wave equivalence and other asymptotic problems in tsunami theory, Physics of the Earth and Planetary Interiors, 30(1), 1-11.

Pelties, C., De La Puente, J., Ampuero, J. P., Brietzke, G. B., \& Käser, M., 2012. Three-dimensional dynamic rupture simulation with a high-order discontinuous Galerkin method on unstructured tetrahedral meshes, Journal of Geophysical Research: Solid Earth, 117(2), 1-15.

Pelties, C., Gabriel, A. A., \& Ampuero, J. P., 2014. Verification of an ADER-DG method for complex dynamic rupture problems, Geoscientific Model Development, 7(3), 847-866.

Poisson, B., Oliveros, C., \& Pedreros, R., 2011. Is there a best source model of the Sumatra 2004 earthquake 
for simulating the consecutive tsunami?, Geophysical Journal International, 185(3), 1365-1378.

Preuss, S., Ampuero, J. P., Gerya, T., \& van Dinther, Y., 2020. Characteristics of earthquake ruptures and dynamic off-fault deformation on propagating faults, Solid Earth, 11(4), 1333-1360.

Pritchard, M. E., Norabuena, E. O., Ji, C., Boroschek, R., Comte, D., Simons, M., Dixon, T. H., \& Rosen, P. A., 2007. Geodetic, teleseismic, and strong motion constraints on slip from recent southern Peru subduction zone earthquakes, Journal of Geophysical Research, 112(B3), B03307.

Ramos, M. D. \& Huang, Y., 2019. How the Transition Region Along the Cascadia Megathrust Influences Coseismic Behavior: Insights From 2-D Dynamic Rupture Simulations, Geophysical Research Letters, 46(4), 1973-1983.

Rettenberger, S., 2017. PUMGen.

Rettenberger, S., Meister, O., Bader, M., \& Gabriel, A.-A., 2016. ASAGI: A Parallel Server for Adaptive Geoinformation, in Proceedings of the Exascale Applications and Software Conference 2016 on - EASC '16, pp. 1-9, ACM Press, Stockholm, Sweden.

Roten, D., Olsen, K. B., Day, S. M., Cui, Y., \& FÃ€h, D., 2014. Expected seismic shaking in los angeles reduced by san andreas fault zone plasticity, Geophysical Research Letters, 41(8), 2769-2777.

Ryan, K. J., Geist, E. L., Barall, M., \& Oglesby, D. D., 2015. Dynamic models of an earthquake and tsunami offshore Ventura, California, Geophysical Research Letters, 42(16), 6599-6606.

Saito, T., 2017. Tsunami generation: validity and limitations of conventional theories, Geophysical Journal International, 210(3), 1888-1900.

Saito, T. \& Kubota, T., 2019. Tsunami Modeling for the Deep Sea and Inside Focal Areas Tsunami modeling including earthquake rupture and seismic waves contributes to mega-thrust earthquake investigation and disaster mitigation, Annual Review of Earth and Planetary Sciences.

Saito, T., Baba, T., Inazu, D., Takemura, S., \& Fukuyama, E., 2019. Synthesizing sea surface height change including seismic waves and tsunami using a dynamic rupture scenario of anticipated Nankai trough earthquakes, Tectonophysics, p. 228166.

Salaree, A. \& Okal, E. A., 2020. Effects of bathymetry complexity on tsunami propagation: a spherical harmonics approach, Geophysical Journal International, 223(1), 632-647.

Schmeling, H., Babeyko, A., Enns, A., Faccenna, C., Funiciello, F., Gerya, T., Golabek, G., Grigull, S., Kaus, B., Morra, G., et al., 2008. A benchmark comparison of spontaneous subduction models-towards a free surface, Physics of the Earth and Planetary Interiors, 171(1-4), 198-223.

Seno, T., 2014. Stress drop as a criterion to differentiate subduction zones where $\mathrm{M}_{\mathrm{w}} 9$ earthquakes can occur, Tectonophysics.

Shearer, P. \& Burgmann, R., 2010. Lessons Learned from the 2004 Sumatra-Andaman Megathrust Rupture, Annu. Rev. Earth Planet. Sci, 38, 103-31.

Shi, F., Kirby, J. T., Harris, J. C., Geiman, J. D., \& Grilli, S. T., 2012. A high-order adaptive time-stepping TVD solver for Boussinesq modeling of breaking waves and coastal inundation, Ocean Modelling, 43-44, 36-51. 
Sobolev, S. V. \& Muldashev, I. A., 2017. Modeling Seismic Cycles of Great Megathrust Earthquakes Across the Scales With Focus at Postseismic Phase, Geochemistry, Geophysics, Geosystems, 18(12), 4387-4408.

Song, Y. T., Fu, L.-L., Zlotnicki, V., Ji, C., Hjorleifsdottir, V., Shum, C., \& Yi, Y., 2008. The role of horizontal impulses of the faulting continental slope in generating the 26 December 2004 tsunami, Ocean Modelling, 20(4), 362-379.

Stephenson, W., Reitman, N., \& Angster, S., 2017. U.S. Geological Survey Open-File Report 2017-1152: Pand S-wave velocity models incorporating the Cascadia subduction zone for 3D earthquake ground motion simulations, version 1.6-Update for Open-File Report 2007-1348, Tech. rep., U.S. Geological Survey.

Sun, T., Wang, K., Fujiwara, T., Kodaira, S., \& He, J., 2017. Large fault slip peaking at trench in the 2011 Tohoku-oki earthquake, Nature Communications, 8, 14044.

Synolakis, C. E., Bernard, E. N., Titov, V. V., Kânoğlu, U., \& González, F. I., 2008. Validation and Verification of Tsunami Numerical Models, Pure and Applied Geophysics, 165(11-12), 2197-2228.

Tanioka, Y. \& Satake, K., 1996. Tsunami generation by horizontal displacement of ocean bottom, Geophysical Research Letters, 23(8), 861-864.

Titov, V. V. \& Gonzalez, F. I., 1997. Implementation and testing of the method of splitting tsunami (MOST) model, NOAA Technical Memorandum ERL PMEL-112, Pacific Marine Environmental Laboratory, Seattle, WA, USA.

Tong, X. \& Lavier, L., 2018. Simulation of slip transients and earthquakes in finite thickness shear zones with a plastic formulation, Nature Communications, 9.

Ulrich, T., Gabriel, A.-A., Ampuero, J.-P., \& Xu, W., 2019a. Dynamic viability of the 2016 Mw 7.8 Kaikōura earthquake cascade on weak crustal faults, Nature Communications, 10(1), 1213.

Ulrich, T., Vater, S., Madden, E. H., Behrens, J., van Dinther, Y., van Zelst, I., Fielding, E. J., Liang, C., \& Gabriel, A.-A., 2019b. Coupled, Physics-Based Modeling Reveals Earthquake Displacements are Critical to the 2018 Palu, Sulawesi Tsunami, Pure and Applied Geophysics.

Ulrich, T., Gabriel, A., \& Madden, E. H., 2020. Stress, rigidity and sediment strength control megathrust earthquake and tsunami dynamics.

Uphoff, C., Rettenberger, S., Bader, M., Madden, E., Ulrich, T., Wollherr, S., \& Gabriel, A.-A., 2017. Extreme scale multi-physics simulations of the tsunamigenic 2004 Sumatra megathrust earthquake, in Proceedings of the International Conference for High Performance Computing, Networking, Storage and Analysis, SC 2017. USGS, accessed 2019-07-22. United states geological survey, m 8.4 - near the coast of southern peru, https://earthquake.usgs.gov/earthquakes/eventpage/official20010623203314130_33/impact.

USGS, accessed 2020-07-03. United states geological survey, m 8.4 - near the coast of southern sumatra, https://earthquake.usgs.gov/earthquakes/eventpage/official20070912111026830_34/impact.

van Dinther, Y., Gerya, T. V., Dalguer, L. A., Corbi, F., Funiciello, F., \& Mai, P. M., 2013a. The seismic cycle at subduction thrusts: 2. Dynamic implications of geodynamic simulations validated with laboratory models, Journal of Geophysical Research: Solid Earth, 118(4), 1502-1525.

van Dinther, Y., Gerya, T. V., Dalguer, L. A., Mai, P. M., Morra, G., \& Giardini, D., 2013b. The seismic cycle 
at subduction thrusts: Insights from seismo-thermo-mechanical models, Journal of Geophysical Research: Solid Earth.

van Dinther, Y., Mai, P. M., Dalguer, L. A., \& Gerya, T. V., 2014. Modeling the seismic cycle in subduction zones: the role and spatiotemporal occurrence of off-megathrust events, Geophysical Research Letters, 41(4), 1194-1201.

van Zelst, I., Wollherr, S., Gabriel, A.-A., Madden, E. H., \& van Dinther, Y., 2019. Modeling megathrust earthquakes across scales: One-way coupling from geodynamics and seismic cycles to dynamic rupture, Journal of Geophysical Research: Solid Earth, 124(11), 11414-11446.

Vater, S. \& Behrens, J., 2014. Well-balanced inundation modeling for shallow-water flows with Discontinuous Galerkin schemes, in Finite Volumes for Complex Applications VII - Elliptic, Parabolic and Hyperbolic Problems, vol. 78 of Springer Proceedings in Mathematics \& Statistics, pp. 965-973.

Vater, S., Beisiegel, N., \& Behrens, J., 2015. A limiter-based well-balanced discontinuous Galerkin method for shallow-water flows with wetting and drying: One-dimensional case, Advances in Water Resources, 85, $1-13$.

Vater, S., Beisiegel, N., \& Behrens, J., 2017. Comparison of wetting and drying between a RKDG2 method and classical FV based second-order hydrostatic reconstruction, in Finite Volumes for Complex Applications VIII - Hyperbolic, Elliptic and Parabolic Problems, pp. 237-245, Springer.

Vater, S., Beisiegel, N., \& Behrens, J., 2019. A limiter-based well-balanced discontinuous Galerkin method for shallow-water flows with wetting and drying: Triangular grids, International Journal for Numerical Methods in Fluids, pp. 1-24, online.

Wang, Y., Day, S. M., \& Denolle, M. A., 2019. Geometric Controls on Pulse-Like Rupture in a Dynamic Model of the 2015 Gorkha Earthquake, Journal of Geophysical Research: Solid Earth, 124(2), 1544-1568.

Ward, S. N., 1980. Relationships of Tsunami Generation Source and, Journal of Physics of the Earth, 28, 441-474.

Watada, S., Kusumoto, S., \& Satake, K., 2014. Journal of Geophysical Research : Solid Earth, Journal of Geophysical Research: Solid Earth, 119, 4287-4310.

Wendt, J., Oglesby, D. D., \& Geist, E. L., 2009. Tsunamis and splay fault dynamics, Geophysical Research Letters, 36(15).

Weng, H. \& Yang, H., 2018. Constraining Frictional Properties on Fault by Dynamic Rupture Simulations and Near-Field Observations, Journal of Geophysical Research: Solid Earth.

Wolf, S., Gabriel, A.-A., \& Bader, M., 2020. Optimisation and Local Time Stepping of an ADER-DG Scheme for Fully Anisotropic Wave Propagation in Complex Geometries, No Title, in Proceedings of the 10th International Workshop on Advances in High-Performance Computational Earth Sciences: Applications \& Frameworks.

Wollherr, S., Gabriel, A. A., \& Uphoff, C., 2018. Off-fault plasticity in three-dimensional dynamic rupture simulations using a modal Discontinuous Galerkin method on unstructured meshes: Implementation, verification and application, Geophysical Journal International, 214(3), 1556-1584. 
Wollherr, S., van Zelst, I., Gabriel, A.-A., Madden, E., \& van Dinther, Y., 2019. Plastic deformation and seafloor uplift in geomechanically constrained dynamic rupture models of subduction zone earthquakes, in Geophysical Research Abstracts, Vol. 21, EGU2019-14651, EGU General Assembly. 
Table 1. Earthquake model results. Characteristics for the blind (Scenario A), surface-breaching (Scenario B) and subduction-initialized (Scenario C) dynamic earthquake rupture models.

\begin{tabular}{cccccccccccc}
\hline & $\begin{array}{c}M_{w} \\
(-)\end{array}$ & $\begin{array}{c}\text { max. } s^{a} \\
(\mathrm{~m})\end{array}$ & $\begin{array}{c}\text { mean } s \\
(\mathrm{~m})\end{array}$ & $\begin{array}{c}\text { mean Vr } \\
(\mathrm{km} / \mathrm{s})\end{array}$ & $\begin{array}{c}\text { mean } \Delta \sigma^{c} \\
(\mathrm{MPa})\end{array}$ & $\begin{array}{c}\min \mathrm{D}^{d} \\
(\mathrm{~m})\end{array}$ & $\begin{array}{c}\max . \mathrm{D} \\
(\mathrm{m})\end{array}$ & $\begin{array}{c}\operatorname{mean} \mathrm{D} \\
(\mathrm{m})\end{array}$ & $\begin{array}{c}\text { max. Df } \\
(\mathrm{m})\end{array}$ & $\begin{array}{c}\text { mean D } \\
(\mathrm{m})\end{array}$ \\
\hline Scenario A & 8.5 & 7.6 & 3.8 & 3.5 & 3.0 & -1.0 & 2.6 & 0.6 & 1.9 & 0.9 \\
Scenario B & 8.6 & 10.9 & 6.5 & 3.7 & 3.9 & -1.1 & 3.3 & 1.2 & 2.6 & 0.9 \\
Scenario C & 9.0 & 95.5 & 42.2 & 2.1 & 2.2 & -5.6 & 28.1 & 3.6 & 15.7 & 3.3 \\
\hline
\end{tabular}

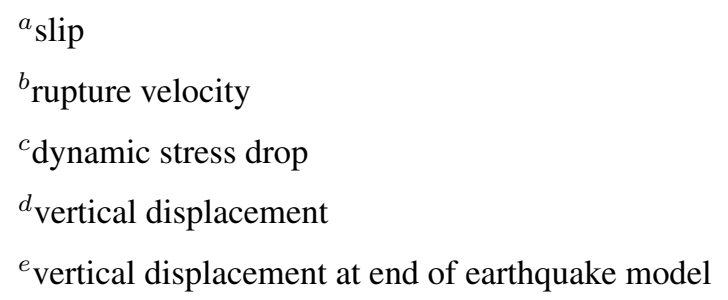

Table 2. Tsunami model results. Characteristics for tsunamis sourced by the blind (Scenario A), surfacebreaching (Scenario B) and subduction-initialized (Scenario C) dynamic earthquake rupture models.

\begin{tabular}{lcccccc}
\hline & $\begin{array}{c}\text { max. ssh }(\mathrm{t})^{a} \\
(\mathrm{~m})\end{array}$ & $\begin{array}{c}\text { time of first in. }^{b} \\
(\mathrm{~s})\end{array}$ & $\begin{array}{c}\text { max. ssh at coast }(\mathrm{t}) \\
(\mathrm{m})\end{array}$ & $\begin{array}{c}\text { max. runup }(\mathrm{t}) \\
(\mathrm{m})\end{array}$ & $\begin{array}{c}\text { total in. area } \\
\left(\mathrm{km}^{2}\right)\end{array}$ & $\begin{array}{c}\text { wave speed }^{c} \\
(\mathrm{~m} / \mathrm{s})\end{array}$ \\
\hline Scenario A & $2.6(56 \mathrm{~s})$ & 1210 & $3.4(1470 \mathrm{~s})$ & $73(1450 \mathrm{~s})$ & 15.6 & 157 \\
Scenario B & $3.7(56 \mathrm{~s})$ & 1220 & $3.75(1480 \mathrm{~s})$ & $73(1400 \mathrm{~s})$ & 18.3 & 142 \\
Scenario C & $28.1(100 \mathrm{~s})$ & 2050 & $24.3(2520 \mathrm{~s})$ & $492(2410 \mathrm{~s})$ & 27.2 & 148 \\
\hline
\end{tabular}

${ }^{a}$ maximum sea surface height at time (t)

${ }^{b}$ inundation

${ }^{c}$ propagation speed calculated for wave peak at $y=0$ from $t=1000$ to $t=1100 \mathrm{~s}$, the time of first inundation 


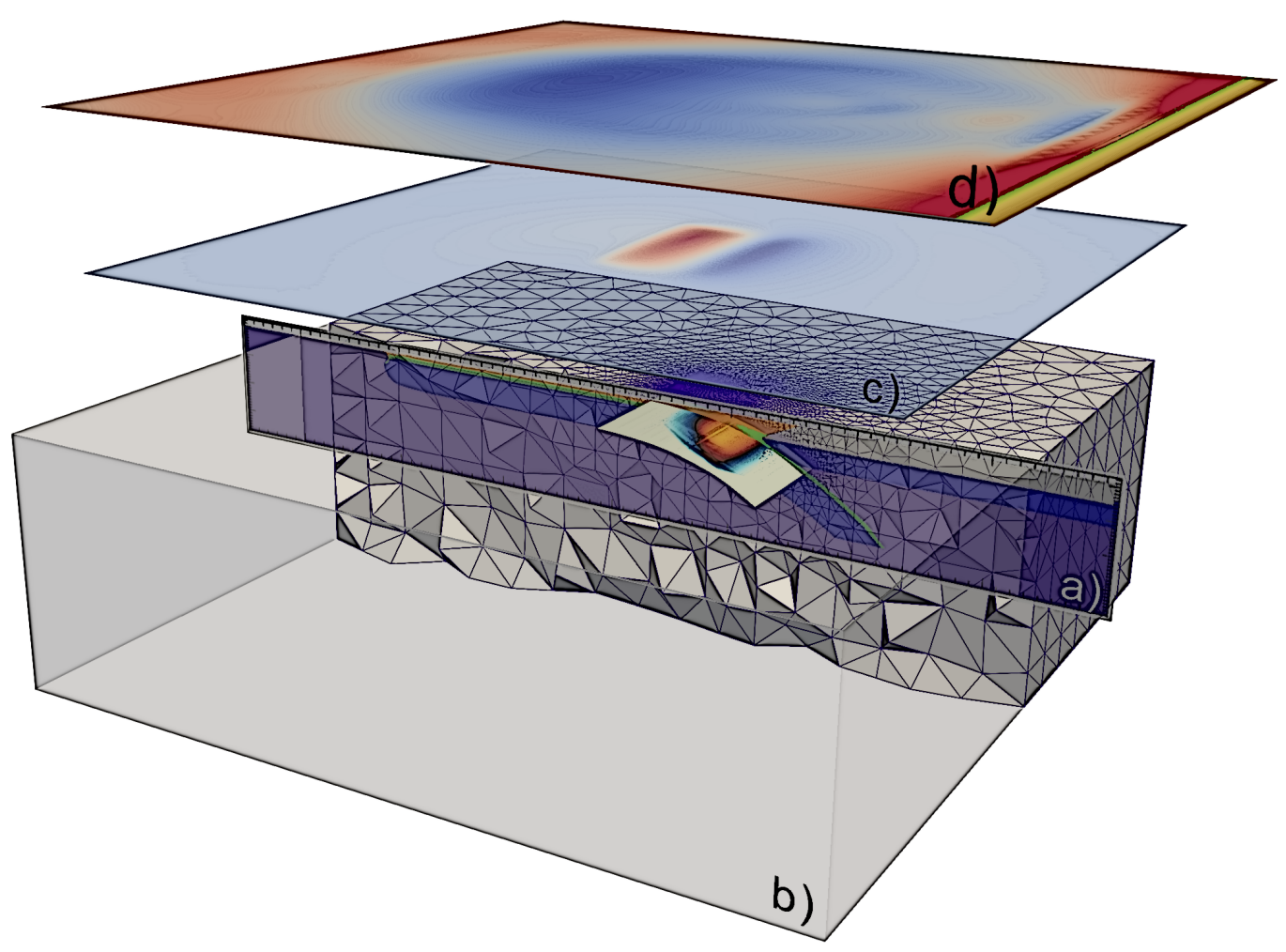

Figure 1. Illustration of model components of the presented virtual laboratory for earthquake-tsunami modeling. (a) 2D subduction seismic cycling model used to initialize the 3D earthquake model (Scenario C only), (b) 3D dynamic earthquake rupture model, (c) seafloor displacement from the earthquake model used as the tsunami source in the tsunami model, (d) 2D tsunami model. Note that dimensions are not to scale in all components. 

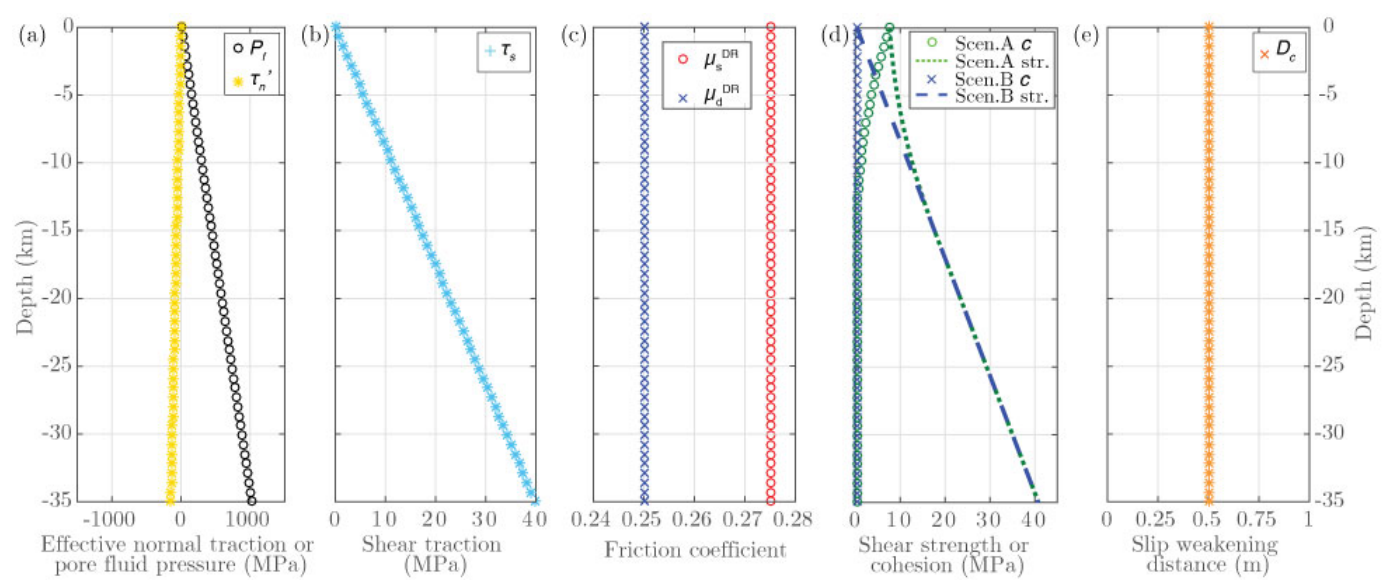

Figure 2. Parameters for the blind and surface-breaching earthquakes in Scenarios A and B (detailed in Sec. 3) along a cross section at $y=0$ through the 3D fault: (a) effective normal traction and pore fluid pressure, (b) shear traction, (c) coefficients of static and dynamic friction, (d) on-fault cohesion and fault strength, and (e) slip-weakening distance. Only the cohesion (shown in d) along the shallow fault differs from Scenario A to Scenario B. 

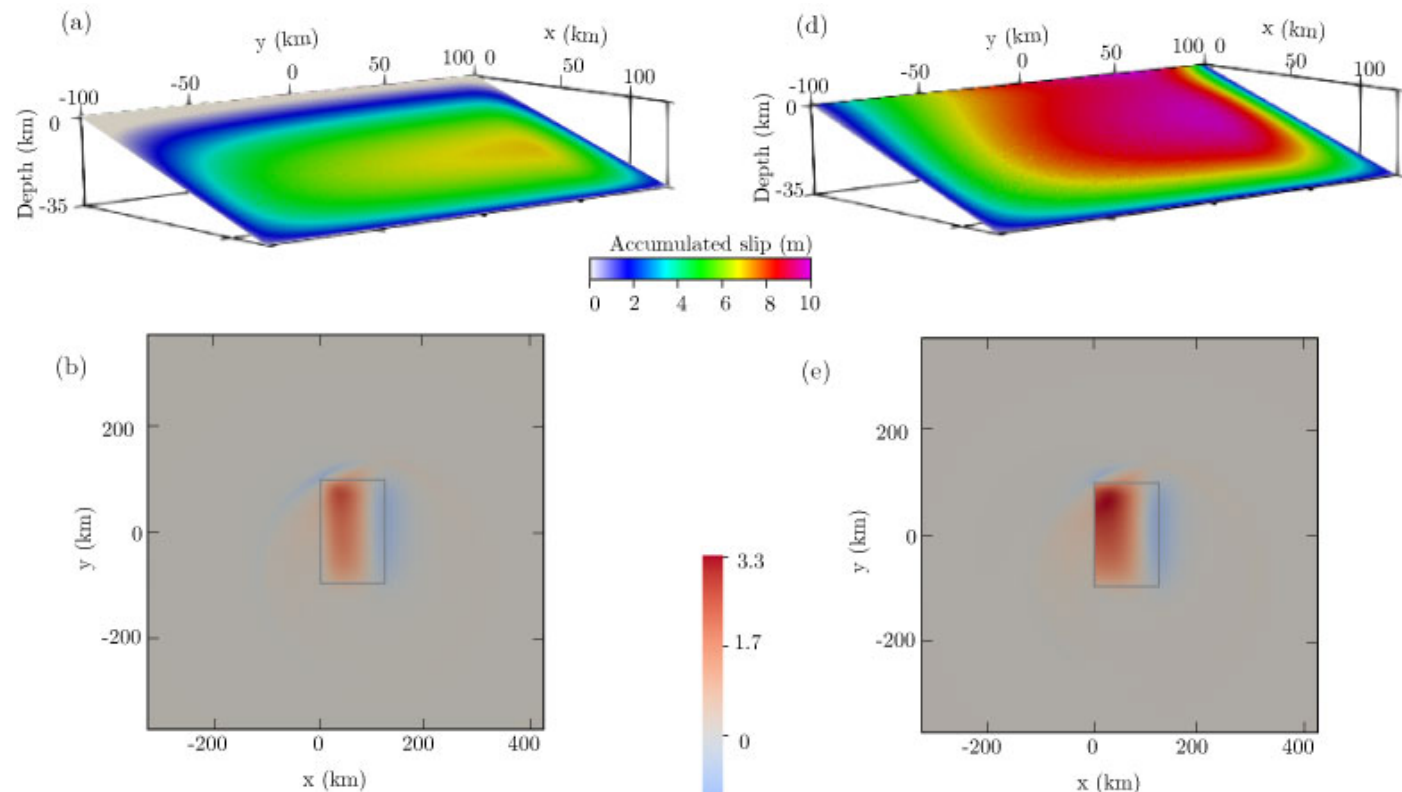

(e)
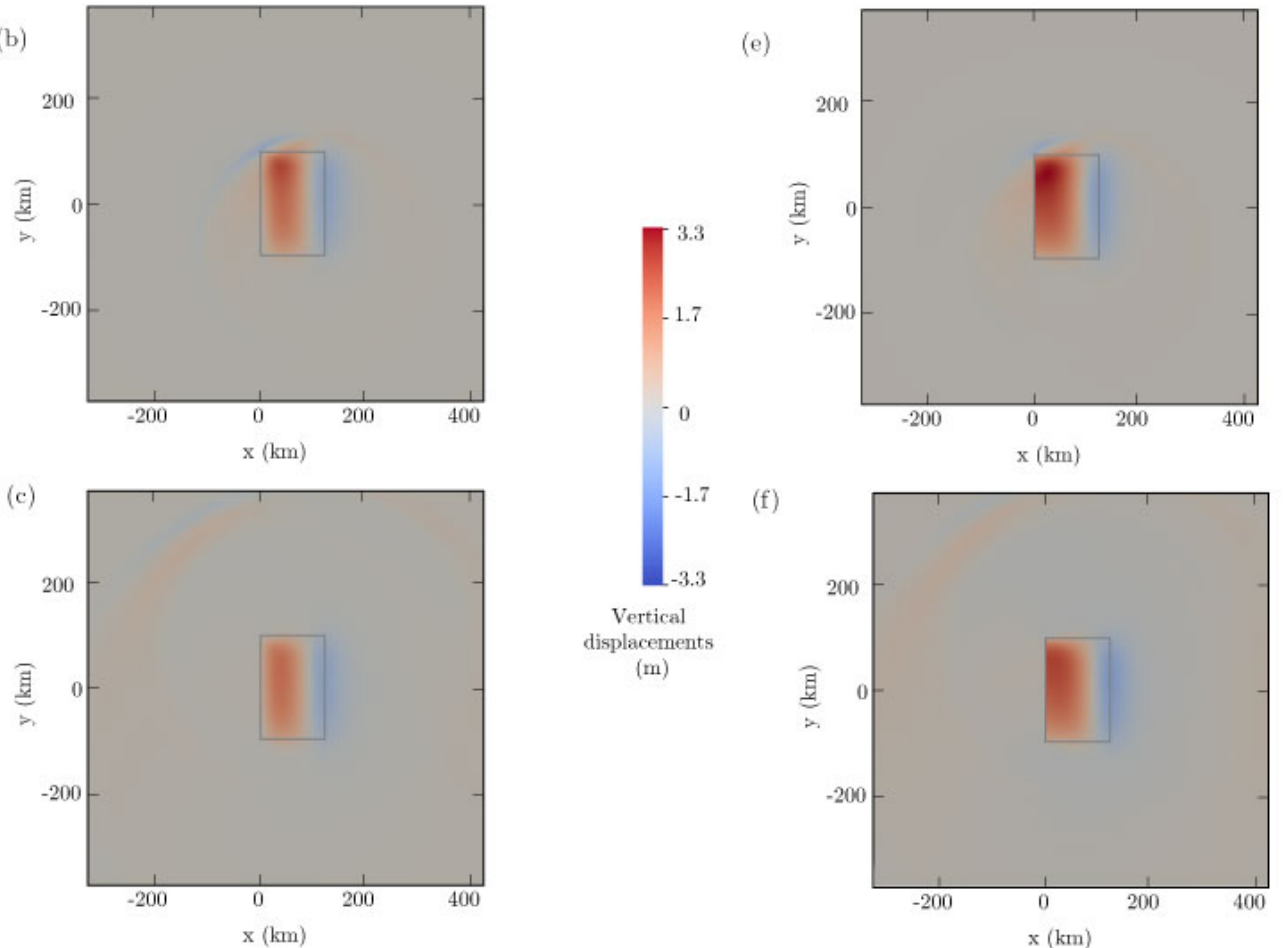

Figure 3. Blind versus surface-breaching earthquake scenarios. Scenario A (blind rupture): (a) accumulated slip, (b) vertical surface displacements at $56 \mathrm{~s}$ (time of maximum uplift) and (c) final vertical displacements. Scenario B (surface-breaching rupture): (d) accumulated slip, (e) vertical surface displacements at $56 \mathrm{~s}$ (time of maximum uplift) and (f) final vertical displacements. 


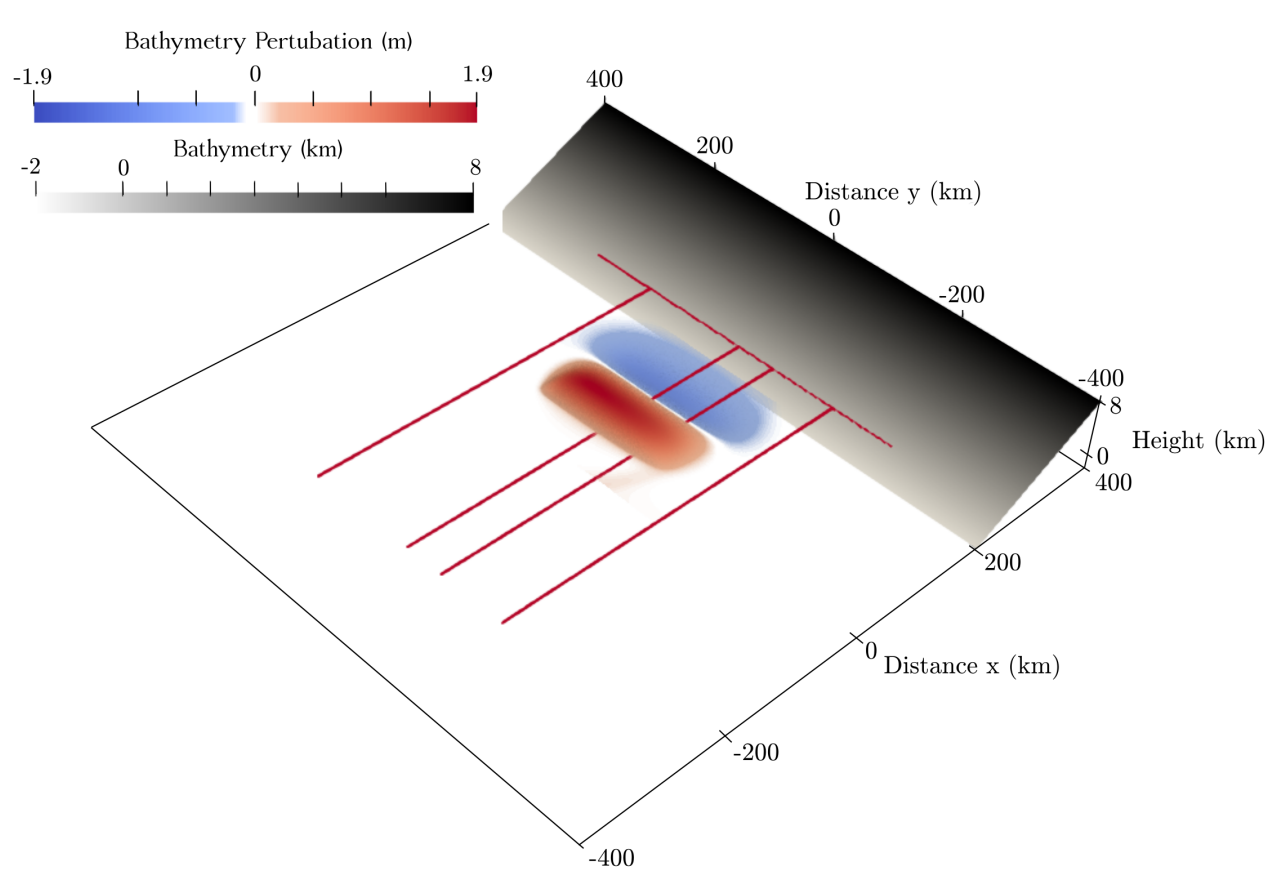

Figure 4. Bathymetry (flat seafloor and a linearly sloping beach) and bathymetry perturbation $(\Delta b(t, x, y))$ used in the tsunami model from the Scenario A blind earthquake at $t=102 \mathrm{~s}$. Red are cross-sections at $y=-150.0,-55,0,150.0 \mathrm{~km}$ and measurement points along the beach at $x=240.0 \mathrm{~km}$. 

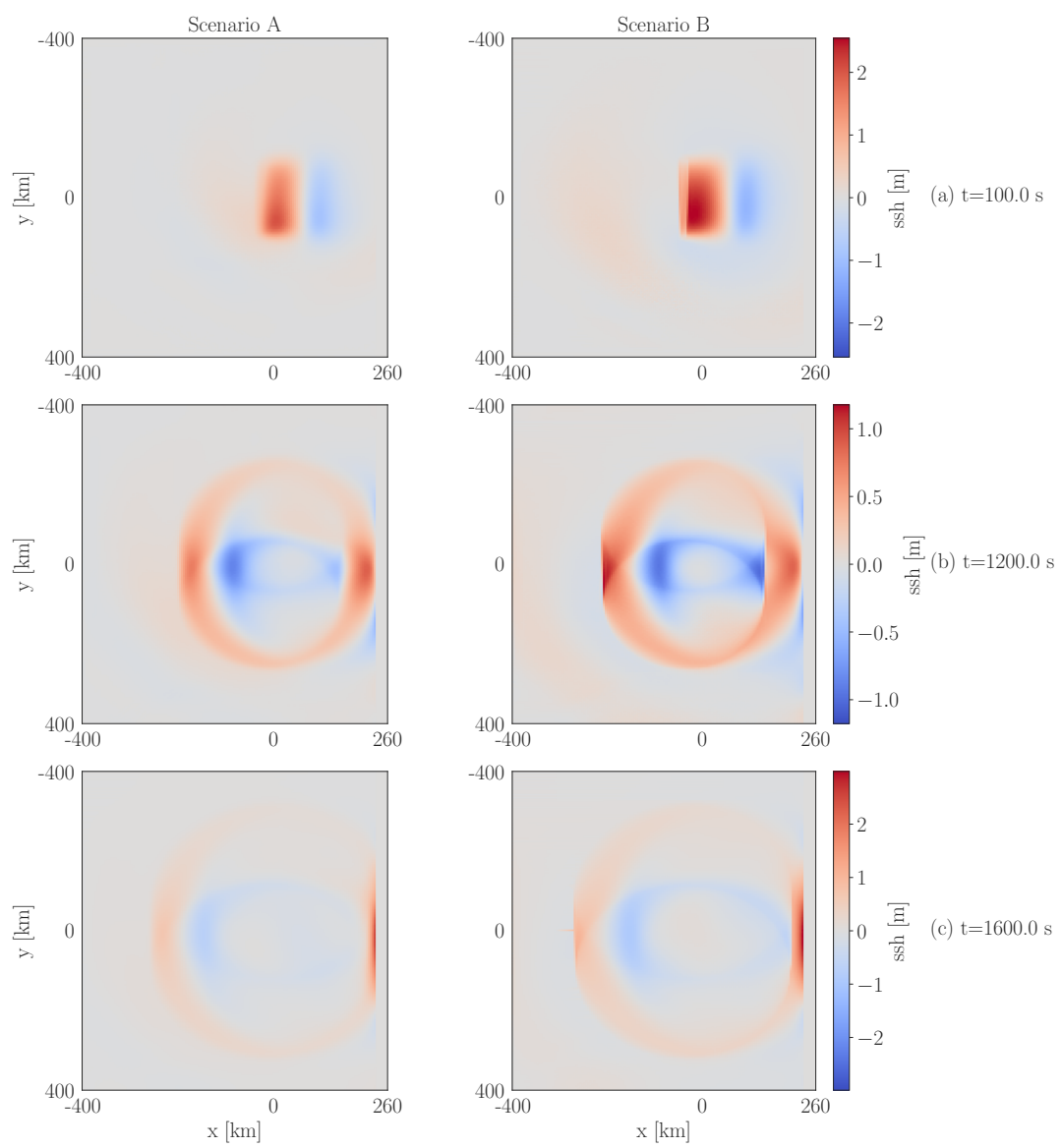

Figure 5. Sea surface height (ssh) in the tsunami sourced by the blind (Scenario A) and surface-rupturing (Scenario B) earthquakes (detailed in Sec. 3) at (a, first row) the final time of the earthquake model, (b, middle row) the approximate time of the first inundation, and (c, last row) the approximate time of maximum inundation. 


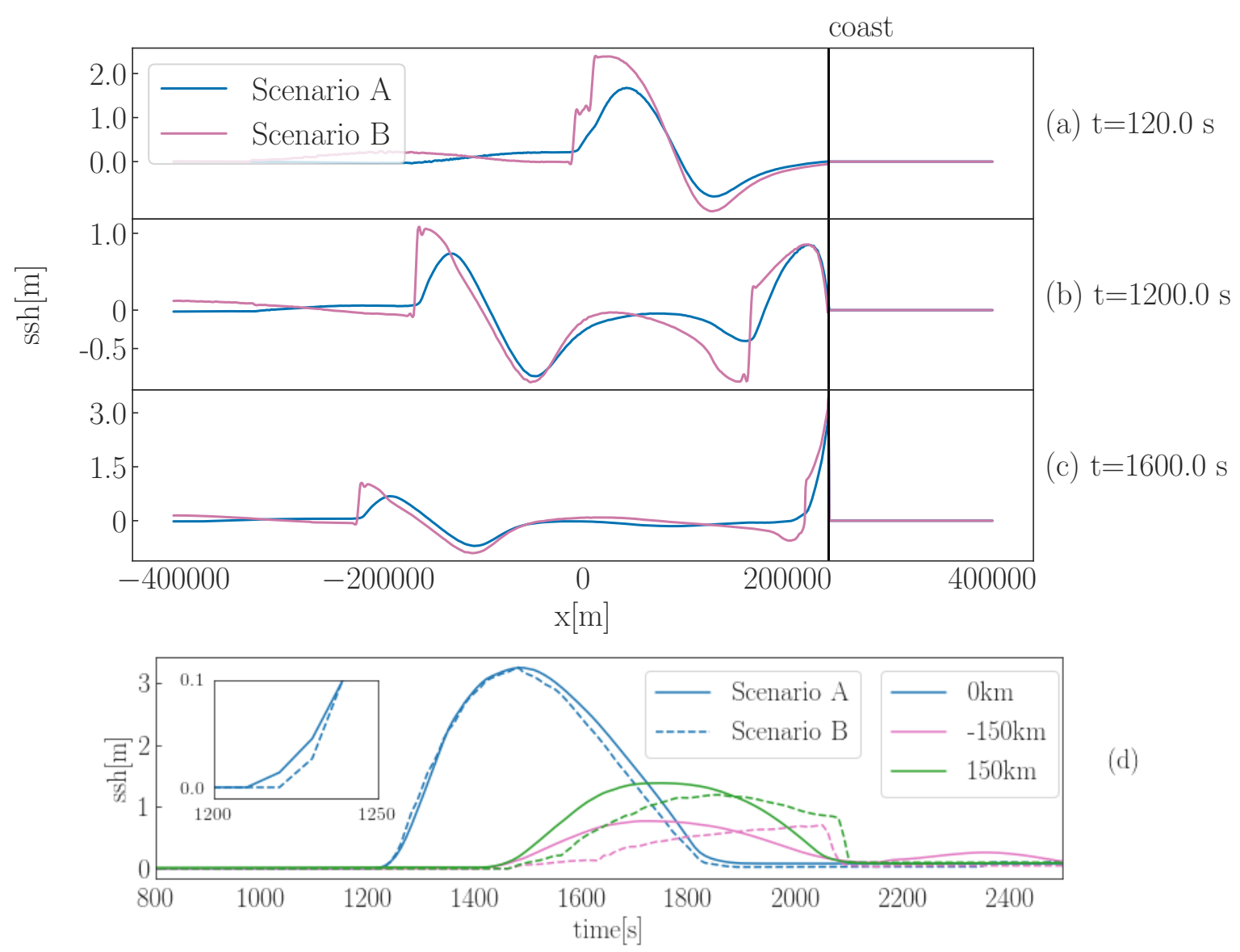

Figure 6. Sea surface height (ssh) in the tsunami sourced by the blind (Scenario A) and surface-rupturing (Scenario B) earthquakes (detailed in Sec. 3 along a cross section at $y=0 \mathrm{~km}$ and at (a) the final time the earthquake model, (b) the approximate time of the first inundation, and (c) the approximate time of maximum inundation. (d) Time series of ssh at 3 points located $10 \mathrm{~m}$ from the coast near $x=240 \mathrm{~km}$ for Scenario A and Scenario B. 


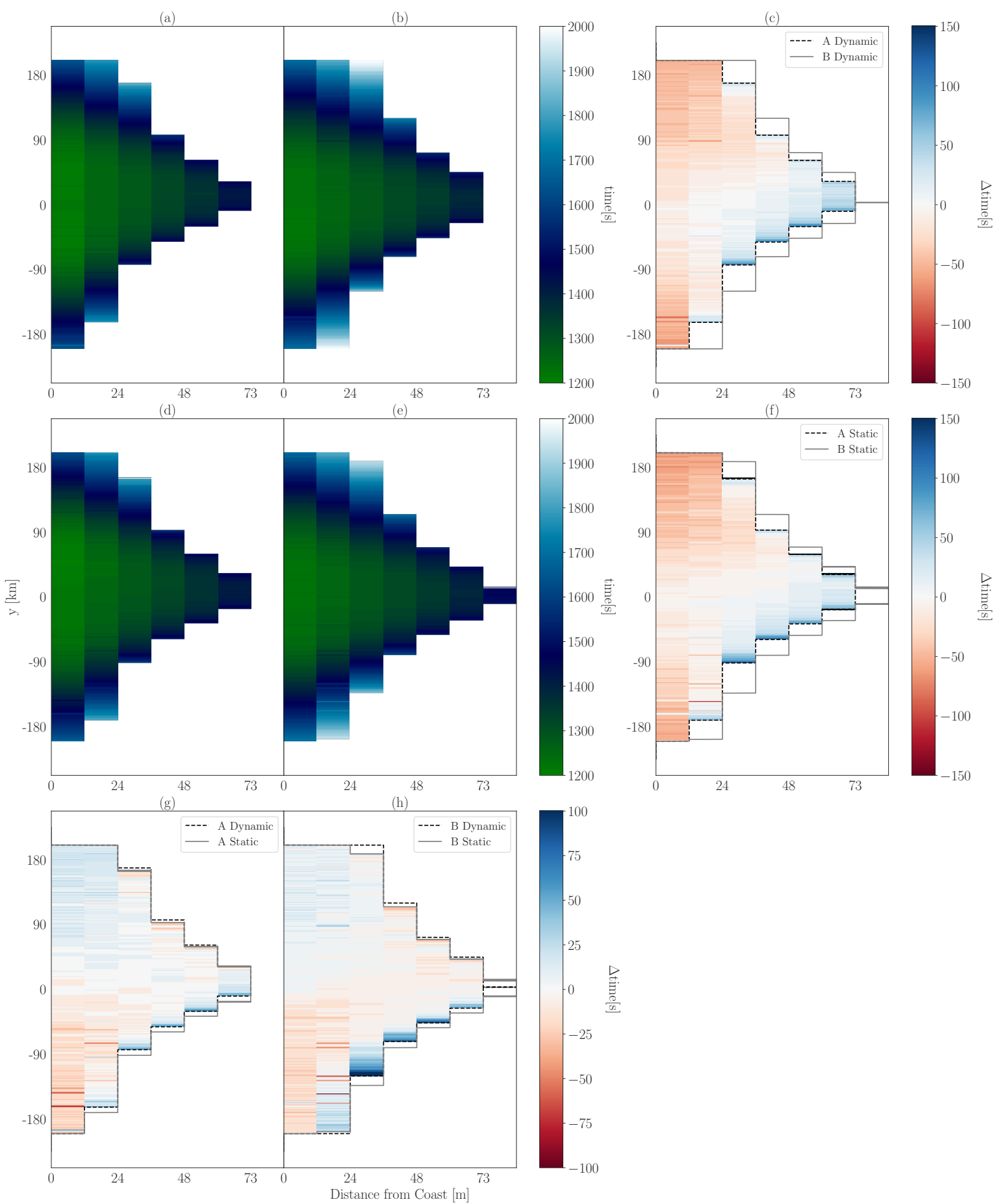

Figure 7. Inundation for Scenario A (blind earthquake rupture, first column) and Scenario B (surface-breaching rupture, second column) (see Sec. 3), incorporating the time-dependent (dynamic) filtered seafloor displacements (first row) or the time-independent (static) displacements (second row). The third column shows temporal differences between inundation in scenarios A and B, with negative values indicating that Scenario B's tsunami waves arrive later. The third row shows temporal differences between inundation from the time-dependent and time-independent sources, with negative values indicating that the waves from the time-independent source arrive later. The coast is located at $x=240 \mathrm{~km}$. The stepwise inundation distribution reflects the spatial mesh discretisation near the coast. 


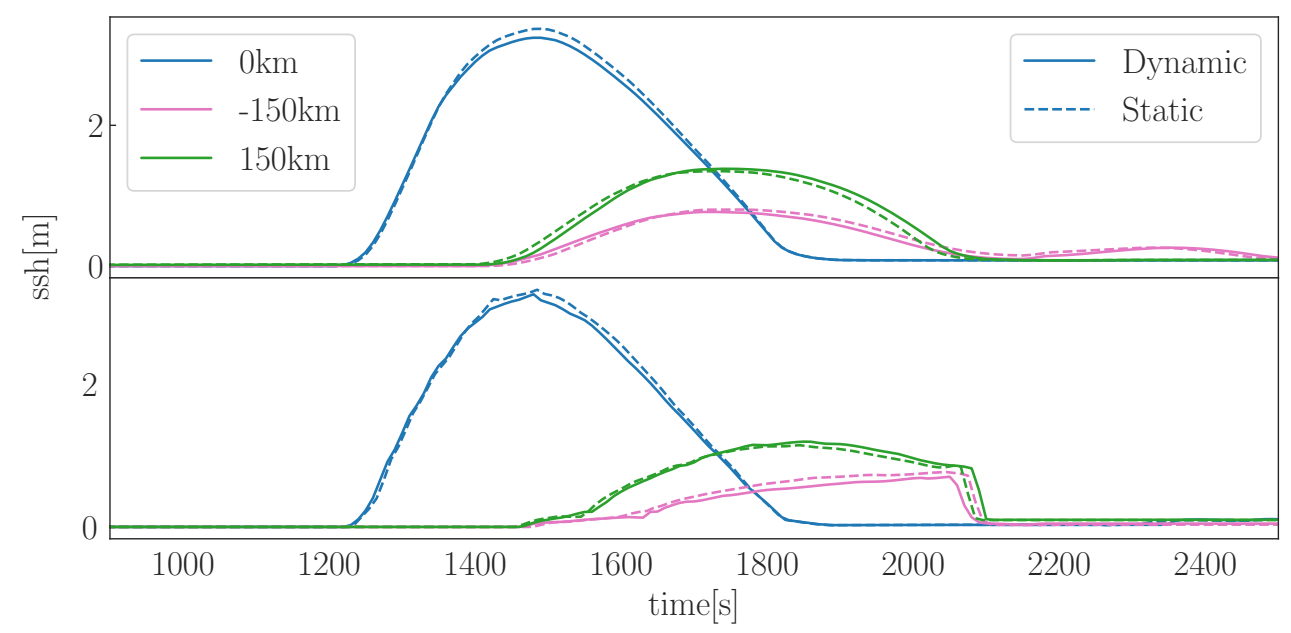

(a)

(b)

Figure 8. Time series of sea surface height (ssh) at 3 measurement points located $10 \mathrm{~m}$ from the coast near $x=240 \mathrm{~km}$ for tsunamis sourced by the time-dependent and time-independent filtered displacements from (a) the blind rupture in Scenario A and (b) the surface-breaching rupture in Scenario B.
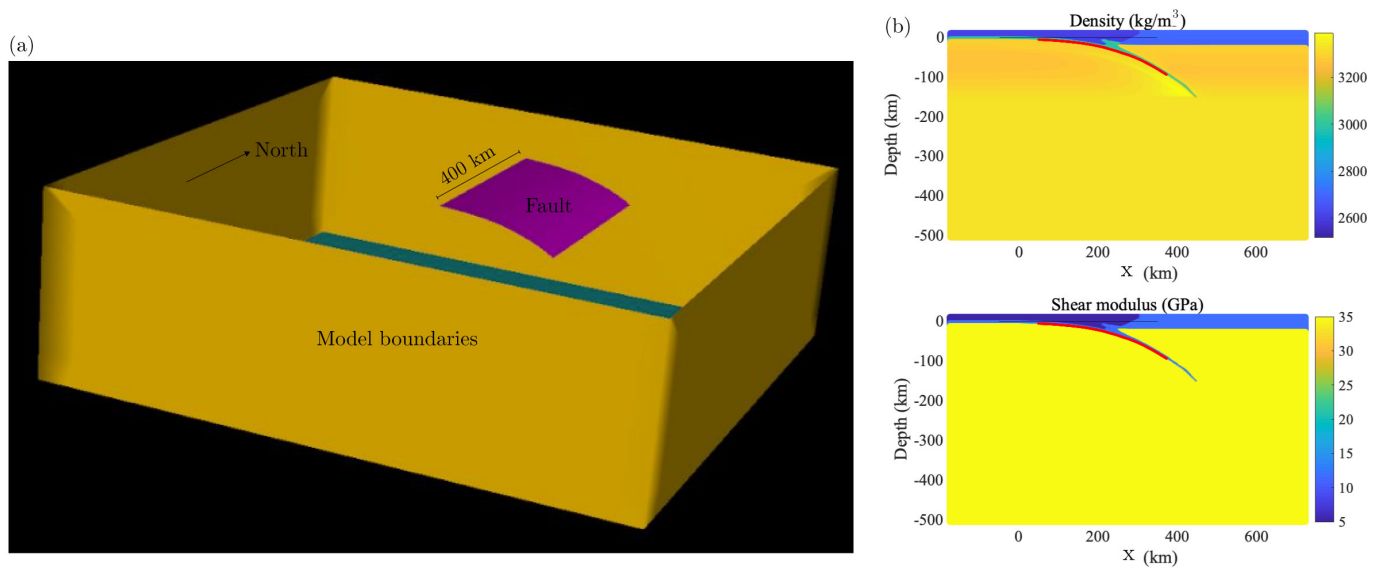

Figure 9. (a) Structure of the earthquake model for the subduction-initialized earthquake in Scenario C (see Sec. 4.1.1). Volume (yellow) is $1600 \mathrm{~km}$ along each side and $500 \mathrm{~km}$ deep. Fault (pink) is $400 \mathrm{~km}$ along strike. (b) Material properties. Red curve shows fault that evolves during the subduction slip event. Lame's parameter is equal to the shear modulus shown here. 

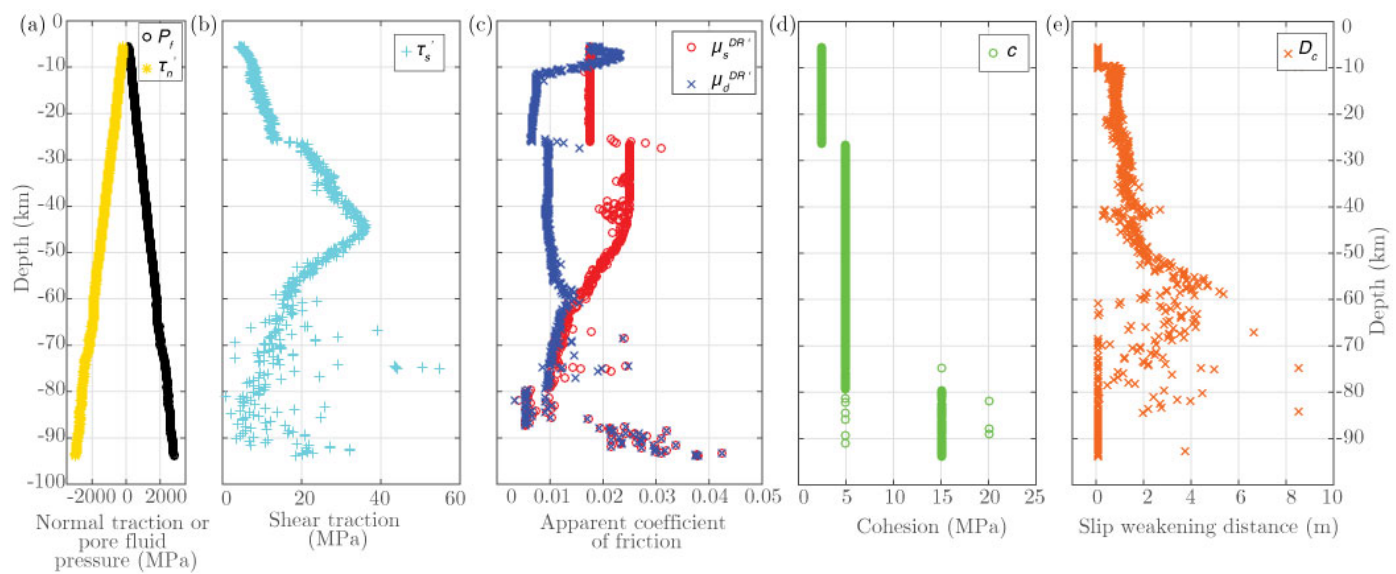

Figure 10. Initial conditions along a cross section at $y=0$ through the 3D fault used in the subductioninitialized earthquake in Scenario C before corrections are made to $c$ in the sediments above approx. $25 \mathrm{~km}$ depth and to $\mu_{s}$ at outliers (see Sec. 4.1.1): (a) normal traction and pore fluid pressure, (b) shear traction, (c) effective static and dynamic friction coefficients, (d) on-fault cohesion and (e) slip-weakening distance.

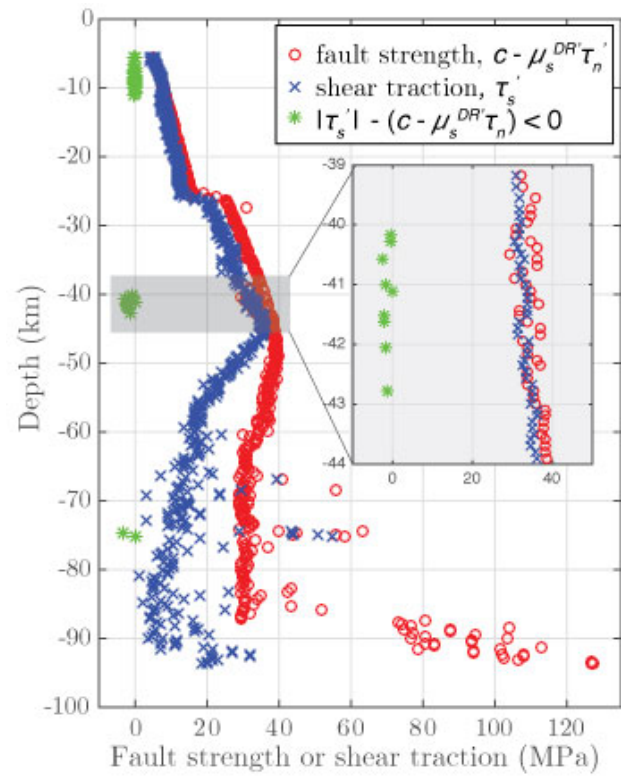

Figure 11. (a) Failure analysis according to the earthquake model failure criterion (Eq. 3) at points along a cross section at $y=0$ through the 3D earthquake model fault in Scenario C. Green stars are locations initially at failure, before adjustments are made to prevent such failure in the sediments and at outliers (see Sec. 4.1.1). Zoom is to the region near the nucleation zone. 


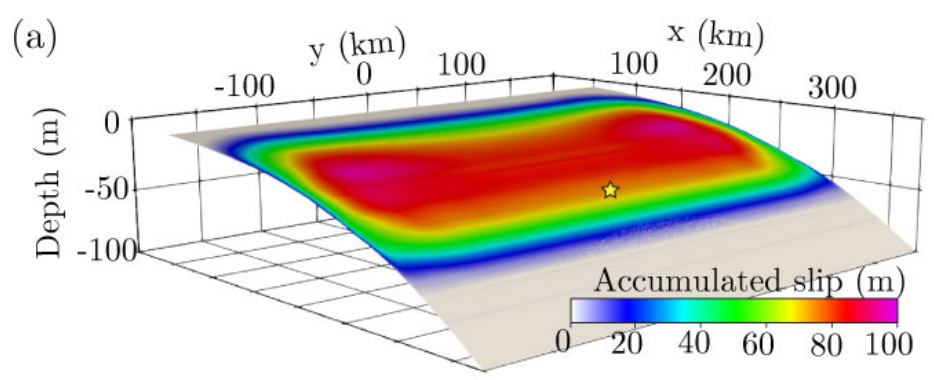

(b)

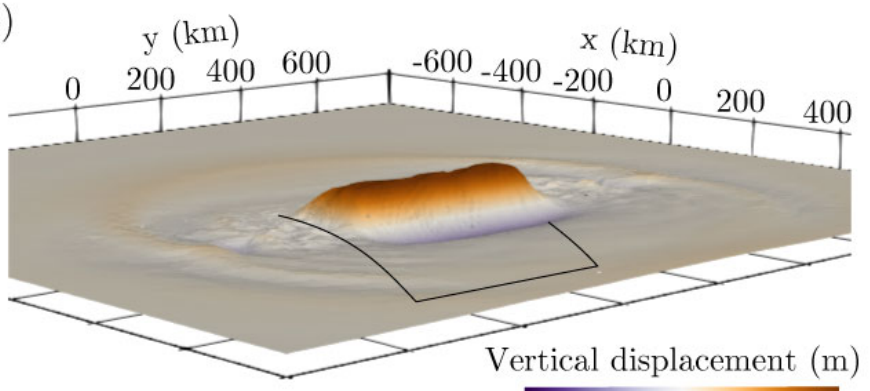

(c)

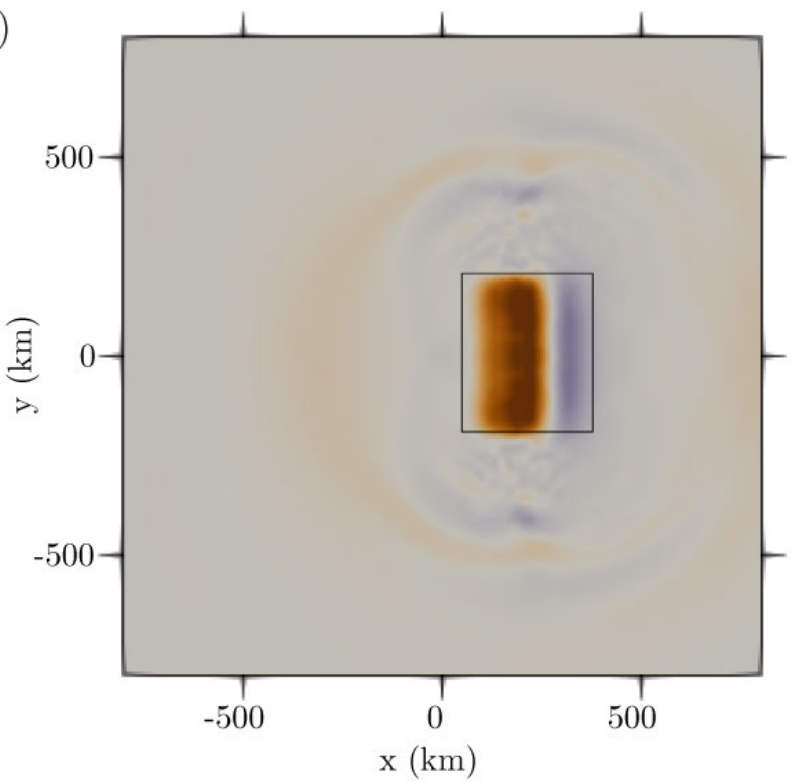

Figure 12. Results from the subduction-initialized dynamic earthquake rupture in Scenario $\mathrm{C}$ at $t=230 \mathrm{~s}$ : (a) accumulated slip on the fault, (b) oblique view of the vertical surface displacements, and (c) map view of the vertical surface displacements. Black lines in (b) and (c) outline the fault. 


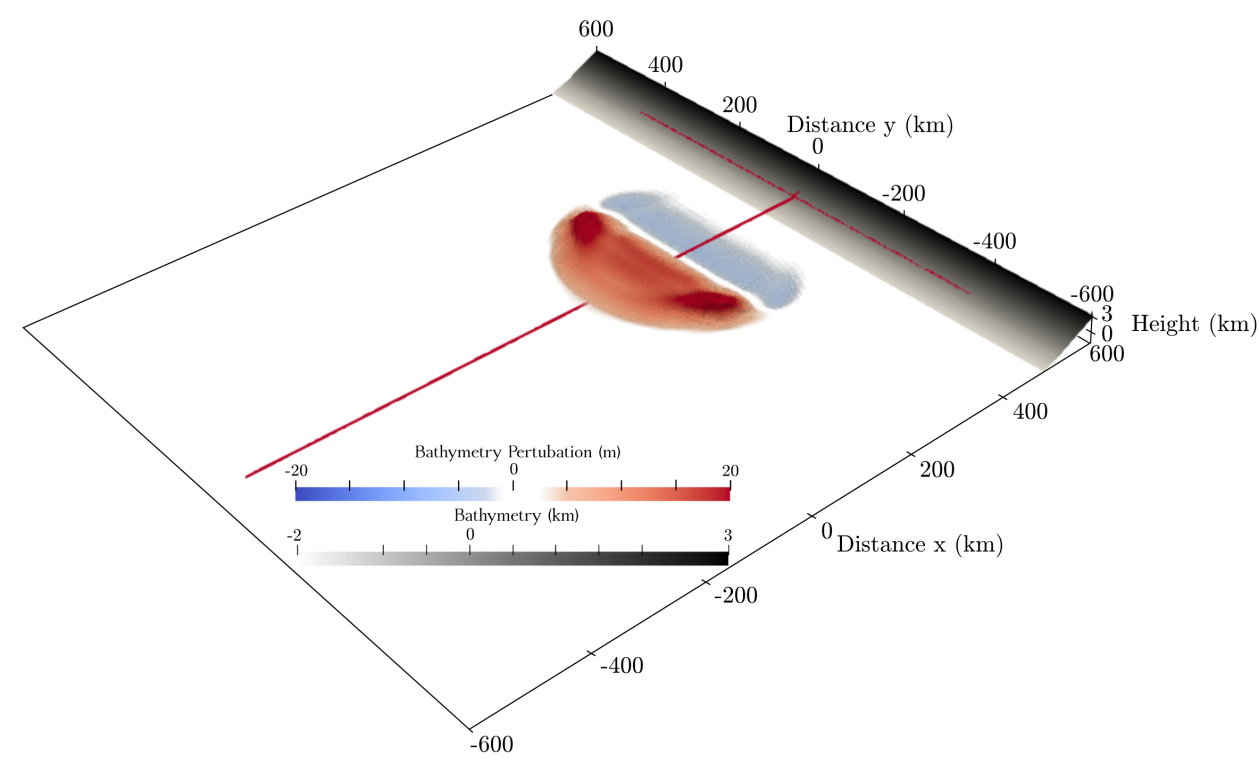

Figure 13. The tsunami physical model showing the bathymetric pertubation, $\Delta b$, at $t=100 \mathrm{~s}$ incorporating displacements from the subduction-initialized earthquake in Scenario C. Red lines are at $y=0$ and at the coast at $x=540 \mathrm{~km}$. 

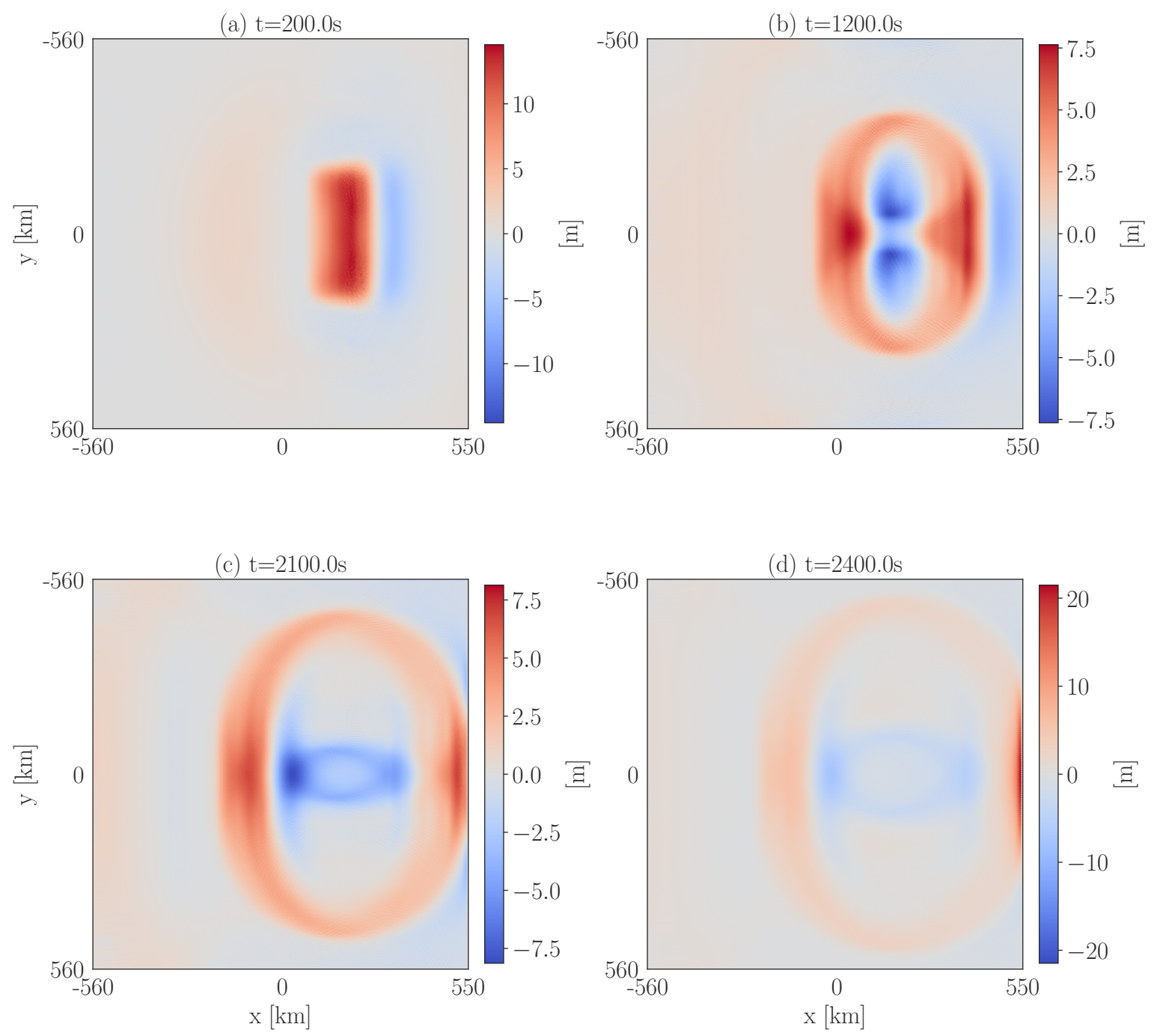

Figure 14. Sea surface height (ssh) from the tsunami sourced by the subduction-initialized earthquake in Scenario $\mathrm{C}$ at (a) the end of the earthquake, (b) after evolving for $1000 \mathrm{~s}$, (c) the approximate time of first inundation and (d) the approximate time of maximum inundation. 


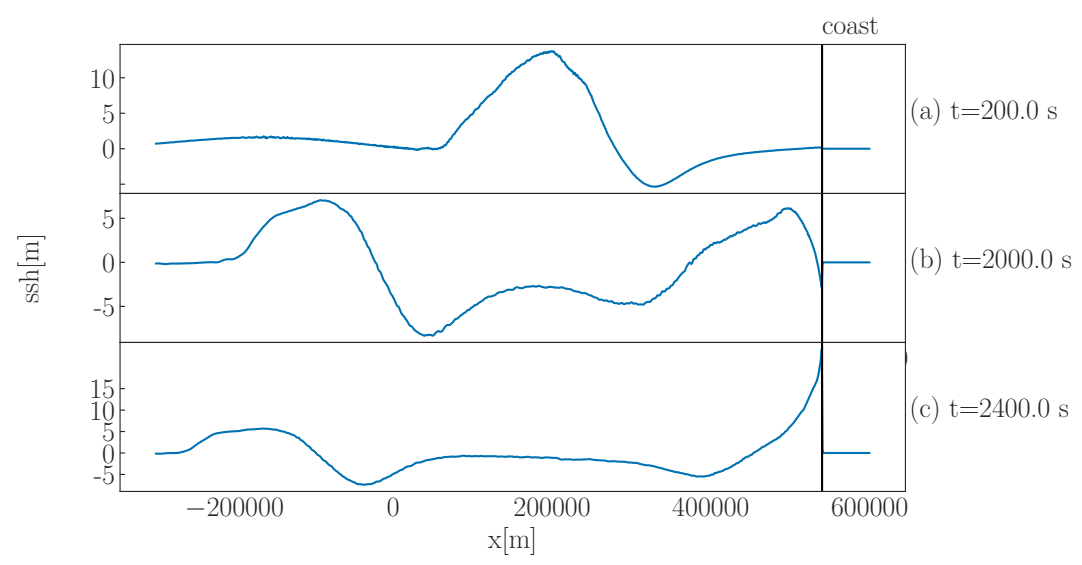

Figure 15. Sea surface height (ssh) from the tsunami sourced by the subduction-initialized earthquake in Scenario $\mathrm{C}$ along $y=0$ at (a) the end of the earthquake, (b) the approximate time of first inundation and (c) the approximate time of maximum inundation.
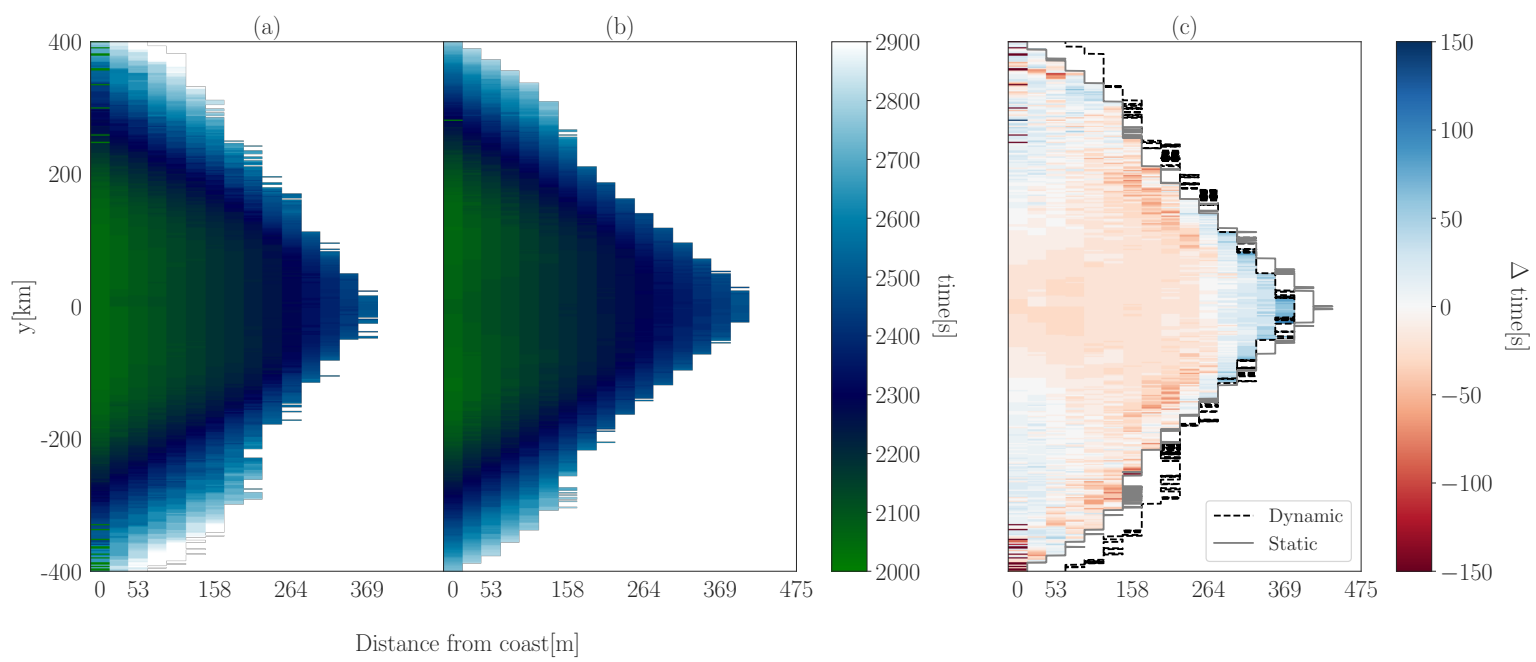

Figure 16. Inundation in space and time for the tsunami in Scenario $C$ from the subduction-initialized earthquake. Coast is at $x=540 \mathrm{~km}$. The first time the coast is inundated by the tsunami from (a) the time-dependent source, (b) the time-independent source, and (c) the difference (time-dependent minus time-independent). Negative values indicate that tsunami from the time-independent source arrives later. 

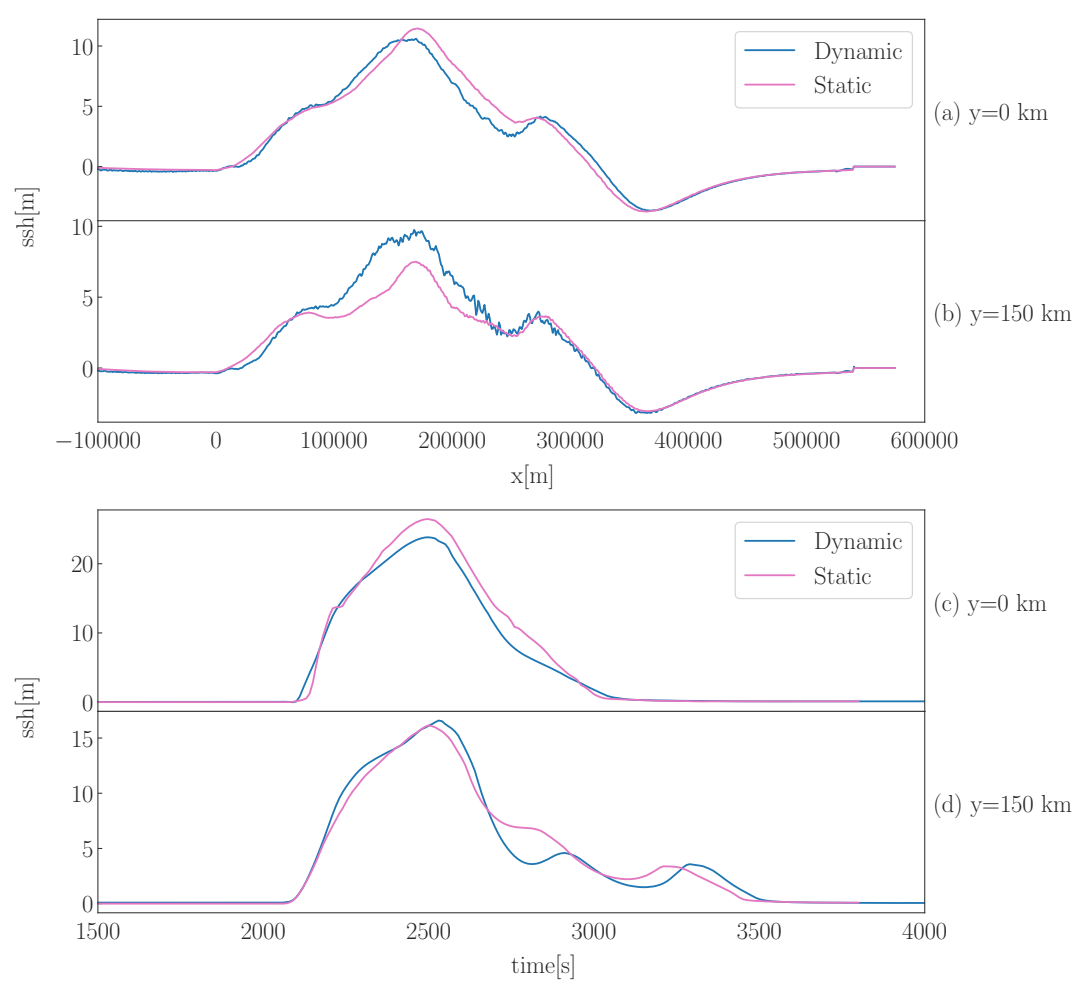

Figure 17. Comparison of sea surface height (ssh) from the tsunami from the time-dependent source and the time-independent sources in Scenario $\mathrm{C}$ at $t=420 \mathrm{~s}$ along cross sections near (a) $y=0 \mathrm{~km}$ and (b) $y=150 \mathrm{~km}$. Comparison of sea surface height (ssh) over time at points on the coast near (c) $x=540 \mathrm{~km}$ and $y=0 \mathrm{~km}$, and (d) $x=540 \mathrm{~km}$ and $y=150 \mathrm{~km}$.
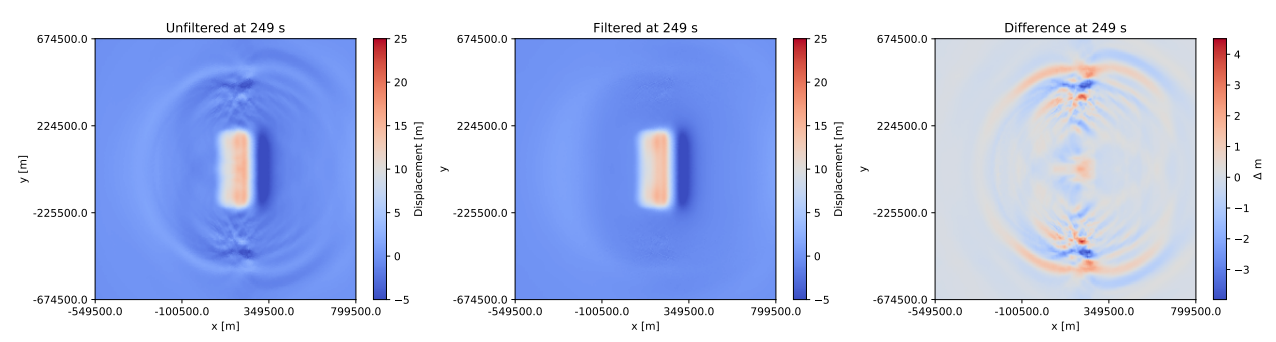

Figure 18. Effect of the time space Fourier filter on the the bathymetric pertubation, $\Delta b$, from the subductioninitialized earthquake in Scenario C at $t=249 \mathrm{~s}$. The filter uses (a) the raw field as input and produces (b) a filtered perturbation field from which (c) unwanted seismic surface waves and trailing seismic waves were cleaned. 
Madden et al.

\section{APPENDIX A: AVAILABILITY OF SOFTWARE AND REPRODUCIBILTY INFORMATION}

\section{A1 Earthquake modeling: SeisSol}

The earthquake simulation software SeisSol (www.seissol.org) is publicly available as open source software athttps://github.com/SeisSol/SeisSol. Documentation how to compile and use SeisSol is provided at https://seissol.readthedocs.io/

SeisSol has been validated against a series of wave propagation and dynamics rupture benchmarks (see the references provided in Sec. 2.1) which are described in the "Cookbook" section of https: //seissol.readthedocs.io/

\section{A2 Tsunami modeling: $\operatorname{sam}(0 a)^{2}$-flash}

The sam(oa) ${ }^{2}$-flash tsunami model (Sec. 2.2 has been implemented within the sam(oa) ${ }^{2}$ framework, which is publicly available as open source software at https://gitlab.lrz.de/samoa/samoa Documentation on how to compile and use $\operatorname{sam}(\mathrm{oa})^{2}$ and $\operatorname{sam}(\mathrm{oa})^{2}$-flash is provided at https:// samoa.readthedocs.io/. The $\operatorname{sam}(\mathrm{oa})^{2}$-flash version used in this paper is permanently archived in the gitlab repository, as branch samoa-flash-gji-2020.

$\operatorname{sam}(\mathrm{oa})^{2}$-flash has been validated against a set of community benchmarks, following the test suite also used for validation of the underlying discontinuous Galerkin scheme, Stormflash2D (Vater et al.2017). These benchmarks include tests for steady state solutions (Resting Lake) and the inundation of coasts (Oscillating Lake, Okushiri Tsunami). The archive at https://zenodo.org/record/ 3836668 includes instructions and required data files to reproduce these benchmarks. Results including a comparison to reference solutions are available at https://zenodo.org/record/3836668/ files/documentation_overview.pdf.

Tsunami modeling that includes inundation must handle varying spatial scales. $\operatorname{sam}(\mathrm{oa})^{2}$-flash uses adaptive mesh refinement (e.g., LeVeque et al. 2011), currently the most advanced approach for tsunami model meshing. This is in contrast to traditional tsunami modeling approaches employing a multitude of nested grids (e.g., Liu et al. 1995; Titov \& Gonzalez 1997) or the alternative approach consisting of non-uniform, predefined meshes that use a priori knowledge about the wave behavior to assign high-resolution areas (Harig et al. 2008). 


\section{A3 Reproducibility}

We provide all necessary information and data sets required to reproduce the results presented in this work at https://tinyurl.com/yxn6zrqc. The archive includes all required configuration files, compilation parameters and input data.

\section{APPENDIX B: MESH GENERATION FOR DYNAMIC RUPTURE MODELING WITH SEISSOL}

The structural model and mesh for the earthquake physical model used in scenarios A and B are generated with the open-source software Gmsh (www.gmsh.info) (Geuzaine \& Remacle 2009). The structural model in Scenario C is built in GOCAD (wWw.pdgm.com) and automatized mesh generation is performed with the software PUMGen (https://github.com/SeisSol/PUMGen/) (Rettenberger 2017), which also exports the mesh into the efficient PUML format used by SeisSol. PUMGen embeds MeshSim from SimMetrix, the underlying mesh generator of SimModeler (www.simmetrix.com), such that the mesh generation may be run in parallel on a compute cluster. The scenarios presented here use mesh sizes of 13 million elements (Scenario C) and 16 million elements (scenarios A and B), which require computational resources well within the scope of typical applications for supercomputing centers or university clusters.

Spatial resolution of earthquake faults has to be small enough to adequately resolve the dynamics behind the earthquake rupture front, where shear stress and slip rate vary significantly. The so-called cohesive zone, by analogy to tensile fracture mechanics, captures shear stress breaking down from its static to its dynamic value (Day et al.2005). In the dynamic earthquake models used in scenarios A and B (Sec. 3.1), $400 \mathrm{~m}$ element edge lengths on the fault are combined with polynomial degree $p=5$ (spatio-temporal order of accuracy of 6) leading to an effective numerical discretization distinctively higher. SeisSol's underlying numerical scheme defines initial conditions such as shear and normal stress at two-dimensional quadrature points located inside each tetrahedral element face which is linked to the fault (Pelties et al. 2014). The effective resolution of the fault can be approximated by the edge length of the mesh divided by $p+2$ additional integration points (De La Puente et al. 2009). This sets on-fault resolution to $400 / 7=57 \mathrm{~m}$ which properly resolves the minimum cohesive zone width of $150 \mathrm{~m}$ and creates a 16 million element mesh. The nucleation patch has a reduced mesh element edge length of $250 \mathrm{~m}$. Failure initiates and evolves into a sustained rupture as the friction is decreased over time in this region. Following Wollherr et al. (2018), assessing the worst local resolution achieved, we determine the following expected maximum errors for the results with this mesh: 
$0.09 \%$ for the rupture arrival, $7.6 \%$ for the peak slip rate, and $0.8 \%$ for the final slip magnitude. These meet the recommendations from Day et al. (2005) for acceptable errors.

For the subduction-initialized dynamic earthquake model in Scenario C (Sec 4.1.1), we discretise the structural model with an element edge length of $1 \mathrm{~km}$ on the fault, $5 \mathrm{~km}$ within a mesh refinement zone surrounding the fault, and a maximum element edge length of $20 \mathrm{~km}$. This properly resolves a minimum cohesive zone width of $193 \mathrm{~m}$, which is appropriate along most of the fault. In Scenario C, it also is crucial that the meshed 3D fault matches the locations of the 2D fault from the subduction slip event (see Sec. D). We achieve this by extruding the 2D fault from the subduction odel along strike in GOCAD (www.pdgm.com), with straight horizontal lines between points at the same depth and no smoothing.

\section{APPENDIX C: GEODYNAMIC SEISMIC CYCLE MODEL}

The physical subduction model that we use has an extent of $1500 \mathrm{~km}$ in the $x$-direction by $200 \mathrm{~km}$ in the $z$-direction. The subducting oceanic plate consists of $4 \mathrm{~km}$ thick sediments, a $2 \mathrm{~km}$ thick basaltic upper crust, a $5 \mathrm{~km}$ thick gabbroic lower oceanic crust, and a lithospheric mantle (Fig. A2 a; Table A1). The continental plate consists of a sedimentary wedge, an upper and lower continental crust and a lithospheric mantle layer. A constant velocity of $7.5 \mathrm{~cm} / \mathrm{yr}$ is applied to a small box inside the subducting plate to initiate and sustain subduction. At the sides and the top of the model, free slip boundary conditions are applied that only allow for tangential velocities along the boundary, while perpendicular velocities are not permitted. There is an open boundary at the bottom of the model where material can flow out, while free slip is externally applied (Gorczyk et al.|2007). The sticky air approximation, common in geodynamic modelling where topography develops, mimics an internal free surface, as low density, low viscosity 'sticky air' material is decoupled from the underlying rocks (Schmeling et al. 2008; Crameri et al. 2012).

The subduction geometry, lithological properties, temperature, viscosity, stresses and strengths develop spontaneously over 3.6 million years through solving thermo-mechanical conservation equations with a time step of 1000 years (compare Fig.s A2 b and A2 k). At temperatures below $100^{\circ} \mathrm{C}$, materials are velocity strengthening and a transition between $100^{\circ} \mathrm{C}$ and $150^{\circ} \mathrm{C}$ leads to velocity weakening at higher temperatures. The down-dip limit of the seismogenic zone develops as viscous deformation becomes progressively more dominant at temperatures above $350^{\circ} \mathrm{C}$ (van Dinther et al. 2013b).

After 3.6 million years, a sufficiently steady-state subduction geometry has developed, suitable for a seismic cycle. The time step is gradually reduced by manually predefined intervals to 5 years, after which the seismic cycle phase of the model begins and lasts for approximately 30,000 years. 
The subduction geometry (Fig. A2 r) shows the oceanic plate subducting with an average dip of $14.8^{\circ}$ above $95 \mathrm{~km}$ depth during this phase.

After a spin-up period at the start of the seismic cycle phase, tens of quasi-periodic slip events occur (see van Zelst et al. (2019), Fig 3). We refer to these as 'slip events' to differentiate them from earthquakes modeled with SeisSol. These slip events represent sudden, spontaneous increases of plastic strain rates during localized plastic failure in a narrow shear band (the 'fault' in the subduction model), which leads to reversed velocities due to elastic rebound and a drop of elastic stresses that were built up by the convergence of the subducting plate towards the overriding plate. Brittle failure is simulated according to Drucker-Prager plasticity and initiates when the second invariant of the deviatoric stress tensor $\sigma_{I I}^{\prime}$ (Fig. A2 d) meets the yield strength:

$$
\sigma_{I I}^{\prime}=C+\mu^{s c}\left[1-\left(P_{f} / P\right)\right] P
$$

Here, $C$ is cohesion, $P$ is the mean pressure, $P_{f}$ is the pore fluid pressure and $\mu$ is the friction coefficient. Note that in the subduction model, there is no differentiation between bulk cohesion of intact rock and on-fault cohesion, $c$, after failure. We define the onset of a slip event as the first time step at which two adjacent points are at plastic failure (van Zelst et al. 2019). At this stage maximum slip rates are around $5.5 \cdot 10^{-11} \mathrm{~m} / \mathrm{s}$, with maximum slip rates of $9.3 \cdot 10^{-9} \mathrm{~m} / \mathrm{s}$ reached during the entire event. We know that this localized failure develops into a slip event because we select it from the series of events after running the entire seismic cycling phase of the subduction model (see Sec. 5.2 for further discussion).

Slip behavior after failure is viscoplastic rate dependent. In the strongly slip rate-dependent friction formulation (van Dinther et al. 2013a), the friction coefficient $\mu^{\text {sc }}$ drops non-linearly from the static coefficient $\mu_{s}^{\mathrm{sc}}$ to the dynamic coefficient $\mu_{d}^{\mathrm{sc}}$ with increasing slip rate $V$, according to:

$$
\mu^{\mathrm{sc}}=\frac{V_{c} \mu_{s}^{\mathrm{sc}}+V \mu_{d}^{\mathrm{sc}}}{V_{c}+V}
$$

where $V_{c}$ is the characteristic velocity at which half of the friction drop occurs.

Slip events occur mainly in the model subduction channel and the accretionary wedge. The events typically nucleate near the downdip limit of the model seismogenic zone in the basalt, after which they progress into the shallow sediments.

We choose one representative slip event to initialize the earthquake model. This event is chosen late in the simulation time of the seismic cycling, to ensure that the change of time step has no lasting effect on the slip events. In the chosen slip event, slip initiates at $x=220 \mathrm{~km}$ (according to the axis in Fig.s A2k, d) and proceeds mainly up-dip, where it is stalled in the velocity strengthening region. Slip also arrests down-dip, in the domain dominated by ductile creep. 


\section{APPENDIX D: ASSESSMENT OF ACCURACY IN MAPPING THE SLIP EVENT CONDITIONS TO THE EARTHQUAKE MODEL}

To accurately map subduction model parameters to the earthquake model, it is crucial that the faults in both models are of the same geometrical shape. This ensures that they experience the same stress field and host the same on-fault properties. To verify this, before running the earthquake model, we compare fault locations, fault dip, effective shear traction, and failure on the 2D subduction model fault and along a 2D slice at $y=0$ through the earthquake model mesh.In the following we show that the two faults have the same shape and capture the same initial conditions.

Linked parameters of the subduction model fault are available at 649 locations and the slice through the earthquake model fault allows initializing 849 fault locations. Values are ported to the earthquake model at the $500 \mathrm{~m}$ resolution of the subduction model. Fig. A3 shows that the differences between fault locations are below the $500 \mathrm{~m}$ resolution of the subduction model output. Fig. A3b shows that the profile of the earthquake model fault is slightly smoother, without the very small variations in dip that are present along the subduction model fault. Along the subduction model fault, the average dip is $14.8^{\circ}$, the minimum dip is $2.3^{\circ}$, and the maximum dip is $34.4^{\circ}$. Along the slice through the earthquake model fault, the average dip is $14.9^{\circ}$, the minimum dip is $2.8^{\circ}$, and the maximum dip is $31.8^{\circ}$.

Variation in shear traction along both faults with depth is shown in Fig. A4. The two model fault host shear tractions that are free of any systematic differences. Along the subduction model fault, the average shear traction magnitude is $14.9 \mathrm{MPa}$, the minimum is $1.3 \mathrm{MPa}$, and the maximum is 54.5 MPa. Along the slice through the earthquake model fault, the average shear traction magnitude is 15.0 MPa, the minimum is $0.9 \mathrm{MPa}$, and the maximum is $54.7 \mathrm{MPa}$.

Fig. A4 shows at each depth the shear traction, the static fault strength, and any points at failure, where the absolute magnitude of the shear traction exceeds the fault strength. Both faults have the same regions at failure: within the sediments and near $42 \mathrm{~km}$ depth, where the subduction slip event begins and where we set the nucleation zone in the earthquake model. A zoom into this region reveals that it extends for $\approx 3 \mathrm{~km}$ with depth along both faults. Note that the slice through the earthquake model fault has more points at failure here, because it has more fault locations overall. 
Table A1. Reference material properties of the subduction model.

\begin{tabular}{cccccc}
\hline Material & $\rho$ & $G$ & $\mu_{s}^{\mathrm{sc}}$ & $\mu_{d}^{\mathrm{sc}}$ & $C$ \\
& $\left(\mathrm{~kg} / \mathrm{m}^{3}\right)$ & $(\mathrm{GPa})$ & $(-)$ & $(-)$ & $(\mathrm{MPa})$ \\
\hline Sediments & 2600 & 5 & 0.35 & 0.105 & 2.5 \\
Continental crust & 2700 & 12 & 0.72 & 0.216 & 10 \\
Upper oceanic crust & 3000 & 12 & 0.5 & 0.15 & 5 \\
Lower oceanic crust & 3000 & 12 & 0.85 & 0.255 & 15 \\
Mantle & 3300 & 35 & 0.6 & 0.18 & 20 \\
\hline
\end{tabular}

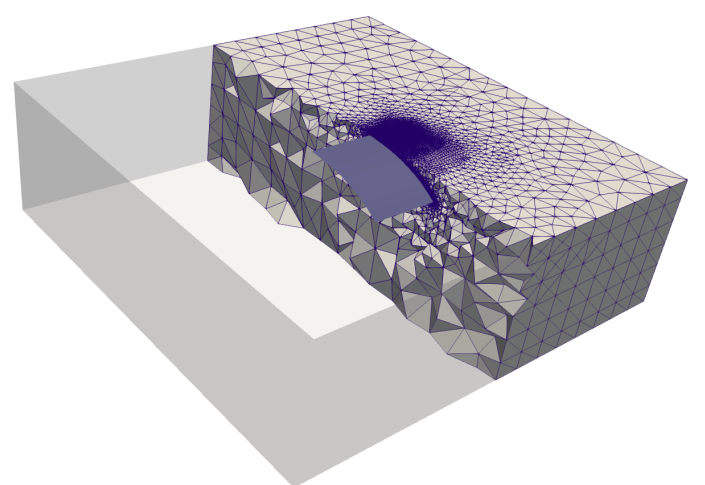

Figure A1. Structural model and mesh used for the subduction-initialized dynamic earthquake rupture model in Scenario C (Sec. 4). 


\section{Madden et al.}

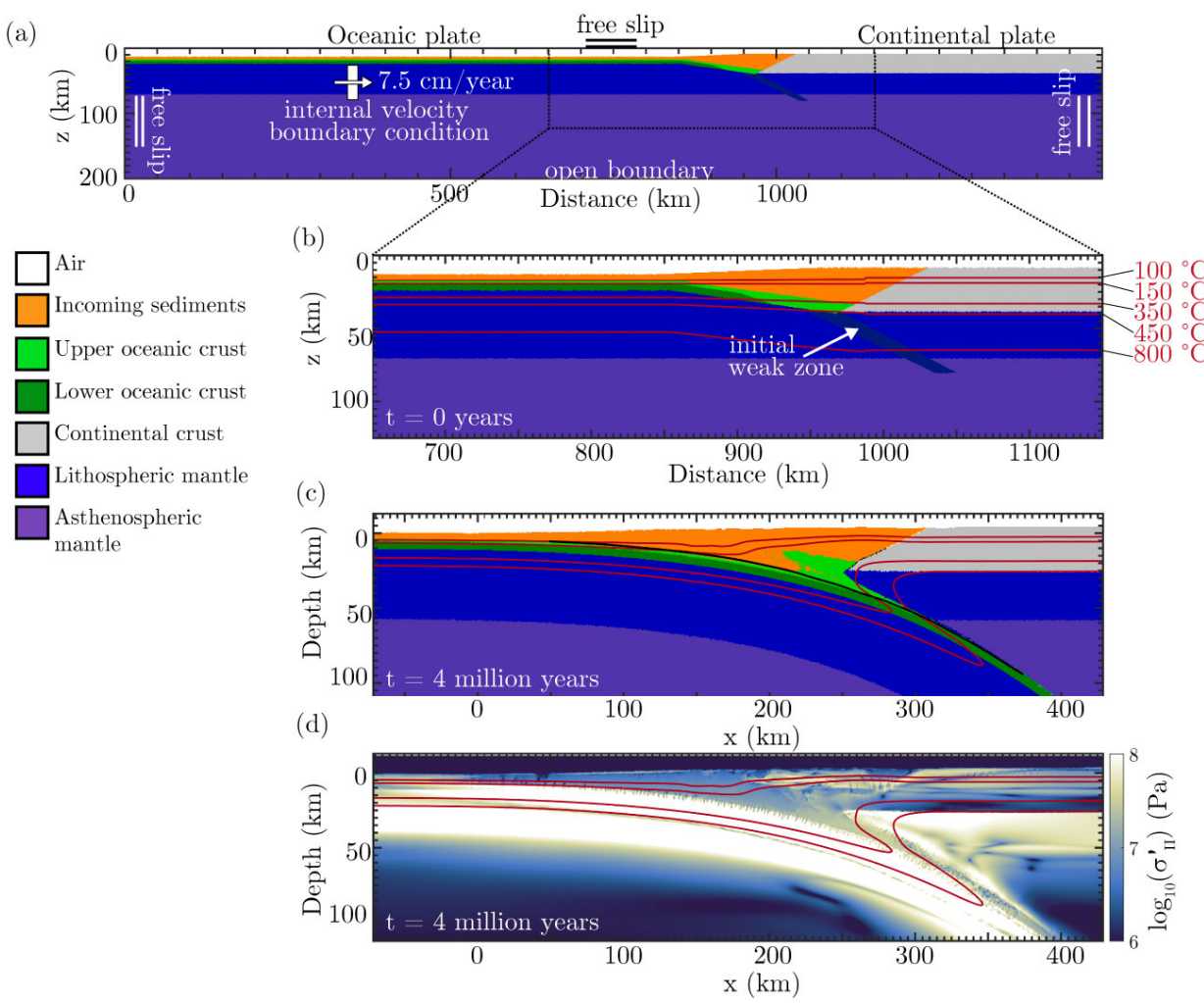

Figure A2. (a,b) Set-up of the subduction physical model and (c) final geometry of the subduction zone at the approximate time of the slip event used to initialize the earthquake model in Scenario C (Sec. 4). (d) Log of the second invariant of the deviatoric stress tensor, $\sigma_{I I}^{\prime}$, which controls yielding in the subduction model (see Eq. C.1 . Note that the coordinates change from $(a, b)$ to $(c, d)$ to coincide with the developed trench. 

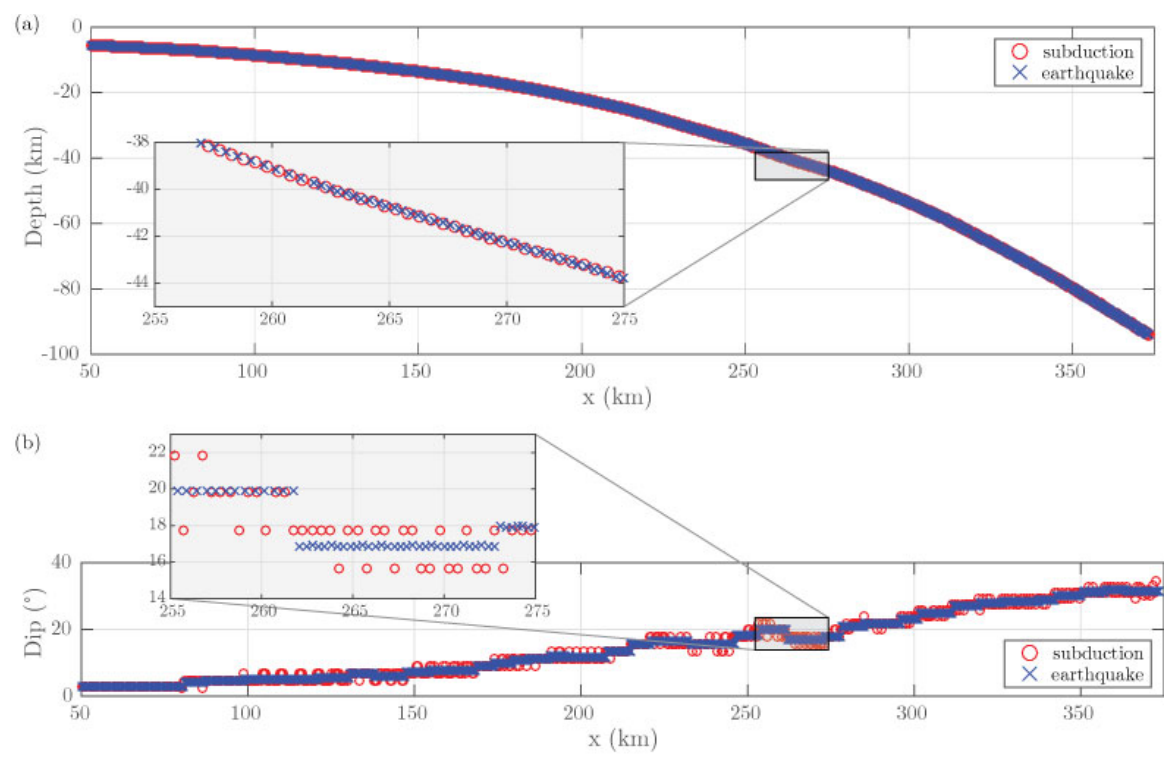

Figure A3. Comparison between (a) locations and (b) dip of faults in the subduction and earthquake models in Scenario C.
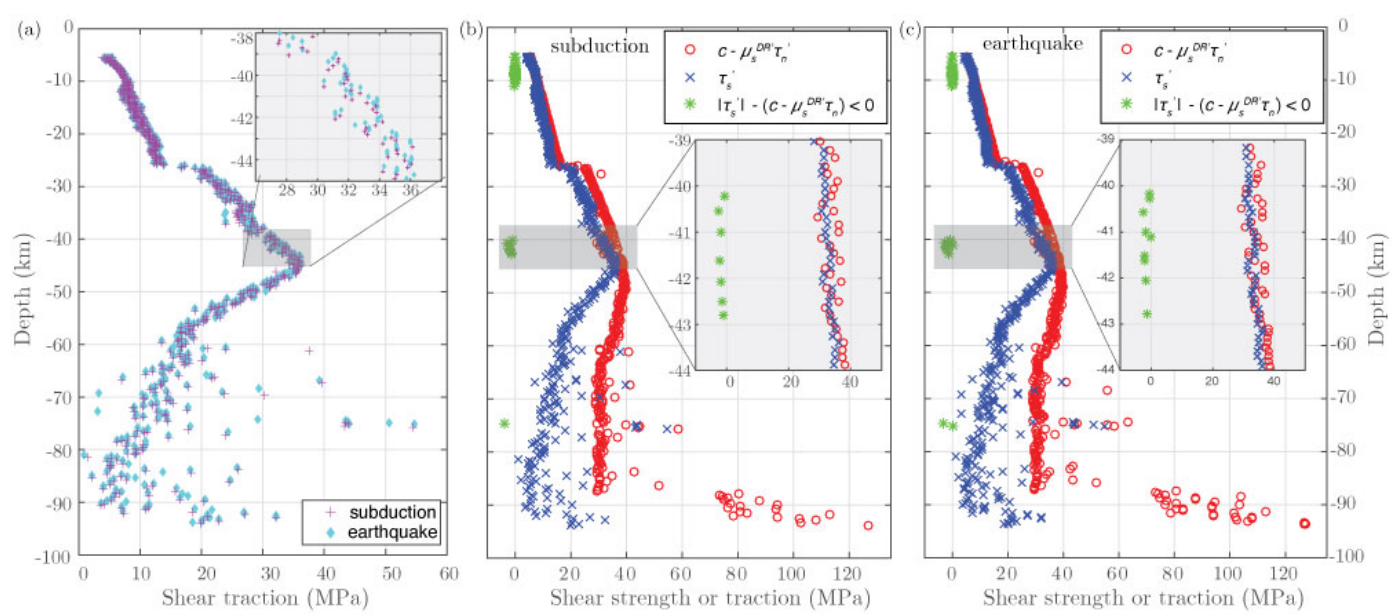

Figure A4. (a) Comparison between the effective shear traction, $\tau_{s}^{\prime}$, on the faults in the subduction and earthquake models in Scenario $\mathrm{C}$ before changes are made to $c$ in the sediments and to $\mu_{s}$ at outliers, as discussed in the text. Failure analysis according to the earthquake model failure criterion (Eq. 3) at points (b) along the subduction model fault and (c) along a slice at $y=0$ through the earthquake model fault. Variables are defined in text near Eq. 3 . 